This item was submitted to Loughborough's Research Repository by the author.

Items in Figshare are protected by copyright, with all rights reserved, unless otherwise indicated.

\title{
Electroplating of sintered iron compacts
}

PLEASE CITE THE PUBLISHED VERSION

PUBLISHER

Loughborough University of Technology

LICENCE

CC BY-NC 4.0

REPOSITORY RECORD

Saleh, Nabil A.. 2021. "Electroplating of Sintered Iron Compacts". Loughborough University. https://doi.org/10.26174/thesis.lboro.15028356.v1. 


\title{
ELECTROPLATING OF SINTERED IRON COMPACTS \\ by
}

NABIL A. SALEH

B.Sc. Chem. Eng. (Baghdad)

Thesis submitted in fulfilment of the requirements for the degree of Master of Science of Loughborough University of Technology (LUT)

NOVEMBER 1978

\author{
Supervisors: Dr. R. Haynes \\ Dr. D. R. Gabe \\ Department of Materials Engineering \\ and Design \\ University of Technology \\ LOUGHBOROUGH
}

(C) Nabil A. Saleh

1978 
I would like to express my thanks to Professor I. A.Menzies for directing the research and my sincere thanks to Dr.R.Haynes and Dr. D. R. Gabe for their encouragement and advice throughout the project.

My thanks also go to the staff and the technicians of the Department of Materials Engineering and Design.

I would like to express my grateful thanks to my wife and to my mother for their continued moral support throughout my studies.

Finaliy, my sincere thanks to the Iraqi Government who have supported me financially. 
Chronological Note

The work on which this thesis is based was started in July 1977. Most of 1977 was spent in a study of the literature and the construction of the equipment which was used later, in particular, in setting up the fumace, Lea and Nurse apparatus and measurement of permeability. At the beginning of 1978 the sintering of the compacts $w$ as completed and the plating was started.

Measuring the permeability of the plated sintered compacts has been performed at the end of March, after which an investigation with scanning electron microscopy and the optical microscopy has been conducted.

The experimental work was completed at the end of July 1978 . 


\section{SYNOPSIS}

Sintered iron powder compacts containing nominally 5,10 and 15\% porosity have heen prepared from Hoganas ASC 100-29 iron powder, which has been fully characterised. They were die compacted and sintered at $1390 \mathrm{~K}$ for half an hour under an atmosphere of dry nitrogen - 3\% hydrogen gas.

Compacts were degreased before electroplating. They were plated with copper from acid, cyanide and pyrophosphate baths, bright nickel, and zinc from acid and cyanide baths. In some cases multi-layer deposits were produced.

A Lea and Nurse permeability apparatus, with a special cell to measure the permeability of sintered compacts was constructed and used to measure the change of permeability during electroplating in order to assess the closure of the surface pores by the electrodeposit. Compacts were also examined using optical microscopy and scanning electron microscopy in order to study the quality and structure of the electrodeposits.

Electrodeposition has been shown to be an effective method of closing the surface porosity of the compacts and multi-layer deposits have been found to be more effective than single layer deposits. A relationship between the permeability and the thickness of electrodeposit has been observed. 


\section{SYMBOLS}

$\mathrm{h}_{1}=$ height of bed monometer before plating the specimen in cm - Hg.

$h^{\prime} 1=$ height of bed monometer after plating the specimen in cm - Hg.

$\mathrm{h}_{2}=$ height of flowmeter monometer before plating the specimen in $\mathrm{cm} \mathrm{-} \mathrm{Hg}$.

$h_{2}=$ height of flowmeter monometer after plating the specimen $\mathrm{cm}-\mathrm{Hg}$.

$\mathrm{Cu}=$ copper deposit from acid copper solution.

$\mathrm{Cu}^{\prime}=$ copper deposit from copper pyrophosphate solution.

$\mathrm{Cu}^{\prime \prime}=$ copper deposit from copper cyanide solution.

Ni $=$ Nickel deposit from bright nickel (Nisol 80).

$\mathrm{Zn}=$ zinc deposit from acid zinc solution.

$\mathrm{Zn} "=$ zinc deposit from cyanide zinc solution.

$\lambda_{1}=$ permeability before plating in $\mathrm{cm}^{2}$.

$\lambda_{2}=$ permeability after plating in $\mathrm{cm}^{2}$. 


\section{INTRODUCTION}

Despite the fact that sintered metal parts are sometimes finished by electroplating, little attention has been given to the scientific study of electrodeposition of metal on porous sintered metal parts. Thus, the present investigation was undertaken to investigate the effect of the porosity content of the sintered compact on the quality of the electro deposit and the ability of electro deposit to seal the porosity. Sintered iron compacts have electroplated with a variety of metals from different types of solutions and the effectiveness of the plating processes have been assessed. 
Chapter 1

$\begin{array}{llr}1-1 & \text { Definition } & 1 \\ 1-2 & \text { Advantages of Powder Metal lurgy } & 2 \\ 1-3 & \text { Disadvantages and Limitations } & 3 \\ 1-4 & \text { Powder Metallurgy Production } & 5 \\ 1-4-1 & \text { Chemical and Physico-Chemical Methods } & 6 \\ 1-4-2 & \text { Mechanical Methods } & 9 \\ 1-5 & \text { Treatment of metal Powder } & 10 \\ 1-6 & \text { Future of Powder Netallurgy } & 11\end{array}$

Chapter 2

$\begin{array}{lll}2-1 & \text { Origin of Porosity } & 13 \\ 2-2 & \text { Control of Porosity } & 15 \\ 2-3 & \text { Porosity in Green Compacts } & 16 \\ 2-3-1 & \text { Introduction } & 16 \\ 2-3-2 & \text { Review of Early Theories of Compaction } & 18 \\ 2-3-3 & \text { Volume Change During the Early Compaction } & 20 \\ 2-3-4 & \text { Effect of Pore Size Distribution on } & 22 \\ & \text { Porosity During Compaction } & 26 \\ 2-4 & \text { Change in Porosity on sintering } & 26 \\ 2-4-1 & \text { Introduction } & 27 \\ 2-4-2 & \text { Effect of Time and Temperature on Porosity } & 28 \\ 2-5 & \text { Change of Porosity During Sintering } & 29 \\ 2-5-1 & \text { Elimination of Porosity on Sintering } & \end{array}$


Chapter 2 (continued)

Page

$\begin{array}{lll}2-6 & \text { Effect of Porosity on Properties } & 29 \\ 2-6-1 & \text { Introduction } & 29 \\ 2-6-2 & \text { Effect of Porosity on Strength, Ductility } & 30 \\ & \text { and Toughness } & 31 \\ 2-6-3 & \text { Effect of Porosity on Hardness } & 32 \\ 2-6-4 & \text { Effect of Porosity on Fatigue } & 33 \\ 2-7 & \text { Porosity in Sintered Compacts } & 33 \\ 2-7-1 & \text { Introduction } & 33 \\ 2-7-2 & \text { Factors affecting the Residual Porosity } & 35 \\ 2-7-3 & \text { Theory of Residual Porosity } & \cdots\end{array}$

Chapter 3

3-1 Mechanism of Corrosion 39

3-2 Corrosion in Powder Metallurgy Products 39

3-2-1 Pitting or Localized Attack in Powder

Metallurgy $\quad \ldots 40$

3-2-2 Uniform Corrosion $\quad 41$

3-2-3 Crevice Corrosion $\quad 41$

3-2-4 Concentration Ce11s 42

3-3 Pore Filling Techniques 42

3-3-1 Electroplating $\quad 43$

3-3-2 Steam Treatment 43

3-3-3 Impregnation 44

3-3-4 Addition of Metals 46

3-3-5 Peen plating 46

3-3-6 Mechanical Methods $\quad 47$ 
Chapter 3 (continued)

3-4 Electropiating $\quad 48$

3-4-1 Introduction 48

3-5 Electroplating Technique $\quad 50$

3-5-1 Current Density 50

3-5-2 Solution Used 50

3-5-3 Rinsing $\quad 51$

3-5-4 Neutralization 51

3-5-5 Plating Thickness 51

3-5-6 Heat Treatment $\quad 51$

3-6 Electroplating Cycle $\quad 52$

\section{Chapter 4}

$4-1$

Copper PIating

$4-1-1$

Introduction

4-1-2 Copper Pyro-phosphate Solution

4-1-3 Copper Cyanide Solution

$4-1-4$

Acid Coppex Solution

4-2

Zinc Plating solution

4-2-1 Introduction

Acid Zinc Solution

61

4-3-2 Function of Bath Constituents 62

4-3-3 Buffers $\quad 63$ 
Chapter 4 (continued)

4-3-4 Anti Pitting Agents $\quad 64$

4-3-5 Brighteners and Levellers 65

4-3-6 Solution Used $\quad 66$

Chapter 5

Experimental Work

5-1 Experimental Work 70

5-1-1 Introduction $\quad 70$

5-1-2 Determination of the Flow Rate 72

5-1-3 Determination of the Apparent Density $\quad 73$

5-1-4 Determination of the Tap Density 74

5-2 Surface Preparation $\quad 75$

5-2-1 Introduction $\quad 75$

5-2-2 Factors Effecting the Selection of the Method and the Cleaner $\quad 76$

5-2-3 Process, Solution Used and Time 76

5-2-4 Sequence of the Surface Preparation Used $\quad 78$

5-3 Plating Procedure with Acid Zinc, Copper Pyro-Phosphate and Bright Nicke1 $\quad 80$

5-3-1 Procedure Using Triple Layer Plating 80

5-3-2 Procedure for Microscopical Study of Pore

Filling at Increasing Time

81

5-4 Plating Procedure with Copper Cyanide,

Acid copper and Zinc Cyanide Solutions $\quad 82$

5-5 Scanning Electron Microscopy $\quad 82$

$\begin{array}{lll}\text { 5-6 Optical Microscopy } & 83\end{array}$ 
Chapter 6

6-1 Result

85

Chapter 7

7-1 Discussion $\quad 86$

7-2 Introduction $\quad 86$

7-3 Discussion of the Compacts Plated with Copper Cyanide Solutions $\quad 88$

7-3-1 Plating with Copper Cyanide Solution for Compacts with $5 \%$ Porosity

7-3-2 Plating with Copper Cyanide Solution for Compacts with $10 \%$ Porosity

7-3-3 Plating with Copper Cyanide Solution for

Compacts with $15 \%$ Porosity

7-4 Comparison between the plating of the Three

Nominal Porosity Level Plated with Copper

Cyanide Solution

90

7-5 Plating with Copper Pyro-Phosphate Solution

7-6 Comparison between the Cyanide, Acid and

Pyro-Phosphate Copper Solution

7-7 Plating of the Compacts Plated with the

Zinc Cyanide Solution

7-7-1 Plating with Zinc cyanide Solution for

Compacts with $5 \%$ Porosity

7-7-2 Plating with Zinc Cyanide Solution for 
Chapter 7 (Continued)

7-7-3 Plating with Zinc Cyanide Solution for

Compacts with 15\% Porosity 93

7-8 Comparison between the Plating of the

Three Nominal Porosity Level Plated with

Zinc Cyanide Solution

7-9 Plating with Bright Nickel Solution $\quad 94$

7-10 Plating with Double Layers of Copper Coating 94

7-11 Comparison between the Mono Layer and the Double Layer Coating $\quad 95$

7-12 Plating with Triple Layers 95

7-13 Comparison between Single, Double, Triple Layers Plating $\quad 96$

7-14 Plating with Quadruple Layers 97

7-15 Comparison between the Plating of Sintered and Unsintered Specimens $\quad 97$

7-16 Effects of the Operating C onditions 97

Chapter 8

Conclusion 99

Recommendation for Further Work $\quad 101$

$\begin{array}{ll}\text { References } & 102\end{array}$

Appendix I Observation on Individual Specimens 108

Appendix II Cell Design $\quad 126$

Appendix III Calculation of the Surface Area of the $\begin{array}{ll}\text { Specimen } & 128\end{array}$

$\begin{array}{ll}\text { Tables } & 129\end{array}$

$\begin{array}{ll}\text { Figures } & 152\end{array}$ 
C H A P T E R 1

Powder Metallurgy Components

Advantages and Disadvantages

Process Routes

Future of Powder Metallurgy 


\section{CHAPTER 1}

\section{1.-1 Definition}

Powdex metallurgy has been defined as the art of producing and utilizing metal powder for the production of massive pieces of material, and of objects of complex shapes. It is recent, but extremely important branch of modern technology which is concerned with the production of metal powders and of the various articles made from them. The development of powder metallurgy has been due to the great advantages which it possesses over other methods in certain applications. By powder metallurgy it is possible to obtain a combination of material and properties which are unobtainable in any other way ${ }^{1}$. The powder metallurgy operation can be summarized as involving the pressing of powders at a definite pressure to form the required shape and sufficient strength to withstand handling prior to sintering. The external form and internal structure of the compact depends on the compaction technique employed and the characteristics of the powder itself. Compaction produces a solid shape which can withstand only small applied stresses. Moreover, it cannot produce a completely densified compact i.e. without any porosity inside the compacts. Subsequent heating of the resulting compact below the mel ting point of at least one major component, in order to cause inter particle bonding markedly enhances the strength. The bonding process Involves diffusion of atoms leading to the development of inter particle necks between particles. The greater the original density of the material the greater the amount of interparticle contact area ${ }^{2}$. The heating takes place in a controlled, neutral or reducing atmosphere in order to prevent oxidation, ( as slight oxidation can prevent the desired properties being attained in a sintered body), and relieves internal stresses, removes adsorbed liquids and gases, and prevents or minimizes 
any chemical reaction between the sinter mass and its environment. Many studies on the effect of the protective atrosphere used during sintering in the properties of Iron-Base materials have been made. A. Yu. Vallikivi, Pugina and Mozberg ${ }^{3}$ have found that these properties (as well as to the composition and structure) were extremely sensitive to atmosphere.

The sintering of Ferrous-graphite materials in many protective atmospheres led to decarburization, but in natural gas atmosphere porous Ferrous underwent carburization. Vacuum-sintered materials had the greatest strength and ductility; the greatest hardness was that of materials sintered.

\section{$1-2$ Advantages of Powder Metallurgy}

The advantages of the process may be summarised as follows:

1. Variation in the rate of production is possible.

2. Fewer manufacturing steps are involved in the production of intricate shapes than with alternative methods.

3. Material wastage is low because of the elimination of machining operations.

4. Precise tolerances can be achieved more easily than in other fabrication techniques, which eliminates the need for surface grinding for most application.

5. It is possible to obtain mixtures of metals which do not alloy by conventional melting and casting techniques, or mixtures of metallic and non-metallic constituents, e.g. heavy-duty copper tungsten electrical contacts of $(\mathrm{Cu}-\mathrm{V} V)$ and friction materials. which cannot be produced by other means except by powder metallurgy techniques. 
6. A consistent and uniform product can be manufactured in very large quantities.

7. One of the great advantages of powder metallurgy is that it permits production of porous materials. Porous metals find their application as filters, bearings, battery plates, fuel cells, catalyst, heat exchangers etc.

\section{$1-3$ Disadvantages and Limitations}

The application of powder metallurgy is subjected to certain limitation, the limitation may be of a technical or economic nature, etc.

(a) Material Limitations

Not every powder available is suitable for moulding and sintering. The powder should be satisfactory in quality and consistent from batch to batch $^{4}$, because the structure and size distribution of the particles influence compacting, sintering and final properties of the sintered product. The characteristics of the powder determine, to a large extent, the properties of the finished products. The purity and density of the powder are important in controlling the quality of the end product. The powder with some quantity of impurity and alloying element may have an important effect on the chemical and other properties. The cost of the powder is important but the possible high cost of metal powder product is more than off-set by economic advantages of the powder metallurgy process.

(b) Equipment Limitations

The equipment used in the powder metallurgy industry imposes certain severe restrictions, both technical and economic. Powders are pressed at a variety of pressures from low to high pressures, depending on the specific application and desired density. The capacity of a press, both in power and number of strokes per minute, determine 
the cost of the press. Other limitations are imposed by the construction of the die and punches. The strength and wear resistance of the punches involve restriction of the size and quantities of the moulded part that can be produced. Othex equipment limitations are imposed by the) complicated and expensive equipment for producing powders, for preparing and conditioning them, and for storing large. quantities without contamination by oxygen or moisture ${ }^{4}$. Cost consideration also plays an important part in the selection of sintering furnace, and the choice of sintering temperature and controlled atmosphere. Maintenance costs of the various equipment also increases with increasing size of the equipment, and with increasing operating temperature in the case of furnaces.

(c) Handling of certain fine powder can present several health hazards in both industrial or research operations. Spontaneous ignition or oxidation is a potential danger for many metals. Toxity of powder is normally related to inhalation and ingestion of the material and the resulting toxic effect. Many diseases arise from the inhalation of some metals' dust such as, Zinc, Cadmium and Nickel etc. Other powder metals when absorbed from the lungs can become general poison in the body ${ }^{5}$. Some metals such as Tin and Iron are deposited in the lungs where they are inocuous but produce marked shadow in radiographs of the chest.

(d) Accuracy Cost and Tolerance

Since during sintering dimensional changes take place which may sometimes be up to $7-25 \%$, difficulties may arise in maintaining tolerances owing to an increase or decrease of the dimensions. The main reason for the increase in dimension are the inequality of the partial diffusion coefficient of the constituent, which 
causes porosity to develop. Moreover, variation in green density will lead to differences in shrinkage, thus parts with high density will shrink more than the parts with low density. The shrinkage also may be due to the presence of temperature gradients - e.g. if a flat plate is heated from above, there is a temperature difference between the top and bottom of the plate that may cause greater shrinkage at the top than at the bottom ${ }^{7}$. The formation of inter-. metaliic compounds with specific volumes differing from those of the orlginal materials (this factor gives rise to serious internal stresseg), and relaxation of elastic stresses, which under unfavourable conditions produce cracks in the intermetaliic compounds and break inter-particle contacts.

\section{$1-4$ Powder Metallurgy Production}

There are two groups of methods used for production of metal powders. These are:

(1) Chemical and physico-chemical methods;

(2) Mechanical Methods.

Although the complete production of any metal powder involves technique from both groups ${ }^{8}$.

The method employed in the manufacturing of metal powders detexmine the characteristics of the powder produced. The difference in properties of the same metal powders prepared by various methods are due to different morphologies of the powder patticles ${ }^{9}$.

MANUFACTURING OF POWDER, METALLURGY POWDFRS 
(a) Reduction

(b) Displacement

(c) Electrolytic deposition

(d) Precipitation from the vapour phase. (a) Comminution

(b) Disintegration of liquid metals

(c) Atomization

1. By condensation of metal vapours;

2. by decomposition of volatile vapours

3. by reduction of gaseous phase by reducing agents.

(e) Oxidation followed by decarburization.

\section{1-4-1 Chemical and Phisico-Chemical Methods}

(a) Peduction

One of the most widely used methods for metal powder production is the reduction of metal oxides or other compounds. The clioice of reducing agent depends on convenience and economics. Carbon is the cheapest reducing agents, and is often used, but with some metals there is the difficulty of accurately controlling the carbon content of the resulting powder, besides the reaction is endothermic and tends to be slower than the ordinaxy process; however, the passage of an electric current accelerates the action and is economically justified ${ }^{10}$. Hydrogen can also be used but its disadvantages include its highly explosive characteristics and high cost. Sodium and Magnesium can be used to reduce halides vapours of highly reactive metals such as, $T i$ and $\mathrm{Z}_{\mathbf{r}}$.

Powder obtained by these methods sometimes have a fine particle size, and consequently a high sintering activity, but low apparent density and poor flow porperties. Example of some of the metals prepared by these reductions are Iron, Copper, Tungsten and Molybdenum. 


\section{(b) Displacement}

This method offers means of producing commercially important powders, such as copper and iron in very large quantities. For example, scrap iron or steel, sometimes even iron powder is used for the manufacturing of copper powder and variety of salt solution are possible. The acidity and flow of solution over cleaned steel scrap must be controlled ${ }^{11}$, because the acidity of the solution is important in determining the rate of deposition and quantity of the deposit produced. The powders produced are very fine, have a low apparent density and flow rate, but are pure.

\section{(c) Electrolytic Deposition}

Some metal powders are produced commercially by electrolytic deposition from soluticns of their salts on the cathode of an electrolytic cell (e.g. copper, iron, beryllium) the deposit must be either a sponge or brittle deposit that can be pulverised and easily converted to powders.

The conditions adopted which lead to a high rate of nuclet formation are: high current density, high acidity, low concentration of metal, and high viscosity.

The electrolysis of fused salts yield powdery deposits provided that the temperature of the bath is below the melting point of the metal.

The grain size of the powder is controlled by the current density and metal ion concentration. The deposit must be carefully washed to remove salt and dried in an inert atmosphere to avoid oxidation, this is combined with an annealing operation as the powders often are hard and reactive after crushing.

The powders produced are of high purity with excellent properties 
for conventional powder metallurgy processes and are free from inclusions. Zenbura, Glodzinska ${ }^{12}$ and Haranczyk have found the influence of electrolytic condition (deposition potential, mixing conditions using rotating electrodes, temperature, concentration of copper ions, shape degree of immersion and material of the cathode) on the grain size of copper depostted from the acidified copper sulphate solution. Under conditions of natural convection the deposition potential is the predominant factor, and under forced convection the efficiency of stirring. The influence of the remaining factors has a minor effect.

\section{(d) Precipitation from the Vapour-Phase}

1. By condensation of metal vapours, e.g. $\mathrm{Zn}$;

2. by decomposition of volatile vapours, e.g. Ni, Iron.

The volatile vapours are the carbonyl which can be produced by passing carbon monoxide over the metal, in the spongy or other finely divided form at moderate temperatures $\left(200-270^{\circ} \mathrm{C}\right)$ and high pressures up to (200 atmosphere). Subsequently, the carbonyl is decomposing at a. similar temperature but at a low pressure "atmospheric pressures", and the material precipitates in a very finely divided form with irregular shapes. The powders are then annealed to reduce the oxygen and nitrogen contents to a low level.

\section{Reduction of the gaseous phase by reducing agents.}

The technique finds an application in the powder metallurgy production. By metalic reducing agent at temperatures about $\left(850-950^{\circ} \mathrm{C}\right), \mathrm{e} \cdot \mathrm{g} \cdot \mathrm{TiCl}_{4}$ reduced by $\mathrm{Mg}$ or $\mathrm{Na}$.

The limitation: of this technique is the highly reactivity of the freshly produced powders. 


\section{(e) Oxidation folloved by Decarburization}

This method involves the reaction between metal carbides aid oxides and both oxygen and carbon eliminated, e.g.

$\mathrm{MO}+\mathrm{MC} \rightarrow 2 \mathrm{M}+\mathrm{CO}$

this producing behind the metal powder and carbon monoxide. It is used for the reactive metals, e.g. Niobium powders.

A new method for the manufacturing of metal powder has been found by Fishberg, V. V. Efremkin and their colleagues ${ }^{13}$, It depends on the crystallization of vapours in parified natural gas. The process makes it possible to manufacture single-fraction powders of various metals and alloys covering a wide range of particle size. The 'process has the adyantages of simplicity, no powder screening is required and no danger to the health of the workers who operate it. Although this process is is still in the experimental stage in furure it might become of industrial significance.

\section{$1-4+2$ Mechanical Methods}

\section{(a) Comminution}

It is an expensive method compared with the other methods but it is used for:

(i) Materials which are easy to fracture, e.g. Bi;

(ii) reactive materials which must be prepared in the absence of oxygen, e.g. Be;

(iii) common metals such as Aluminium, iton which are desired in the form of flake powders.

Comminution includes machining to produce chips, filings, etc., crashing which yields coarse particle size, milling to reduce its 
particle size. Further milling is carried out in a ball mill, rod mill and vibratory mill.

\section{(b) Disintegration of Liquid Metals}

By shotting and granulation. This method involves the pouring of molten metal through a screen or similar device into air or a neutral atmosphere. The molten current is broken up into a number of droplets. If these droplets solidify during falling aspherical particles are obtained (shot), e.g. Sn, $\mathrm{Ph}, \mathrm{Zn}, \mathrm{Al}, \mathrm{Cu}$ and $\mathrm{Ag}$. If solidification is caused by falling into a water or cooling medium, irregularly shaped particles result.

\section{(c) Atomization}

This is achieved by employing a jet of high pressures, high velocity fluid to disintegrate a stream of molten metal. Grintsov, and Medvedovski ${ }^{14}$ have investigated that the production of pure iron powder by atomization the molten metal with compressed air requires further treatments due to the thin oxide film on the surface of powder. They suggested a reduction with dry hydrogen to remove this film at a temperature of $400^{\circ} \mathrm{C}$. The time requixed for the reduction of the oxide film may be halved by initially subjecting the powders to ultrasonic vibrations. The shape of particles produced depends on the time of cooling of the atomized powders. Metal powders produced by this method are iron, copper, aluminium and lead.

\section{$1-5$ Treatinent of Metal Powders}

\section{(a) Annealing.}

It is used to remove the effect of cold working and increase plasticits and soften the powder. This could be done in a reducing 
atmosphere to remove any oxide films.

\section{(b) Spherodization}

This is a heat treatment used to modify the particle shape especially for filter manufacturing. Spherodization is done by allowing the particles to fall freely through a heated space in which they melt and spherodize; further fall into a cooler zone allows solidification of spherical particles.

\section{(c) Agglomeration of fine particles}

This is used to improve apparent density and flow rate by pressing the powder into bars and then disintegrating again.

\section{(d) Blending and Mixing}

This is employed to get as homogeneous product.as possible and mininize segregation of particles of different sizes.

\section{$1-6$ Future of Powder Metallurgy}

The use of powder metallurgy in industry will make it possible to improve the quality of the materials and articles, increase the productivity and reduce the cost of some products.

The industry is likely to benefit from the introduction of new types of products, as engineers seek to make improved use of materials in order to achieve better performance and minimize costs. As the cost of manpower becomes an ever greater consideration in the total cost, so the use of sintered engineering components is 1ikely to expand ${ }^{15}$ : The introduction of powder metallurgy considerably reduces the metal consumption as compared with other methods of forming metals. Besides, 
the cost of finished articles in mass production is, as a rule, lower than the cost of articles produced by normal machining methods ${ }^{16}$.

The use of iron powder to produce a wide range of sintered engineering components has been growing rapidly over the last 25 years. This has been due in part to efforts made by iron powder producer to develop powders which meet a range of pxoperty requirements ${ }^{17}$. There is a great future in the production by powder metallurgy of high-quality, defect-free metal in which defects occurring during solidification are eliminated. Thus, the production of self-lubricating bearing is of great practical interest, for example; in domestic appliances, air-craft and automobile engineering. There is no doubt, however, that powder metallurgy is a serious competitor to other manufacturing methods: such as casting, forging and machining. Moreover, the ability to apply those spectal finishes which can be applied to the latter can increase the competitiveness of powder metal parts.

Because of the inherent porosity of powder metal parts the final appearance of the finished product may not be identical with that achieved on pore-free metals, but the performance should be similar ${ }^{18}$. 
C H A P

Porosity in Powder Metallurgy Parts

Green and Sintered compacts

origin of Porosity

Effect of Porosity on Properties 


\section{2 - 1 Origin of Porosity}

The porosity of metal powder is reported as the main source of difficulty encountered. The presence of appreciable porosity has important effect on the properties, structure and composition of the products.

The porosity is defined as the ratio of the pore volume to the total volume of the material itself. Pores may be of two types: closed and open, the latter in turn may be subdivided into through pores (inter connected) and pores open at one end only, which are termed self-evident blind.

Inter connected porosity can never be greater than the total porosity.

The relation between total and inter connected porosity is determined by the character of the starting material and by the processing technique used to produce the porous metal, e.g. the use of spherical rather than irregular powder also maximize inter-connected porosity. The amount of porosity is controlled largely by the external characteristics of the particles such as their size, shape and surface conditions. The pore shape is clearly not spherical, moreover, it must be influenced by powder shape and size, compaction pressure and the sintering heat treatment cycle.

p. Schwarzkop $f^{19}$ has illuminated the origins of porosity in Powder Metallurgy. He found by the analysis of the structure comprised of arrays of single-sized spheres, that a number of systematic packings of spheres is possible. The most open arrays contain an interstitial void volume of $48 \%$ with each sphere in contact with six neighbours. The most dense (rhombohedral) packing forms only $26 \%$ porosity and each sphere is in contact with 12 neighbours. Experimentally, however, poured aggregates of spheres and regular equiaxed particles contain 
30-35\% porosity, indicating the formation of relatively non-homogeneous exrangements with highly irregular pore networks. Particle powder metallurgy deviates even more from such idealized packing. Although spherical and equiaxed powder particles are fairly common, some distribution in particle size almost always exists. If the size distribution becomes 1arge, smaller particles may be fitted in the voids between larger particles to reduce both pore size and porosity of the packing. Another deviation from ideal packing occurs as the fineness and. irregularity of the particles increase. The high specific surface area of such powder tends to produce packings of minimum inter particle contact and high porosity. Porosities in excess of $50 \%$ may be formed as the result of large packing imperfections caused by particle bridging. Voids formed by particle bridging have a vastly greater number of particles that make up the pore wall than in the case of inter stitial porosity and the pore size may be orders of magnitude larger than the particle size. Bridging is the basis of a technique that will be described as induced porosity, and if controlled, can yield useful structures of high porosity. Induced porosity is the systematicalarrangments of particles accomplished by the introduction of a powder pore-former. Metal powder is packed around pore-former particles which are either subsequently removed by vaporization, solution or decomposition or allowed to remain as one component of a composite material. The characteristics of an induced-pore structure are primarily related to the shape, orientation, size distribution and volume of the pore-former particles. As in the case of random bridging, induced-pore diameter may be order of magnitude larger than the metal particle size and . porosities in excess of $90 \%$ are possible ${ }^{19}$.

Part of the porosity consists of finer interstitial voids in the 
induced-pore walls which contribute to the inter-connection and permeability of the microstructure.

\section{2 - 2 control of the Porosity}

The source and, consequently, the primary means to control microstructural porosity resides in powder properties. However, Powder Metallurgy must also be concerned with the consolidation of a loose. powder mass into a coherent structure. Consolidation is usually accomplished by compaction followed by sintering. Compaction may drastically alter or even remove porosity, and a common practice in the fabrication of porous products is to relax those process conditions normally used to achieve high densities. Thus, little or no compaction pressure may be used for initial consolidation and powder may be simply taped or vibrated in a die or mould. As a result, the essential porosity of a loose packing is preserved, but at the expense of appreciable interparticle bonding. Higher compaction pressure increases the number and area of inter-particle contact, reduces the frequency of bridging and alters pore size and shape by deformation or fracture of particles. High pressure can be accommodated if pore-forming additives can support particle bridges under load and minimize inter-particle contact. Bridge (green) strength would be enhanced at the expense of inter-stitial porosity in induced pore walls $^{21}$. Additional inter-particle contacts, bonding and related changes in porous microstructure occur during sintering. The driving force for sintering is the reduction of compact surface area. Individual pores become more smooth and cylindrical as inter-particle necks form, pore diameters decrease until pinching-off. occurs, and ultimately, spheroidization and elimination of porosity result, however, as in the related process of grain growth, large pores may remain stable during sintering or may grow at the expense of fine pores. 
In practice, total elimination of compact porosity rarely occurs during usual sintering times. The time, temperature and additives to the powders or sintering atmosphere control both compact porosity and the stability of pores at elevated temperatures. The importance of various powder metallurgical processing variables on resulting porous microstructure is illustrated by the components described in the following sections.

M. Stevanovic and V. Petrovic ${ }^{20}$ have found the porosity of the same powders will differ from specimen to another depending on the concentration of added organic binder used and on the procedure applied in removing it.

\section{2 - 3 Porosity in Green compacts}

\subsubsection{Introduction}

The relationship between compaction pressure and porosity in powder compacts is important because pxessure more than any other factor controls the attainment of high density, high strength and low porosity in green compacts and markedly influences the same properties in the sintered product. The density-pressure relationship can give an idea about the pressure required for a certain level of density or porosity. The compaction and consolidation depend on the physical structure and properties of the various powder material types used. Thus, the behaviour of powder during compaction may be due to difference primarily in:

(a) Mechanical properties e.g. hardness, plastic flow and rate of work-hardening;

(b) chemical bonding between particles;

(c) surface effects, e.g. friction, adhesion, adsorbed layer;

(d) geometrical factors e.g. size, shape, surface area and distribution of powder particles; 
(e) the use of additives or lubricants to the powder;

(f) mode of compaction, e.g. whether pressure is applied unicirectionally or hydrostatically.

The inftial act of compaction in effect constitutes the first step in the sintering process before any heat has been applied. Merely bringing the particles into close contact enables the cohesive force innate in the metallic type bond to be called into play, as compaction never produces a completely densified or solid shape. This, total porosity of the compact decreases sharply in the early stage of compaction and then more slowly as the compaction pressure increases. This change of the total porosity takes place due to the changes in the pore size and pore size distribution. The compaction technique used is also very important since it affects the distribution of porosity within the compact. The compaction technique can be used to control the total porosity and pore size distribution in the green compact, which is decreased as the compaction pressure increases. 
$2-3-2$ Review of Earey Theories of Compaction

Below are Formulas proposed by various authors to describe the powder compacting process.

\begin{tabular}{|c|c|c|c|}
\hline Author & Year & Formula & Materials Investigated \\
\hline Walker (1) & 1923 & 1 & Salts and lead powder \\
\hline Balshin (2) & 1938 & & $\begin{array}{l}\text { Metallic \& ceramic } \\
\text { powders }\end{array}$ \\
\hline Balshin (3) & 1948 & $1-U=\frac{p}{\sigma_{k}} 1 / a$ & $\begin{array}{l}\text { Metallic and ceramic } \\
\text { powders }\end{array}$ \\
\hline Smith (4) & 1948 & $v_{f}-v={\frac{c_{p}}{\gamma_{t}}}^{1 / 3}$ & $\begin{array}{l}\text { Definition of a } \\
\text { compactivility factor } \mathrm{C} \\
\text { no experimental data }\end{array}$ \\
\hline
\end{tabular}

Athy (5) $\quad 1930 \quad U=U_{0} e^{-K x}$

Density, porosity, and compaction of sedimentary rocks at depth $x$

$\begin{array}{lll}\begin{array}{l}\text { Saphiro and } \\ \text { Kolthoff (6) }\end{array} & 1947 \quad U=U_{0} e^{-K P} \\ \text { Konopicky (7) } & 1948 \quad U=U_{0} e^{-K P} \\ \text { Torre (8) } & 1948 \quad U=U_{0} e^{-\left(/ 3 \sigma_{0}\right) P} \\ \text { Heckel (9) } & 1961 \quad U=U_{F} e^{-B} e^{-K P}\end{array}$

Silver Bromide powders

Iron steel, magnetite, quartz and magnesite powders

Model of the hollow sphere

Iron, steel, nickel, tungsten and graphite powders

Ballhausen (10) $1951 \quad V=\frac{U_{F}}{1-A\left(1-U_{F}\right) P}$

Iron and copper powder steel balls and leadshot

Nikolev (11) $1962\left(\frac{U}{1-U}\right)^{1-U}=e^{-\left(C / \sigma_{0}\right) P} \quad \begin{aligned} & \text { Iron steel, copper and } \\ & \text { aluminium powders }\end{aligned}$

Cooper and Eaton $(12)^{1962} \quad U_{0}-U=a_{1} e^{-\left(K_{1} / P\right)}+a_{2} e^{-\left(K_{2} / P\right)+\ldots} \quad A_{2}{ }^{O}{ }_{3}$ powders Saphi ro (13) 
Burr and Donachie (14)
Copper powder

$$
\begin{aligned}
1-U=f_{1}(P)+f_{2}(P)+f_{3}(P)+A & f_{1}, f_{2}, \\
& f_{3}=\text { undefined }
\end{aligned}
$$

$u=$ porosity at pressure $P ; \quad U_{F}=$ porosity of loose powder fill;

$v_{0}=$ porosity extrapolated to zero pressure; $K, \sigma_{0}=$ yield stresses;

$\sigma_{t}=\gamma_{t}$ theoretical density; $B, B, C, K, k_{1}, K_{2}, a_{1}, a_{2}=$ constant factors. 
A number of equations have been proposed to describe the relationship between compaction pressure and porosity or density.

Most of these equations are empirical. The most general form of equation is that proposed by Burr and Donachie ${ }^{21}$ which takes into account the various stages of the compaction process:

$$
\mathrm{D}=1-\mathrm{U}=\mathrm{f}_{1}(\mathrm{P})+\mathrm{f}_{2}(\mathrm{P})+\mathrm{f}_{3}(\mathrm{P})+\mathrm{A}
$$

where $\mathrm{D}=$ relative apparent density (i.e. $\frac{\mathrm{D} \text { apparent }}{\mathrm{D} \text { true }}$

$U=$ porosity (at pressure $P$ )

$f_{1}(P)=$ function of pressure applying to region of transitional restacking.

$f_{2}(P)=$ function of pressure applying to the "region" of local flow

$f_{3}(P)=$ complex function of pressure applying to the region of isostatic (elastic + plastic) compression but including elastic distortion of die and punches.

$A=$ 'geometrical' constant related to material shape size, etc.

(Die wall friction forces àre neglected.

This equation seems to be widely applicable.

\section{$2-3-3$ Volume change during the early stages of compaction}

Kostelnik, Kludt and Beddow 2 investigated the initial stage of compaction which they defined as the stage during which the density increases from the apparent density to the tap density. The change in volume with increasing pressure for various type of copper powder are shown in Fig. 1 and Fig. 2. Variation in pressing characteristics can rise from change in the particle size distribution. Spherical powders compacts least and flake powders the most. This is due to the fact that 
spherical powders are able to assume a closer initial packing than other shapes of powder, particularly flakes. On the other hand, particle size is found to be less important than shape.

Balshin ${ }^{23}$ found that the pressure imposed on a compact affects the relative volume (which is the volume of the compact relative to that of the material without porosity) of the compact according to the following relation:

$$
\operatorname{Ln} \mathrm{P}=-\operatorname{LV}+\mathrm{c}
$$

where $\mathbf{P}=$ applied pressure

$V=$ relative volume of the compact

$\mathbf{L}=$ a constant described as the modulus of pressing and is determined by the slope of a plot of In P vs. $V$ and $C=a$ constant which is determined by the intercept of a plot of In P vs. V.

I. Shapiro and Kolthof $\mathrm{f}^{24}$ have found that, in practice the value of $\mathrm{L}$ and $\mathrm{C}$ were not constant but varied with the conditions of the experiments. However, Hecked ${ }^{25}$ found that when plotting $\log P$ vs. V, first the curve was not linear, thus extrapolation would lead to serious errors. Secondly, the analysis is relatively insensitive to variation in pressure values at high pressures. A. Duffield and P. Grootenhuis ${ }^{26}$ drew some conclusions from their work on a spherical copper particles which relates the pressure and the change in volume during compression.

(1) Immediately on application of the load repacking takes place, causing a volume change of $2-4 \%$.

(2) Thereafter, the mechanism of pressing is mainly by plastic distortion of particle contact points.

(3) Up to a pressure of about $1000 \mathrm{lb} / \mathrm{in}^{2}$ transitional repacking persists causing a total volume change of the order of $1 \frac{1}{2} \%$. 
(4) Particle size distribution affects the pressure/volume characteristics of the powder only by its effect on the initial volume.

(5) This initial volume is sensitive to the method of filling and there is a random variation of the oxder of $2 \frac{1}{2} \%$.

Kostelnik, Kludt and Beddow ${ }^{2}$ found that the effect of shape of powder (Fig. 3.) was more marked than the effect of particle size (Fig. 4) and as particles become less irregular in shape the effect of particle size upon the pressure/volume curve decreased.

\section{$2-3-4$ Effect of Pore Size Distribution on Porosity}

\section{During Compaction}

In the recent york on compaction the fact that the total porosity of a powder compact cannot be changed without affecting this pore size distribution is taken into consideration. This offers an ideal opportunity to gain deeper insights into the mechanism of powder compacting.

$\operatorname{Torr}^{27}$ deduced a formula based on the model of a hollow sphere which indicated that the largest pores are expected to shrink and disappear first and subsequently the smallest ones. He considered the compression of a hollow metal sphere subjected to a uniform external hydrostatic pressures (Fig. 5). From the theory of elasticlty ${ }^{2} 1 t$ can be shown that a hollow. metal sphere cannot yield unless the external pressure exceeds a certain threshold, $\mathbf{p}$ min. which is higher, the smaller the volume of the hole compared to the volume of the solid metal. The final equation in the derivation explained qualitatively why, in the average, larger pores disappear at lower pressures than smaller ones. 
Torre argued as follows:

From the theory of elasticity, the condition of equilibrium for the radial stress $\sigma_{r}$ and the tangetial stress $\sigma_{t}$ in a hollow sphere external radius $r_{a}$ and internal radius $r_{i}$ is:

$$
\frac{d \sigma_{r}}{d r}+\frac{2}{r}\left(\sigma_{r}-\sigma_{t}\right)=0
$$

and the condition for plastic flow is:

$$
\sigma_{\mathbf{x}}-\sigma_{\mathbf{t}}=\sigma_{\mathrm{o}}
$$

where $\sigma_{0}=$ upper yield stress in tension. He assumed that equation (2) and equation (3) adequately defined the problem and by substituting equation (3) in equation (2), rearranging and integrating he obtained:

$$
\sigma_{r}=-2 \sigma_{0} \text { In } r+\text { constant }
$$

If $\sigma r\left(r_{a}\right)=-P$ (outside pressure) and $\sigma r\left(r_{i}\right)=0$ (zero pressure

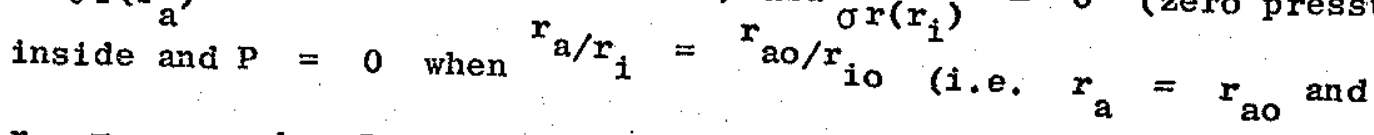
$\mathbf{r}_{\mathbf{i}}=\mathbf{r}_{\text {io }}$ when $\mathbf{p}=0$ ) equation (4) becomes:

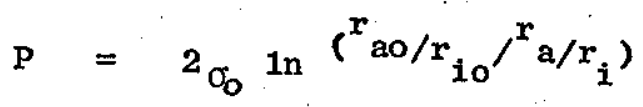

If at pressures $P$ and 0 the porosities $U$ and $U_{0}$ are defined as:

$$
\left({ }^{\left.r / r_{a}\right)^{3}} \text { and }\left(^{r_{\text {ao }} / r_{i o}}\right)^{3}\right. \text {, then it follows that: }
$$

$$
\ln \frac{U}{U_{0}}=-\frac{3}{2} \frac{p}{\sigma_{0}}
$$


which is of same form as Xonopicky's expression (Table 1). It seems impossible to extend this model, in a quantitative manner, to the case of a porous body containing irregularly shaped pores. None the less, it does suggest that a certain minimum pressure may be needed to cause pores of a specified size to shrink.

Bockstiege1 ${ }^{13}$ criticised the assumptions made by Torre and questioned the validity of his expression. He recalculated the model assuming that the condition of equilibrium is:

$$
\frac{d \sigma_{r}}{d_{r}}+\frac{2}{r}\left(\sigma_{r}-\sigma_{t}\right)=0
$$

The condition of compactibility is

$$
\frac{d}{d}\left(\frac{d e r}{d r}+\frac{2 e r}{r}\right)_{1_{r}}=\text { radial displacement }
$$

where $1_{x}=$ radial displacement

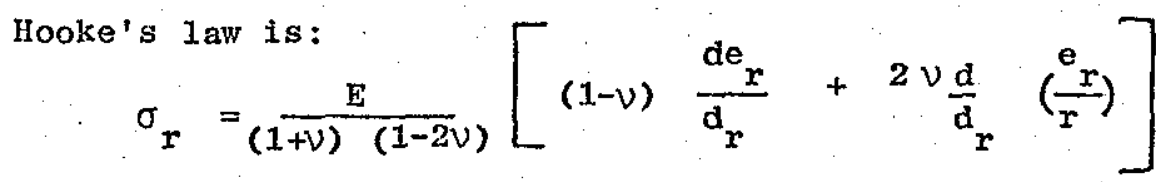

$\mathrm{E}=$ Young's Modulus $\nu=$ Poisson's Ratio

Boundary conditions are: $\sigma_{r\left(r_{i}\right)}=0, \sigma r\left(r_{a}\right)=-p$

From the solution of these simultaneous differential equations it follows that the maximum sheer stress, $1 / 2\left(\sigma_{r}-\sigma_{t}\right)$, is

$$
1 / 2\left(\sigma_{r}-\sigma_{t}\right)=3 / 4 \frac{r_{a}^{3} r_{i}^{3}}{r^{3}\left(r_{a}^{3}-r_{i}^{3}\right)}
$$

From equation (10) the maximum shear stress, $\frac{1}{2}\left(\sigma_{r}-\sigma_{t}\right)$, in the solid material of the hollow sphere is seen to be inversely proportional to the cube of the distance from the cnetre of the sphere, $r$, and directly proportional to $P$. Thus the hollow sphere cannot yield to the outside pressure $P$ before the condition of plastic flow is satisfied at all distances $r$, from the centre and within the material of the sphere. This condition is: $\sigma_{x}-\sigma_{t} \geq \sigma_{0}$ 
From equation (10) it is seen that $\left(\sigma_{\mathbf{r}}-\sigma\right)$ decreases as the distance from the centre of the sphere increases. Thus, yielding will occur when equation (3) is satisfied at $r=r_{a}$ (i.e. when equation (3) is satisfied at $r=r_{a}$ the value of $\left(\sigma_{r}-\sigma_{t}\right)$. at $r=r_{i}$ will be $\left.\sigma_{0}\right)$. Hence, the minimum pressure $P_{\text {min }}$ at which plastic deformation can occur is obtained from equation (10) by putting $\mathbf{r}=\mathbf{r}_{\mathbf{a}} \cdot$ Thus

$$
\mathrm{p}_{\min }=\frac{2}{3} \text {. } \sigma_{0} \frac{\mathrm{r}_{a^{3}}-\mathrm{r}_{1}^{3}}{r_{1}^{3}}
$$

From this equation (11) it is seen that Pmin becomes larger, the smallex the volume of the pore, $\frac{4 \pi}{3} \quad r_{i}{ }^{3}$, compared with the volume of the solid material, $\frac{4 \pi}{3}\left(r_{a}{ }^{3}-r_{i}{ }^{3}\right)$. Therefore, extending the model to a porous body it is reasonabie to assume that similar pressure thresholds will apply to pores of different sizes in a porous body, i.e. the largest pores will be expected to shrink first and smaller pores subsequently. However, note that equation (11) indicates only the conditions for the onset of plastic flow. When significant plastic flow occurs the equation is no longer valid, since it is based on Hooke's Law, equation (8) which refers only to elastic conditions. 


\section{2 - 4 Change in Porosity on Sintering}

\section{2-4-1 Introdiction}

The basic driving force for the sintering of a particulate compact of equilibrium compositon is the reduction in free energy of the compact which arises through the reduction in the surface (solid/vapoir interface) area of the compact. Also, in case where theoretical density is desired. Pores must be associated with grain boundaries (solid/solid interface) during the entire sintering process ${ }^{11}$.

In the uncompacted powder a higher percentage of the total volume is pores, while after a compacting the powder the porosity decreases sharply and most of the porosity is interconnected porosity. Prior to sintering, the pores are extremely irregular in shape due to the many sharp cornered crevices formed by the particle contact area. During sintering important changes occur in the amount of porosity, in the size and shape of pores and in the distribution of the pores. The total porosity decreases and some of the interconnected porosity changes to isolated porosity.

So that the pro-portion of the closed porosity increases with the degree of sintering while the pro-portion of interconnected porosity decreases ${ }^{30}$. The decrease in the interconnected porosity is affected by a number of processes, the primary of which are volume diffusion and plastic flow, with surface diffusion and evaporation and condensation also taking part. It is not always the aim of sintering to produce nonporous bodies. Typical applications of porous sintered materials are for catalysts, bearings, filters, engineering components and electrical application $i . e$ deliberate residual open porosity can be of advantage. 


\section{$2-4-2$ Effect of Time and Temperature on Porosity}

As the sintering time increases the mean pore size increases while the total porosity decreases and the 1 argest pores grow at the expense of the small pores, thus the average pore size existing in the compact increases with time of sintering. Late in the sintering process there exist pores which are larger than any present at the beginning of sintering. E. Dudrova ${ }^{30}$ has shown that the amount of total porosity. present depends on the time of sintering and on the compacting. pressure applied. M. K. Carlson and Hirschhorn ${ }^{31}$ on writing on sintering of copper and $\mathrm{Cu}$ - Sb compacts have found one of the causes of the neckpore which is dependent on pressure compaction. It is believed that small disparities on planar interface formed between particles during pressure compaction lead to neck pores. Hence, the less plastic $\mathrm{Cu}$ - Sb alloy exhibits more pores. The stability of such extremely fine pores at: the high sintering temperature and long time studied indicate that pores closure is probably prevented by gas entrapment and/or pore surface contamination. Pores acting as vacancy sinks may also be of importance. While A. Salak and E. Dudrova ${ }^{32}$ demonstrated that the type of porosity 1.e. closed or interconnected, depends upon sintering temperature and the total number of pores decreases progressively during sintering at all temperatures.

Hausne $r^{3}$ has found how the porosity characteristics change during sintering as the time and temperature increase. Thus:

(a) The total pore volume decreases.

(b) Pores change their shapes from "irregular" to "round" to "circular".

(c) The total pore surface area (inner surface) decreases because.

(a) and (b).

(d) The number of fine pores decreases considerably. 
(e) The number of coarse pores increases slightly.

(f) The average pore diameter increases.

(g) The total pore length decreases.

(h) The number of dead-end closed pores increases.

(i) Outside pores sometimes close under conditions where inside pores still exist.

Katanic, Popovik and Petrovic ${ }^{34}$ have found a relationship between sintering time and temperature and strength from their work on two types of samples of the $\mathrm{UO}_{2}$ powder, they found that with increasing sintering time and temperature, the total porosity decreases, but the mean grain diameter gets increased in the both groups of $\mathrm{UO}_{2}$ samples. The density reached was $94 \%$. Theoretical density and maximum strength value of about $600 \mathrm{kp} / \mathrm{ft}^{2}$ was reached at $1300^{\circ} \mathrm{C}$ in six hours in the samples of group II, the corresponding strength in the sample of group I was ontained by sintering at $1600^{\circ} \mathrm{C}$ for six hours, with some lower total porosity value and a mean grain size twice as big.

\section{$2-5$ Change of Porosity During Sintering}

Prochazka and $\mathrm{Alzbeta^{35 }}$ found a relationship between porosity changes during sintering of compacts made from reduced copper powder. They demonstrated the effect of the properties of reduced powder at temperatures in the range $300-700^{\circ} \mathrm{C}$ on changes in the porosity of compact during sintering. They showed that compacts prepared from powder obtained by low temperature reduction exhibited a maximum increase in closed porosity after sintering at $1000^{\circ} \mathrm{C}$. At this sintering temperature the total porosity increased and a reduction in mechanical properties was observed. No increase in porosity was observed in compacts obtained from powder prepared by reduction at higher temperature. 


\section{2-5-1 Elimination of Porosity on Sintering}

Marger and Ediex $x^{36}$ have found that elimination of porosity is possible in very thin specimens by selecting a relatively fine particle size. With thicker compacts it is also necessary to bring the specimen very slowly up to the sintering temperature. When the dimensions exceed a few centimeters, however, porosity can only be eliminated by increasing the rate of sintering by the addition of another metal.

\section{$2-6$ Effect of Porasity on Properties}

\section{2-6-1 Introduction}

Many materials prepared by Powder Metallurgy are characterised by some porosity. The mechanical behaviour of these metals depends on the amount of porosity, the type of pores, (interconnected or closed), the location of the pores (on grain boundaries or in the bulk) and the size and shape of the pores. The type and the amount of impurities present in the powder also affect the mechanical properties of the metal powder parts. Joshi, Wildermuth and Stein $^{37}$ found a correlation between some of these impurities and the properties of the powdex metallurgy specimens. Awano and Himura $^{38}$ studied the effect of impurities in sinter-forged irons on their mechanical properties. They found that tensile strength was not effected significantly by an increase in the content of nonmetallic inclusion where as elongation and reduction in area decreased linearly. Hansner ${ }^{39}$ has shown that by assuming identical porosity it can be stated that:

(a) Small pores decrease the strength to a lesser degree.

(b) The rupture strength of the porous material with rounded pores is greater than when the pores are irregular shaped and breakage starts at the edge of the pores. 
(c) Pores located at grain bounderies affect the strength more than pores located in the bulk of the material.

\section{2-6-2 Effect of Porosity on Strength; Ductility and Toughness}

Audier 40 has shown that in the case of spheroidal holes in a ductile metal, the strength of the sintered material at a small porosities may be expressed as:

$$
\begin{aligned}
R=R m K \varepsilon^{2 / 3} \\
\text { where } R m=\text { the U.T.S. of solid metal } \\
x=\text { a constant } \\
\varepsilon=\text { the porosity }
\end{aligned}
$$

At a I arge porosities:

$$
R=R i K \varepsilon^{2 / 3}
$$

where $R=$ the true breaking stress.

Koczak and Lawley ${ }^{41}$ have determined the dependence of Tensile strength on the residual porosity of iron.

A reduction of strength and ductility occurred with increased porosity and the spherical pores show a higher strength of the sintered parts.

Haynes ${ }^{4.2}$ has derived an equation which described the variation in relative strength with porosity content. The equation is shown to agree well with published experimental data. Unlike Eudier's model it is based on the assumption that the pore structure does not give rise to certain cross-section that contain less solid material. Haynes in his paper predicted upper and lower limits between which the strength of porous material must lie. As shown in Fig. 6 .

McAdam ${ }^{43}$ has reported on the elastic modulus of a range of sintered steels and iron-base alloys and has found this to be relatively insensitive to change in composition, but related to porosity. he has found the 
elasticity modulus ratio En/E is related to the porosity according to the expression:

$$
\mathrm{En} / E=(I-\varepsilon)^{3.4}
$$

where: $\mathrm{En}$ = the nominal elasticity of the compact

$E=$ the Young's modulus

$\varepsilon \quad=$ the fractional porosity

and $\quad K=a$ constant

Goetze $1^{4}$, shas shown that ductility and toughness are properties that are markedly influenced by the magnitude and nature of porosity as shown in the Fig. 7. As total porosity decreased both properties increased sharply which may be due to the elimination of interconnected porosity. Haynes ${ }^{45}$ has shown that initially the effect of porosity on ductility is smali and to good approximation proportional to the porosity content. This region is followed by a second region in which the ductility falls more steeply as the porosity content increases as shown in Fig. 8. He has derived an equation using a simple model that describes the variation of ductility with porosity content. The equation fits published experimental data for both elongation and reduction in area satisfactorily. He has pointed out that porosity has more severe effect on reduction in area than elongation and he attributed this to the constrain on overall lateral concentration during deformation imposed by the powdex particles.

\section{$2-6-3$ Effect of Porosity on Hardness}

Hardness measurements on sintered materials are difficult, particularly in the case of complex shapes where the variation in density of the part from one section to another may be in doubt. Goetzel 48 found the hardness of sintered iron increased with increasing in density of the sintered product. The same relation is obtained if repressing and 
resintering of the specimen.

Kaufman and Mocarski ${ }^{4}$ have demonstrated the effect of residual porosity on the mechanical properties of a powder forged material. The pores were irregular in shape and appeared to generate some sort of notch effect there by causing deterioration of mechanical properties, they concluded that:

(1) Yield strength, tensile strength, percentage reduction in area and percentage elongation are all strongly affected by residual porosity.

(2) Strength and ductility decreases as volume fraction of pores increases.

\section{$2-6-4$ Efgect of Porosity on Fatigue}

Haynes ${ }^{48}$ in his review of the fatigue behaviour of sintered metals and alloys demonstrated:

(1) Porous sintered material exhibit fatigue behaviour similar to that of cast and wrought materials, including fatigue limits in Ferrousmaterials.

(2) Their endurance ratio are slightly lower than those of similar wrought materials, and they may depend on porosity content.

(3) Total porosity content, is the most important factor influencing fatigue behaviour "endurance ratio depends on the porosity".

(4) Endurance limit decreases as the porosity content increases.

(5) Environmental and surface conditions seem to influence the fatigue behaviour of porous materials in the same manner as they influence pore-free materials.

(6) Fatigue cracks tend to start at the free surface of specimen in preference to the internal surface of pores.

(7) Fatigue fracture of sintered materials appears to occur in the 
same mannex as in pore-free materials.

(8) Comparison of the fatigue properties of sintered materials, with those of pore-free materials demonstrates that sintered materials possess fatigue strength in the same range as those of the majority of pore-free materials and indicates that under fatigue condtions sintered materials should behave in as satisfactory a manner as wrought and cast materials.

\section{$2-7$ Porasity in sintered Compact}

\section{7-1 Introduction}

Sintering: can be defined as the process by which additional bonding is achieved by heating below the melting point of at least one major constituent, (in order to cause interparticle bonding). Sintering is a solid state consolidation process which utilizes surface energy to produce its driving force. When sintering, cannot be employed, bonding agent such as plastics, may be used to impart strength to the powder body. In sintering when the metal powder is heated, there will be a change in the amount of porosity in the shape and size of pores, in the grain size and the surface area will decrease as well. This arises from the increase in the interparticle contact and smoothing of the surfaces of the particles and irregularities which lead to a shape dictated by the basic framework of nodes and branches. Densification occurs by the shortening of branches which shrink the framework. The characteristics of porosity depends on the characteristics of the metal powder and the condition of compaction and sintering.

\section{$2-7-2$ Factors affecting the Residual Porosity}

A number of variables affecting the description of residual porosity 
in sintered materials. Jenkins ${ }^{49}$ has demonstrated that these variables are the total pore volume; open and closed porosity; the size, shape and spacing of the pores and their distribution between grain and grain boundaries; the chemical nature of the surface of the pores and of the space which they occupy. Particle size and shape are important factors influencing the nature and distribution of porosity. They determine the surface activity of the particles and they influence the number and nature of the points of interparticle contact established during the initial compaction of the powder. Finer powders may yield lower sintered densities but more widely dispersed porosity than the coarser grades. Particles of irregular shape, which may be microporous, such as oxide-reduced and annealed electrolytic varieties will sinter to higher densities than those produced by atomization or by comminution ${ }^{50}$. Sintering environment may be expected to influence densification and hence, the nature of residual porosity. Atmospheres that lead to the cleaning up of internal surfaces can clearly have an important effect, a form of activated sintering, provided that the gaseous products of any surface reaction are removed. Inert gases may be harmful because of their inability to clean up contaminated surface and if trapped in closed pores, will eventually slow down and inhibit pore closure. Vacuum sintering may or may not be beneficial depending. on the quailty of vacuum and the metal involved ${ }^{49}$. Jenkins ${ }^{49}$ recognized that increase in temperature favours a decrease in residual porosity. Addition of certain chemicals, e.g. sulphur and copper to iron may reduce the residual porosity and provide a means of effecting the desired pore closure. The additon of copper produces a liquid-phase. which is sucked into and clogs the capillary channels between the pores and decreasing the residual porosity. However, this process has the disadvantages of forming some microcells which facilitate corrosion ${ }^{50}$. 
The additon of sulphur has some advantages as the sulphur is inexpensive and can easily be blended with iron powder. Apart from this, the presence of sulphur in iron powder compacts may have an additional activating effect on sintering owing to the fact that iron sulphide reacts with residual iron oxides on the surface of the iron powder particles, forming oxy-sulphides and metallic iron.

$$
\left(2 \mathrm{FeS}+\mathrm{FeO} \leftrightarrow \mathrm{Fe}_{2} \mathrm{OS}_{2}+\mathrm{Fe}\right)
$$

This reaction is responsible for the improved mechanical properties of sintered structural parts made from sulphatized iron powder. The disadvantages of this method are the alteration in size change during sintering, possible effects of sulphur on the fumace atmosphere and heating elements and it forms bxittle, low melting point FeS-Fe eutectic.

\section{$2-7-3$ Theory of Residual Porosity}

The condition for retention of any appreciable residual porosity in the sintered compact is the elimination of grain boundaries by a process in which the temperature is very close to the melting point. Norton reported that the coalescence of the particles involces transport of material which may take the form of:

(i) viscous or plastic flow;

(ii) volume diffusion;

(iii) surface diffusion; or

(iv) evaporation and condensation.

The first two types of mechanisms are capable of bringing about a change in volume of a porous system, while the latter two types of transport could lead to a change in shape of the particles and pores, but not to densification of a compact. Each method of transport is 
associated with a particular relationship between the growth of the neck and the shrinkage as a function of time and temperature.

G. Kuczynski ${ }^{51}$ has investigated a theory of the residual porosity depends on Zener's equation, $i . e$. the limiting diameter ( $\delta)$ of spherical inclusion of radius $(r)$ and volume fraction ( $f$ ) is:

$$
\delta=\frac{4}{3} \frac{r}{f}
$$

In powder compacts the inclusion anchoring the grain boundaries are pores. In case of synthetic compacts such as the spool of wires used in the work of Alexandex and Balluffi, secondary recrystallization started at $r=10^{-3} \mathrm{~cm}$ and $f=4 \times 10^{-2}$. This gives, accroding to equation (A) $\delta=3 \times 10^{-2} \mathrm{~cm}$. The actual diameter of the wires used was $\simeq 1.3 \times 10^{-2} \mathrm{~cm}$. Thus, it may be concluded that as soon as the pores radius decreases to the value corresponding to $\delta>4(a) 1$ arge grain sudden iy starts to grow. The growth is synchronized with the pore shrinkage, $i . e$. the radius of voids near to or in the grain boundaries decrease by the mechanism described by the equation:

$$
* r^{3}=r o^{3}-\frac{3 \gamma V D}{R T} t
$$

where:

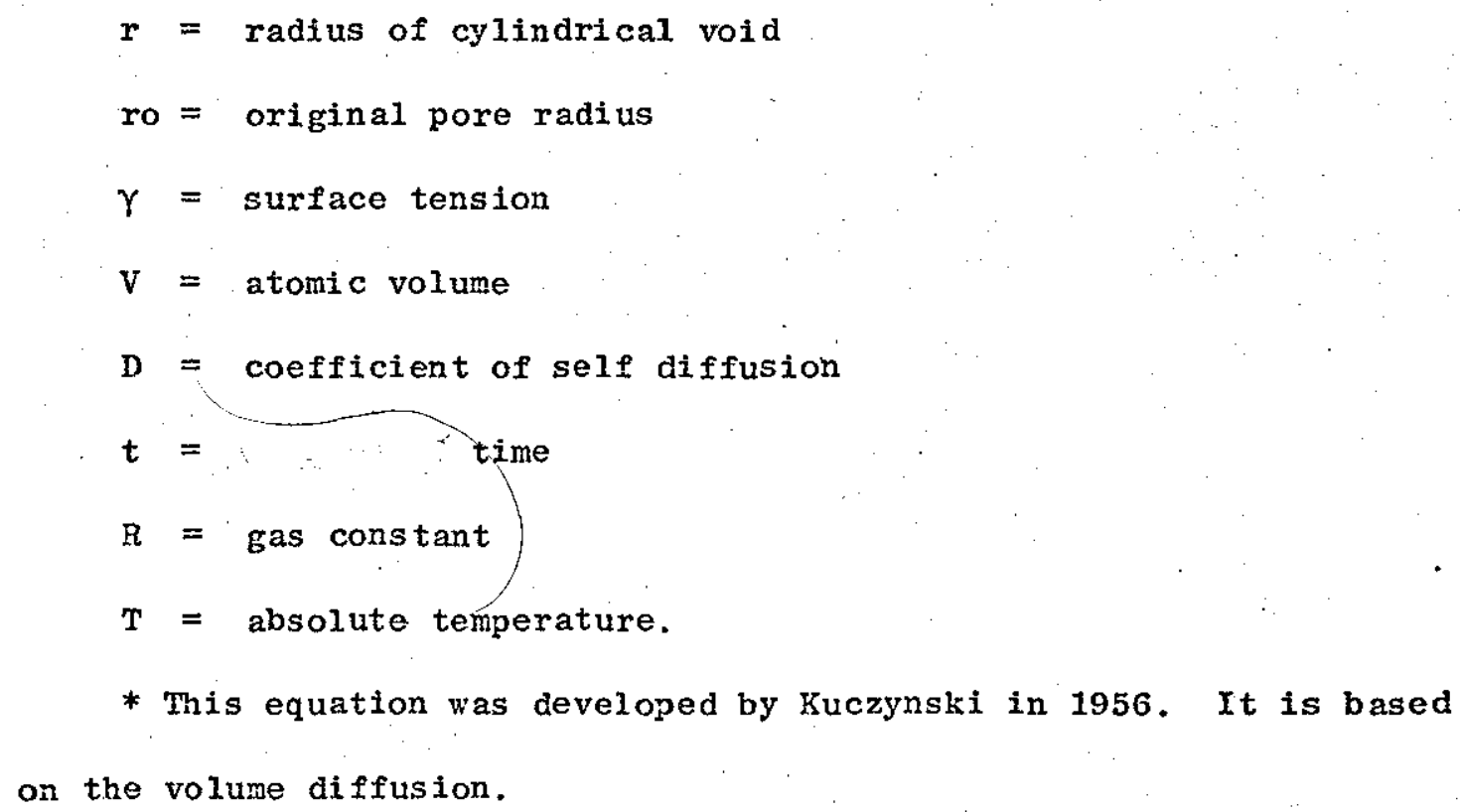


This allows the grain to grow to larger and 1 arger diameters, in accordance with equation (A). Indeed, decrease in the diameter of voids or their complete disappearance in the vicinity of grain boundaries has frequently been observed. Another indication that the initiation of secondary recrystallization is controlled by pore shrinkage to radius corresponding to $\delta>a$, can be obtained by further analysis of the data contained in Alexander and Balluffi's paper. The pertinent information is listed in Table 1.

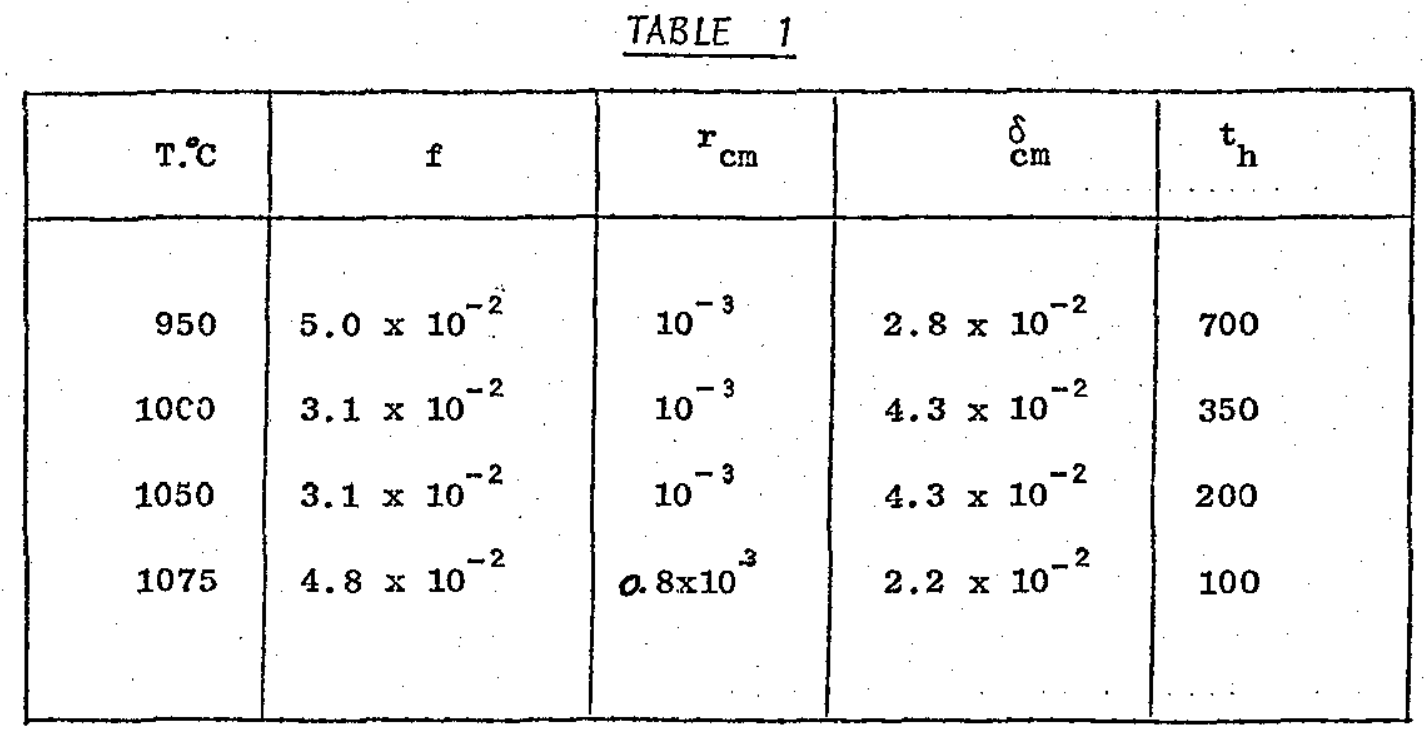

In pure metal large grains grow by transfer of atoms from small grains across the grain boundaries to the 1 arge grains. In real compacts the situation is more complex because the pores are of different size and shape. The most important consequence of the non-uniformity of the pore size is that the large pores are likely to serve as effective sinks for vacancies emanating from the small ones.

As sintering progresses, necks first grow at the point of contact between two particles, the basic driving force being the tendency to. minimize the surface energy of the assembly. The grain boundaries formed in the necks are effectively anchored because their displacement 
towards the centre of the particle would increase the grain boundary area and consequently its energy.

Siegle $e^{53}$ has questioned the assumption that the grain boundaries are the only or even the most important vacancy sink. He cites the experiments of Pranat1s on wire compacts of nickel and copper. After undergoing preliminary low temperature sintering, some of the compacts were given a critical strain so that on reheating to the sintering temperature about half the grain boundaries were removed almost immediately by recrystallization and grain growth. Thus compacts which were practically identical except for the grain boundary configuration could be compared. In the case of nickel, it was quite clear that the shrinkage was least for the compact with the fewest grain boundaries. In copper, however, there appeared to be no difference between the stained and unstrained compacts, perhaps owing to the very rapid growth even in the unstained copper compacts.

Nevertheless, it did appear that voids continued to shrink in both copper and nickel after isolation from the grain boundaries. Another outcome of these experiments was the observation that the presence or absence of grain boundaries had no influence on the rate of neck growth. Fron all this, Siegle concluded that grain boundaries play an important though perhaps not the exclusive role in densification, whereas they are of negligible importance in those aspects of sintering that involve only interparticle bonding. 
C H A P T E R 3

Surface Treatment of Powder Metallurgy Components

Corrosion Process

Pore-Filling Techniques

Coating System to be considered as a competitive Finishes 


\section{$3-1$ Mechanism of Corrosion}

Corrosion can be defined as the reaction of a metal or alloy with its environment with the formation of corrosion products. Corrosion is always destructive, but this depends on the rate of corrosion and its extent.

The corrosion process can be explained in terms of a simple electrochemical circuit. Fig. 9 shows two different metals placed in a conducting solution and the two metals are connected together by an extermal conductor wire. Current starts to flow spontaneously from the metal which has a high potential, to the metal of low potential. The driving force is the difference in the electric potential between the two metals. These two metals are called the electrodes. The electrode at which oxidation takes place is called the anode, the electrode at which reduction takes place is called the cathode. At the anode electrons are produced due to the dissolution of metal, and as the anode corrodes it is converted to ions with the releases of energy in the form of electrical energy and heat energy, the electrical energy being transferred through the external conductor to the cathode. At the cathode electrons are consumed by the positive ions and result in their reduction to the metal atoms or liberatation of hydrogen. Therefore, current will flow, and the flowing of the current depends on the amount of the driving force between the anode and the cathode.

\section{3 - 2 Corrosion in Powder Metallurgy Products}

Any sintered products are porous which increase the active surface area and the corrosion of powder metallurgy may be caused by two main effects. 
(a) The metal is not uniform at all, but consists of crystals having different chemical or physical characteristics, and this being due to the amount of pores, the distribution of pores and the type of pores (closed or interconnected).

(b) Different regions of powder metallurgy parts are exposed to different conditions, particularly to the difference in oxygen concentration inside the pores.

Therefore, corrosion taking place in powder metallurgy has various aspects, e.g. pitting, uniform attack etc.

\section{$3-2-1$ Pitting or Localized Attack in Powder Metallurgy}

Pitting is one of the most dangerous and common type of corrosion. Various metals are subjected to it including iron, nickel, aluminium, magnesium, zirconium, copper, tin, zinc and many of their alloys.

In pitting, the major surface areas of the product remains almost unattacked while certain small areas are attacked vigorously. The high corrosion rate of these attacked areas is due to the heterogeneities in the metal (e.g. grain boundaries, different phases, bimetallic etc.) and/or the environment in contact with the metal. The two anode and cathode areas can be distinguished visually.

In powder metallurgy and due to the presence of pores, water ingress in the pores either by absoxption from the atmosphere or by contact, besides some condensation on the surface of the sintered parts, provides a conducting solution between the higher potential areas (anodes) to the lower potential areas (cathodes). A shallow pit will form at first, with increasing intensity of pitting at longer times.

Another example of pitting in powder metallurgy product is the presence of dirt on the surface and due to the low concentration of 
oxygen underneath the dixt these areas become anodes, forming deep pits of corrosion, the clean parts becoming the cathode and discharge the electrons produced from the dissolution of the anodes.

Pitting is also caused by localized breakdown of passive surface films in the presence of certain critical ions in solution such as chlorides, bromides or lodides, the formation of pits is observed most often in the presence of chlorides ions. This is due not only to theix greater aggressiveness but also to the wider distribution of chlorides in nature. Aggressive anions can stimulate the development of pitting corrosion if they are present in the solution above a certain critical concentration. The critical concentration of the aggressive anion depends on the nature of the metal or alloy, its thermal treatment, and the state of its surface ${ }^{54}$.

\section{$3-2-2$ Uniform Corrosion}

In uniform corrosion the major body of the surface is affected at the same rate. It is impossible to distinguish between the anode and the cathode sites, e.g. oxidation and tarnishing. the main causes of uniform corrosion in powder metallurgy is the exposure of the large, reactive and clean surface after sintering to the atmosphere or the attack by the corroding solutions. It is relatively unusual and occurs when the corrosion rate is controlled entirely by environmental factors.

\section{$3 .-2-3$ Crevice Corrosion}

This is due to the differential aeration and can range from near. uniform attack to pitting and ranging from noble metal to the very electro-negative metals. Most cases of crevice corrosion take place in near-neutral solutions in which the dissolved oxygen is the cathode 
reactant or take $p l a c e$ due to the difference in concentration of solutions.

In powder metallurgy this takes place at the pores because the deep lying sections of inter-connecting porosity are devoid of oxygen and the moisture which is adsorped from the atmosphere cannot evaporate, while the surrounding area is exposed to fresh air. Thus, becomes the cathode, thereby the rate of corrosion will be high. By the presence of same solution but of differing compositions inside the pores, the areas in contact with the dilute solution will be the anodes while the area in contact with the concentrated solutions will be the cathodes.

\section{$3-2-4$ concentration cells}

Corrosion may also take place after electro-plating. The process is due to the formation of differential cells and these may arise during changes in the characteristics of the plating electrolyte which penetrates in the pores by diffusion and capillary process ${ }^{55}$.

\section{3 - 3 Pore Filling Techniques}

The majority of components produced by the Powder Metaliurgy technique have a degree of porosity. Pores formed as a consequence of the incomplete particle packing process despite the pressure used, although it is preferred to reduce the porosity to the minimum. It was this particular characteristic enabling the porosity of powder metal parts to be filled in order to prevent corrosion. In spite of the high pressure employed in cold pressing the metal powder and the degree of welding that takes place during subsequent operation of sintering; a number of pores remain between the individual metal particles, these 
pores either closed or connected to the surface of the products; thus metal powder compacts are always porous. The porosity of powder metal compacts governs the choice and operation of the procedure employed, where by filling surface pores we hope to separate the electrolyte and the corrosion sites. If the pore-sealing methods were simple that advantage would be reflected in the cost of the finished parts. The degree of porosity may be minimized or eliminated on the surface by using:

\section{$3-3-1$ Electro-plating}

This process can be successfully carried out on sintered parts. It is used to improve corrosion resistance, appearance, wear, resistance and to impart some properties to the metal powder parts, e.g. Increased conductivity, colour and decorative effects. The electro-plating technique can be used in the same way as for pore-free metals but care must be taken to avoid as much as possible the ingress of cleaning and plating solutions into the pores. This troublesome characteristic can be minimized by neutralization and alternate rinsing in hot and cold water and increasing the time of rinsing. The plating solution must have a good microthrowing power in order to fill the inside pores. The use of multi-layers can be used successfully in order to divert the path of corrosion and to protect the powder netallurgy product from both the inside and outside attack. Solutions with brightener and levelling agents can give better results than those without.

\section{$3-3-2$ Steam Treatment}

Steam treatment may be used for copper and aluminium but it is probably best for iron. The metal powder products are subjected to the 
action of super-heated steam at temperature of from $450-750^{\circ} \mathrm{C}$. The iron is then oxidized to the stable black oxide $\mathrm{Fe}_{3}, \mathbf{0}_{4}$, (Magnetite) which forms a passive layex on the surface of the product and also on the surface of the pores ${ }^{50}$. This film prevents contact between the pure metal and the surrounaing atmosphere. At the same time open porosity is diminished, and the pores are filled as the volume of the oxide is greater than the volume of the pure iron. The decrease in porosity achieved is considerable. Steam treatment improves both the wear and corrosion resistance of the surface. Because the steam penetrates the pores, the adhered oxide layer tends to close the fine interconnecting channels, reducing interconnected porosity, increasing the compressive strength of the part, and Imparting oan attractive blueblack colour ${ }^{56}$.

\section{$3-3-3$ Impregnation}

Impregnation is a term used to describe the filling of the porous structure with liquids, metals and oils.

\section{$\cdots[a]$ Impregnation with Liquids}

Impregnation with liquids which fill the inside pores, find wide applications for metal powder parts as it is easy to employ, cheap and there are a variety of liquids and solutions which might be used, e.g. sodium silicate, waxes, resins and other organic compounds. Rushbrook ${ }^{5}$ ? has suggested that the compact is pre-heated to approximately $205^{\circ} \mathrm{C}$. and quenched in a $4 \%$ solution of silicon in carbon tetrachloride or tetrachlorethylene. The vapour will fill the pores left by the escape of air. The compact is then dried and baked for 30 minutes at $205^{\circ} \mathrm{C}$ and pickled to remove superficial tarnish caused by the heat treatment. 
Hoffman ${ }^{50}$ suggested another procedure for impregnation by extracting the al $x$ from the sintered component and filling the compacts with saturated medium under vacuum. The vacuum pressure is changed to high-pressure and saturation is completed.

\section{(b) Infiltration with Metal}

This process has been suggested as a base for finishes but it is expensive and sometimes can produce corrosion as microcells may exist on the metal. It has the advantages of usually increasing the density and corrosion resistance.

It is very useful prior to electro-plating as it increases the adherent forces between deposit and substrate. The impregnation with metal (i.e. infiltration) takes place by capillary forces through the pore-channels capillary tubes. Provided the distances within the component are not too large the impregnated metal will be sucked in and Pill the pores. Rushbrook ${ }^{57}$ has laid down some conditions for impregnation with metals:

(i) The melting point of the infiltrating metal must be less than that of the metal of which the compact is made.

(ii) There should be little reaction between the two metals and only a low solubility at the infiltration temperature.

(iii) The melting point of any alloy produced must be below the temperature of infiltration.

(iv) The viscosity of the molten metal and the surface tension between the metal must be sufficientiy small to allow smooth flow and easy wetting.

\section{(c) Impregnation with oil}

Impregnation with oil is carried out so that the sintered components 
are protected by the oil, so that the oil penetrates into the accessible pores of the compacts. Components protected in this way have better anti-corrosion properties than components manufactured from pore-free materials, as the pores act as a reservoir for continuous lubricating of the parts, e.g. in bearing applications.

$3-3-4$ Addition of Metals

Some metals can be added to the powder, for example, copper and molybdenum ${ }^{50}$. Bockstiegal ${ }^{58}$ has suggested adding sulphur in the range of $0.25-0.75 \%$ to iron powders to close the pores, as the sulphur has a low melting point which can enable rapid dispersion over the whole skeleton of the iron powder compact. The disadvantages of this process. is the dimentional changes in size during sintering andthe effect of sulphur on the furnace atmosphere and elements ${ }^{59}$. Copper is also used but its disavantages are the formation of microcells in the vicinity of particles of pure iron which may then corrode, and the shrinkage in the coppex after cooling which may cause cracking.

\section{$3-3-5$ Peen Plating}

Peen plating can be used to close the pores. Peen plating process has some similarity to metal spraying, since in both processes the coating metal is impacted on the surface of the object. In Peen plating processes the parts of sintered metal powder must be heated and some roughness must be left on the surface in order to promote good adhesion between the coating and the substrate of the object. Jenner and Hoar 60 have listed the advantages of the Peen plating process:

(a) Freedom from hydrogen embrittlement.

(b) No solution entrapment in the pores, during cleaning and plating by the conventional electro-plating techniques which can cause 
corrosion if badly treated.

(c) Alloy plating on the surface of the product can be employed.

(d) Deposition on non-metals. Metals such as zinc, aluminium and chromium etc., can be deposited upon gilas, ceramics and othe $x$ abrasive grains without difficulty.

(e) Parts that requixe thick coatings ${ }^{61}$.

(f) Most metals can be coated including steels, Powder Metallurgy irons, cast irons and zinc die-casting.

(g) No cyonide wastes are produced.

There are also some limitations in Peen plating:

(a) Since it is necessary to deform the metal particle on the object surface, the metal particles must be sufficiently soft that they can be deformed by the mechanical forces in the tumbling operation.

(b) The object surface must be clean.

(c) The basis metal must not be too reactive.

(d) The shape and size of the object may raise some difficulties in Peen plating, e.g. deep narrow crevices.

The recent development in Peen plating is to plate the parts without touching by human beings. The, parts are dumped in to hopper and theyare discharge from an oscillating conveyor. When the plating is completed the load is discharged and the parts taken to the next step (e.g. chromating, drying etc.). The drying is accomplished in a chamber served by two 300,000 B.T.U. hot air furnaces. The development of this technique by the 3M's company has been termed "Mechanical Plating"61.

\section{3.-3 - 6 Mechanical Methods}

Rushbrook ${ }^{57}$ has demonstrated that the surface porosity may be almost entirely eliminated by coining or repressing the compact: Rolling 
in the case of ductile metals will give similar results but these techniques are expensive to apply for the purpose of electro-plating. polishing, employed for decorative plating may manage to utilize pore closure at least to a satisfactory level in order to use the conventional bright plating solutions. The polishing will reduce the plating time, current density and given good appearance to the metal powder products.

\section{3-4 Electroplating}

\section{3-4-1 Introduction}

With the very rapid growth of the powder metallurgy field, a large variety of powder metal parts are being made, many of which will be subjected to a plating operation. The primary function of the coating is to provide a barrier that is more resistant to attack than the reactive pores and substrate, and isolate the substrate from tile environment, and secondly to improve the appearance and to obtain decorative finishes. Any papex concerned with the plating of powder metallurgy products must return to the principles of powder metallurgy and the consequences powder metallurgy products are characterized by their porosity and the porosity either connected to the surface or closed. The porosity. in the metal powder parts is the main source of difficulty encountered. The main reasons, therefore, for considering electro plating are:

(a) Protection against corrosion for the articles produced by the powder metallurgy methods against any specific chemical reaction and environment and protection of metal parts against wear and abrasion. Furthermore, plating of metal powder parts is more effective than ordinary pore-filling materials, in this case, closing the pores is beneficial though this is not essential. On the other hand, metal powder products operating in chemical solutions must have their pores completely closed and the plating must form a 
continuous non-porous shell to prevent attack on the metal powder products.

(b) Good plating will retain its colour and appearance, in this case, closing of the pores is necessary to obtain a polished finish, in order to plate with bright nickel and chrome.

Equally, it must be recognized that there are disadvantages to electroplating. In particular, there are many problems encountered in attempting to plate porous products, amongst them:

(i) Low conductivity of the metal powder parts, which can lead to non-uniform distribution of current and hence nonuniform adhesion and thickness of deposit;

(ii) removing the cleaning or plating solution entrapped in the pores during plating process. Such entrapped solutions can affect tho deposit in three ways:

1. They may exude through the coating after plating and cause "spotting-out" particularly on copper, zinc and cadmium.

2. They electrolytically accelerate corrosion between the coating and the basis metal and cause the coating to peel.

3. Contamination of solutions by transferring residues from one bath to another.

(iii) Cyanide solution absorbed into the pores is extremely difficult to remove. Within a few days the absorbed cyanide decomposes to $\mathrm{Na}_{2} \mathrm{CO}_{3}$ by combination with atmospheric $\mathrm{CO}_{2}$.

$$
\mathrm{H}_{2} \mathrm{O}+2 \mathrm{NaCN}+\mathrm{CO}_{2} \rightarrow \mathrm{Na}_{2} \mathrm{CO}_{3}+2 \mathrm{HCN}
$$

The carbonates formed have a greater molar volume than the corresponding compound causing them to flow outward, spoil the surface and promote corrosion ${ }^{59}$. 
(iv) Many components are required to be zinc-plated and this is one of the most difficult metals to plate on sintered materials. Cadmium is less difficult to process but the metal is more expensive ${ }^{59}$.

(v) Hydrogen embrittlement can be induced in sensitive ferrous alloys by virtue of the low cathode current efficiencies achieved in many complexed metal plating solutions.

\section{3 - 5lectro-Plating Techniques}

Variables to be considered in selecting and formulating an electroplating sequence are as follows:

\section{$3-5-1$ Current Density}

Higher current densities are employed as the metal powder has a greater surface area than the pore-free metals. Acid solutions can be used more easily than alkaline solutions. Cyanide solution can be used as they have better throwing power and covering power and this may help to fill the pores except at high current density. The actual current density and plating time depends on experience particularly in low density products and on the thickness of deposit required.

\section{$3-5-2$ Solutions used}

Solutions with good micro-throwing power are preferred in order to fill the pores and provide a layer on the insides of pores, e.g. acid solutions, copper-pyrophosphate solutions, highly alkaline solutions tend to have low cathode current efficiencies and are most likely to give rise to problems of hydrogen embrittlement. 


\section{$3-5-3$ Rinsing}

Changing the rinsing from hot to cold is useful when treating porous coatings of high or low porosity. This technique will remove the entrapped solutions as by expansion and contraction a change in volume is achieved for the pores, and so is helpful in rejecting the entrapped solutions. Increasing the time of rinsing will lead to dilution of the solution inside the pores.

\section{$3-5-4$ Neutralization}

Neutralization is used to reduce the action of strong acids or alkalis which are entrapped in the pores. Initial immersion in a harmless liquid, e.g. water or weak sodium carbonate solution, prior to cleaning and electroplating is recommended. The entry of the detrimental solutions can then only take place by relatively slow diffusion processes and displacement. The cleaning and plating times, have a large influence on the success of this suggestion.

\section{$3-5-5$ Plating Thickness}

Solutions with good micro-thowing power and levelling action can reduce "spotting-out" with increase in plating thickness. If solutions with low micro-throwing power are used the increase in plating thickness and time of plating will allow more plating solution to enter the pores and initiate corrosion.

\section{$3-5-6$ Heat Treatment}

This process is used to volatilise residual cleaning and plating solutions. Sintering after plating has the dual effect of volatilising 
plating solution and also to improve the adhesion of the deposit by partial diffusion of the coating into the base, the heat treatment has a marked effect on the porosity of the coating itself and it may reduce to a large extent, besides allowing alloying of duplex coating to take place, e.g. copper-nickel. Heat treatment may also be specified to remove hydrogen from hydrogen sensitive ferrous alloy. A typical treatment would be $20-30$ minutes at $105^{\circ} \mathrm{C}$.

\section{$3-6$ Electro-Plating cycle}

1. Rinsing in hot boiling water.

2. Anodic Degreasing.

3. Cathodic Degreasing.

4. Alternate hot and cold rinsing (twice).

5. Pickling in HCl Solution.

6. Altemate hot and cold rinsing (twice)

7. Neutralization with $\mathrm{Na}_{2} \mathrm{CO}_{3}$

8. Al ternate hot and cold rinsing (twice).

9. Plating Cycle.

10. Alternate hot and cold rinsing (twice)

11. Heat Treatment. 
C H A P T E R 4

Characteristics of Electroplating Solutions

Range of Solutions

Throwing Power

Efficiency 


\section{4-1 Copper Plating}

\section{4-1-1 Introduction}

Copper is electrodeposited for a number of purposes, of which providing an under layer coating to various other plating systems is the most important. Copper plating is used to cover zinc-die castings and form a protective film, thus protecting zinc die casting from attack by acid and other environments. Also, this layer can provide an under layer for nickel and chromium plating.

The cyanide copper deposit is used successfully to cover steel and other substrate as it has a good throwing power and can provide a good surface for nickel and chomium as the copper is a good conductive metal. Copper is used when the thickness is of great importance ${ }^{62}$. It may often be done by plating first with cyanide copper and then by acid copper to effect as rapid a deposition process as possible.

Copper can be deposited from three types of solutions: cyanide, acidic and copper pyrophosphate. The cuprous cyanide bath is more economical than the cupric bath, and the deposition rate twice that from the other bath provided the same current density and time is used. Besides this, the cyanide bath requires a steel tank where as the others require a lead, rubber or plastic lining.

On the other hand, the efficiency of the acidic bath is $100 \%$ while the efficiency of the cyanide is not more than $70 \%$ unless high concentration of cyanide and high alkalinity are used ${ }^{63}$. The adhesion of the cyanide copper deposit is far better than that obtained by acid baths since the acid bath deposit may be forming by simple immersion. 


\section{$4-1-2$ Copper Pyrophosphate Solution}

The solution has many advantages since it has a good throwing power, higher current efficiency, is non-corrosive and non-toxic and offers rapid deposition. The solution is used to plate steel, plating on plastic and electroforming ${ }^{69}$.

The properties of the deposit from these solutions are:

1. smooth and bright;

2. Freedom from nodules;

3. high tensile stress;

4. higher current density is possib́le and therefore higher plating speed can be achieved.

The solution contains copper pyrophosphate, either sodium or potassium pyrophosphate, amonia, nitrate and citric acid. The pyrophosphate reacts to form the alkaline complexes $\left[\begin{array}{lll}\mathrm{Cu} & \left(\mathrm{P}_{2} \mathrm{O}_{7}\right)_{2}\end{array}\right]^{6-}$ and $\left[\mathrm{Cu}\left(\mathrm{P}_{2} \mathrm{O}_{7}\right]^{2-}\right.$ which are stabilized at $\mathrm{pH}$ value approximately 8 by ammonia additions 63 .

A typical copper pyrophosphate solution is shown below ${ }^{64}$ :

$\mathrm{Cu}$

$\mathrm{P}_{2} \mathrm{O}_{7}$

wt. ratio $\mathrm{P}_{2} \mathrm{O}_{7} / \mathrm{Cu}$

NO $\overline{3}$

$\mathrm{NH}_{3}$

pH

Temperature

Cathode current Density

Agi tation
22.5 to $30 \mathrm{~g} / \mathrm{l}$

170 to $210 \mathrm{~g} / 1$

7.0 to $8.5 \mathrm{~g} / 1$

7.5 to $15 \mathrm{~g} / \mathrm{l}$

0.5 to $2 \mathrm{~g} / 1$

8.0 to 8.5

38 to $60^{\circ} \mathrm{C}$

1-7 amp $/ \mathrm{dm}^{2}$

Mechanical and air. 
The pH has an important effect on maintaining the complexes, e.g. above $\mathrm{pH}$ value $11 \mathrm{Cu(OH})_{2}$ will precipitate and below pH 7 either $\mathrm{CuH}_{2} \mathrm{P}_{2} \mathrm{O}_{7}$ or $\mathrm{CuP}_{2} \mathrm{O}_{7}$ will precipitate. The optimum $\mathrm{pH}$ value is between (8-9). The ratio of $\mathrm{P}_{2} \mathrm{O}_{7} / \mathrm{Cu}$ is very important and it has been found that at about ratio $7 / 1$ the conductivity is the highest.

The temperature employed depends on the degree of agitation and the current density and the optimum temperature is between $50-60^{\circ} \mathrm{C}$.

The throwing power of the pyrophosphate solution is higher than that of acid copper solution but inferior to that of the cyanide solution, while the efficiency is lower than the acid solution but better than that of the cyanide solution excepting the high efficiency copper cyanide solution.

\section{$4-1-3$ Cyanide Copper Solution}

The cyanide copper solution is used in plating of zinc die casting parts to protect the zinc die castings from chemical attack by acidic baths used for plating. Steel can be plated directly by this solution since this solution does not tend to deposit copper by simple immersion which provides an underlayer for nickel and chromium plating.

At $100 \%$ cathode efficiency, 1 ampere-hour deposits $2.373 \mathrm{gm}$ of copper from cuprous baths and $1.186 \mathrm{gm}$ from cupric bath, so it is clear that the cuprous baths would always be more economical. Moreover, the cyanide baths may be kept in steel tanks, and there is no need for rubber or plastic lining ${ }^{68}$.

The major constituents of the cyanide solution are copper cyanide and etther sodium or potassium cyanide. A typical solution is shown be $10 w^{69}$

$\mathrm{CuCY}$

Free $\mathrm{KCN}$ or $\mathrm{NaCN}$
20 to $45 \mathrm{~g} / \mathrm{l}$

4 to $15 \mathrm{~g} / \mathrm{I}$ 
$\mathrm{K}_{2} \mathrm{CO}_{3}$ or $\mathrm{Na}_{2} \mathrm{CO}_{3}$

Rochelle Sal $t$

$\mathrm{pH}$

Temperature

Cathode Current Density

Efficiency

Agitation
15 to $60 \mathrm{~g} / \mathrm{l}$

30 to $60 \mathrm{~g} / 1$

12 to 13

50 to $70^{\circ} \mathrm{C}$

1 to $10 \mathrm{amp} / \mathrm{dm}^{2}$

30 to $80 \%$

Mechanical and Air.

Rochelle salt is added to enhance anode corrosion. The beneficial erfect of Rochelle salt and substitutes and improvements over this compound which are sold today as proprietory additives, are perhaps due to the complexing and solubilizing action these materials have on divalent copper.

Many types of additives have been investigated for cyanide copper plating as grain refiners, brighteners, levellers and as anti-pitting and wetting agents.

The cyanide copper solution has a poorer micro-throwing power than the acid copper solution buthas an excellent macro-throwing power. The efficiency of the cyanide solution is less than $100 \%$ and this is one of the drawbacks, but the proper choice of the concentrations of the constituents and the bath operating conditions the efficiency is improved and nearly becomes $100 \%$. The other disadvantage of the solution is the toxicity of the solution since the cyanides are highly poisonous and require some special attention during handling and working with the solution.

\section{$4-1-4$ Acid Copper Solution}

Copper is almost unique from the stand point of the variety of acid systems from which it has been plated. The reasons are the 
excellent solubility of copper salts in acid solutions, the high cathode efficiency at a very low $\mathrm{pH}$ values, and the ability of copper to form many kinds of complex compounds in the solution. The acid solution is used mainly to build up a heavy deposit and in electroforming, as a base for buffing ${ }^{67}$ and manufacturing of copper powder ${ }^{6}$. The solution can work at high current density up to $50 \mathrm{Amp} / \mathrm{dm}^{2}$, is very cheap and easy tomaintain and control. The anodic and cathodic polarization are small, therefore the voltage applied is less than for the alkaline baths. The throwing power of the acid copper is less than that for the alkaline solution due to the low cathodic polarization. Copper is deposited in preferential to the hydrogen since the hydrogen is above the copper in the electrochemical series, therefore copper can be deposited from a solution with a very low $\mathrm{pH}$ value and a high conductivity. A typical solution for the acid copper is shown below ${ }^{69}$ :

$$
\begin{aligned}
& \text { Copper Sulphate CuSO }{ }_{4} \cdot 5 \mathrm{H}_{2} \mathrm{O} \quad 150 \text { to } 300 \mathrm{~g} / \mathrm{I} \\
& \text { Sulphuric Acid Sp. Gr. } 1.84 \quad 10 \text { to } 110 \mathrm{~g} / 1 \\
& \text { Temperature } \quad 20 \text { to } 50^{\circ} \mathrm{C} \\
& \text { Agitation Mechanical } \\
& \text { Cathode Current Density } 2.5 \text { to } 50 \mathrm{Amp} / \mathrm{dm}^{2} \\
& \text { Anode Current Density } 15 \text { to } 50 \mathrm{Amp} / \mathrm{ft}^{2} \text {. }
\end{aligned}
$$

From the above compositions it has been shown that a wide range of $\mathrm{H}_{2} \mathrm{SO}_{4}$ concentration is possible; concentrations below $30 \mathrm{~g} / 2$ are recommended with the use of addition agents for brightening, grain refining, levelling and other purposes since at the low concentration of $\mathrm{H}_{2} \mathrm{SO}_{4}$ the decomposition of the addition agents is lower. The presence of chlorides in the acid copper baths is objectionable due. to the detrimental effects on the appearance of the copper deposit ${ }^{69}$. A variety of additon agents are used for grain refinement, smoothing 
the deposit, brighten the deposit, increasing the leveliing and to obtain other special characteristics.

The characteristics of the copper deposit is influenced by the concentration of salt, temperature, cathode current density and degree of agitation.

\section{$4-2$ Zinc Plating}

\section{4-2-1 Introduction}

Zinc is widely used for protecting steel since zinc comes above iron in the electrochemical series and therefore dissolves preferentially to iron, thus protecting steel. Electroplating of zinc can give a more uniform deposit than other methods of zinc coating and; moreover, the electro plating could be done by either acid or cyanide solutions. All the zinc plating baths are easy to control and maintain, most of them are operated at room temperatures and the zinc salts are readily available commercially.

\section{$4-2-2$ Acid Zinc Solutions}

The solution is used for plating steel and iron castings and especially wire and sheet where good throwing power is not required, small manufacturing parts, hardware ${ }^{63}$. The solution is characterized by high plating rates with a low operating cost. The macro throwing power is poor but it has a good micro-throwing power. (The theoretical throwing power of acid zinc solution varies from $(-3$ to $+4 \%)$. As measured by Harning and Blum cell with $5: 1$ ratio ${ }^{70}$ ). The cathode efficiency of the solution is $100 \%$ and the polarization at both the cathode and the anode is quite low, less than $0.1 V^{70}$. 
The acid zinc baths classified by theix chemical composition are sulphate, chloride, mixed sulphate and chloride and fluoborates. A Typical compositions and operating conditions of the various baths are given below? 1

1. Sulphate Bath

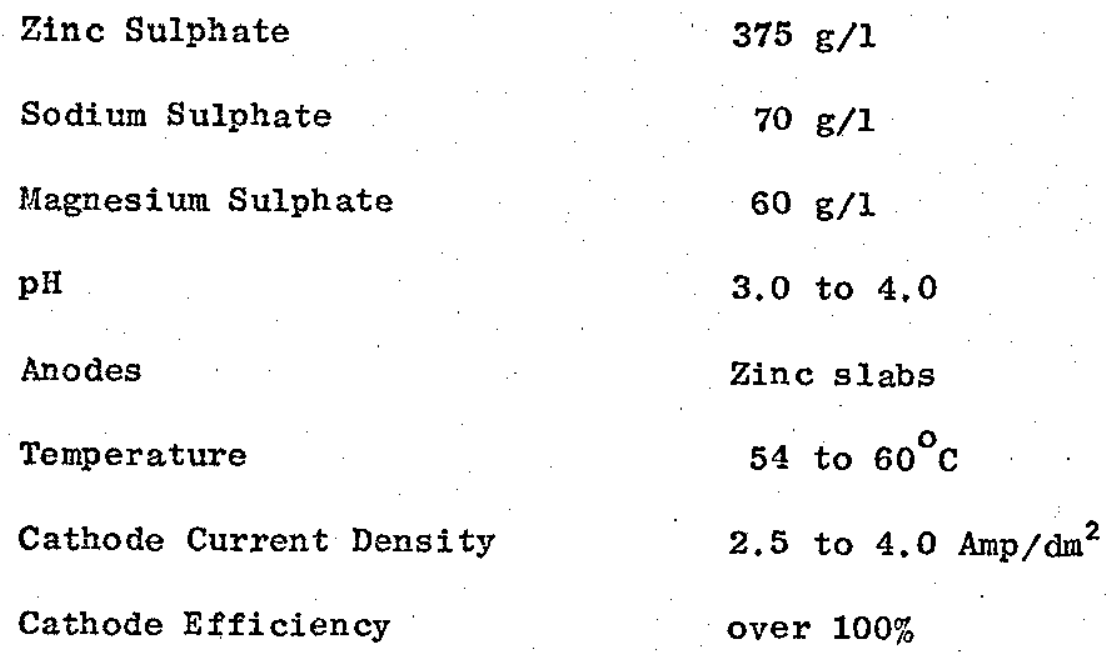

2. Chloride Bath

Zinc Chloride $135 \cdot \mathrm{g} / 1$

Sodiun Chloride $230 \mathrm{~g} / 1$

Ammonium Chloride

$22 \mathrm{~g} / 1$

pH

3.0 to 4.0

Temperature

40 to $60^{\circ} \mathrm{C}$

Current Density

up to $50 \mathrm{Amp} / \mathrm{dm}^{2}$

3. Mixed Sulphate-ChIoride Process

Zinc Sulphate

Sodi um ChIoride

Boric Acid

Aluminium Sulphate

Dextrin

Temperature

Cathode Current Density
$360 \mathrm{~g} / \mathrm{l}$

$15 \mathrm{~g} / 1$

$22 \mathrm{~g} / 1$

$30 \mathrm{~g} / 1$

$15 \mathrm{~g} / 1$

38 to $55^{\circ} \mathrm{C}$

up to $30 \mathrm{Amp} / \mathrm{dm}^{2}$ 
Addition agents can be added to improve the rate of deposition and to produce finer grained deposits and slightly improve the throwing powder, e.g. dextrine, glycerin, licorice etc. 66

\section{4-2-3 Cyanide Zinc-Plating}

The zinc-cyanide solution is used where the throwing power for zinc-plating solution is of great importance ${ }^{72}$. The solution is either based on zinc cyanide or zinc oxide with sodium hydroxide. The concentrations are very critical and require considerable attention. The concentration of each component depends on the concentration of the others, and on the operating conditions, such as pH and temperatures. The ratio of cyanide to zinc has a great effect on the cathode efficiency and throwing power of the solution: low ratios are characterized by relatively high cathode efficiency and poor throwing power, at high ratios cathode efficiency increases. But at the optimum ratio, good coverage is obtained in low current density areas ${ }^{70}$.

The zinc oxide or zinc cyanide provides the bath with zinc ions; while the cyanide is to stabilize metal in soluble form and affect the mode of ion cischarge through its complexing action. Cyanide also renders the bath responsive to addition agents, besides which the cyanide itself might produce lustrous, bright and adherent zinc plate. The hydroxide acts as a good anode depolarizer, minimizes the hydrolysis of cyanide, increasing plating speed, and increasing the conductivity. The cyanide solution is more expensive in making up, maintenance and working, but these crawbacks are offset by the good quality of the deposit obtained. 


\section{$4-2$ - 4 Alkaline Zinc Solution}

This solution became important because of the problems in handling and treating cyanide solutions. The solution gives a satisfactory zinc deposit, is characterized by high throwing power and only slightly less than conventional cyanide baths. The main constituents of the solution are zinc oxide and sodium hydroxide. The hydroxide content is critical regular additon of $\mathrm{NaOH}$ have to be kept in $\mathrm{mind}^{78}$ due to the dependence of the efficiency on the chemicals used. The efficiency is about (85 to $95 \%$ ) and $i t$ is a very critical function of the metal content. Increasing the caustic and zinc metal content and increasing temperature increase the bath efficiency ${ }^{73}$. Fig. 10 shows a relationship between current efficiency and concentration of zinc. The biggest drawbacks of the alkaline zinc solution are to find a good brightener and to increase the cathode efficiency ${ }^{73}$.

\section{$4-3$ Nickel Plating}

\section{4-3-1 Introduction}

The electrodeposition of nickel is now an old, well-tried process, the fundamentals of which are well-understood. Nickel is one of the most important metals applied by electrodeposition. The deposit is used principaliy as a bright coating underneath a much thinnex chromium electro-plate which provides a very bright and corrosion resistance finish for articles of steel, brass and zinc-die casting. A thin gold or brass electroplate with clear lacquer finish is also used as a decorative coating on such bright nickel deposits. Nickel electrodeposits are used for electroforming of printing plates, gramaphone records, etc. Nickel deposition is also used extensively for electroforming, particularly in the manufacturing of dies. Nickel is successfully used for lining 
vessels used in the food industry as the nickel is non-toxic and resists corrosion. Furthermore, for the former applications of nickel it is essential that good adhesion between coating and substrate is more important than for decorative plating. In the $\mathrm{Cr}$ plating industry the chromium plating for decoration depends upon the nickel layer coats winich w111 protect the steel or other basis metal against corrosion, since chromium over layer coatings are relatively porous and hence do not prevent corrosion.

\section{$4-3-2$ Function of baths constituints}

There are a large number of different electrolytes from which nickel can be deposited and the choice of any one of them depends partly on the mechanical properties desired in the deposit and oven more on the type of article to be plated. Therefore, nickel baths nay be classified according to their application. Deposits for protection against corrosion and for appearance and those that are to be chromiumplated can be either plated dull and subsequently buffed or semi bright requiring only light buffing, or bright with no budding. For registance to wear, e.g. on printing plates, relatively hard, tough nickel is employed. Thick coating of nickel deposit is used for engineering purposes and the increase in the hardness is achieved at the expense of other properties. The main constituent of nickel bath is either nickel sulphate or nickel chloride and essentially the nickel salt is to provide the bath with nickel ions. The nickel sulphate is relatively cheap, highly soluble and easily available commercially either as $\mathrm{NiSO}_{4} \cdot 7 \mathrm{H}_{2} \mathrm{O}$ or $\mathrm{NiSO}_{4} \cdot 6 \mathrm{H}_{2} \mathrm{O}$.

All nickel baths nowadays contain either nickel chloride or chloride ions, these being necessary to ensure anode corrosion with high anode efficiency of the nearly pure nickel anodes, i.e. prevent 
them being passive. The chloride also increases the conductivity, increases the throwing power of the nickel solution and increases the diffusion coefficient of nickel ions thus increasing the limiting current density ${ }^{74}$.

\section{$4-3-3$ Buffers}

The addition of buffers can control the rise in $\mathrm{pH}$ within the cathode l layer.

Al though nickel deposits can be obtained from baths with $\mathrm{pH}$ values from 1.5 to 6.0 , there are three roughly defined pH ranges in use in nickel plating. The first is the "low pH" bath which is operated at $\mathrm{pH}$ from 1.5 to 3.0 , at alternatively high temperatures and current density. Most of the bright-nickel baths are used in the pH range from 3.0 to 4.5. Baths used at low temperatures and current densities, for thin deposits or for hard coatings are generally used at $\mathrm{pH}$ values from 4.5 to 6.0 .

If these baths contained only nickel salts or other sulphate and chloxide, they would be only slightly buffered, hence a small difference between the anode and cathode efficiencies would cause a relatively large change in $\mathrm{pH}$ and necessitate its frequent adjustment by addition of acid or alkali. The most commonly used buffer in nickel baths is boric acid, $\mathrm{H}_{3} \mathrm{BO}_{3}$, which is used to maintain the acidity of the solution and prevent wide fluctuation of $\mathrm{pH}$. Boric acid is a very weak acid and exerts its maximum buffer effect at a $\mathrm{pH}$ from 5 to 6 . It might therefore appear that use of boric acid in baths operated at lower pH would be unwarranted.

Acetic acid $\mathrm{CH}_{3} \mathrm{COOH}$ is relatively weak, though stronger than boric acid. It exerts its maximum buffer action in a somewhat lower pH range than boric acid, e.g. from 3 to 5 , because it is a weak 
organic acid. The buffer action of acetic acid is obtained by adding nickel acetate $\mathrm{Ni}\left(\mathrm{CH}_{3} \mathrm{COO}_{2}\right.$

Formic acid, (HCOOH), is somewhat stronger than acetic acid. It exerts a buffer action when added as a formate, e.g. in the nickel cobalt bright bath ${ }^{66}$.

\section{$4-3-4$ Antipitting Agents}

One of the most common and unpredictable defects of nickel baths is their tendency to yield pitted deposits. A pit is associated with the presence and retention of gas bubbles, usually hydrogen, on the cathode surface which prevents deposition of metal at that point. A pit may start at the cathode surface in which case it constitutes a pore through which corrosion can occur. In other cases the pit may originate during depositon and may not extend to the basis metal. Certain antonic wetting agents are used in nickel baths to prevent bubbles of hydrogen from adhering to the cathode and causing pits in the deposit. They function by reducing the surface and interfacial tension. The bubbles disengage before they can grown to a size to cause pitting by blocking the plating at the point of contact of the bubbles. Hydrogen peroxide $\left(\mathrm{H}_{2} \mathrm{O}_{2}\right)$ furnishes a material that is more easily reduced at the cathode than is the hydrogen or nickel ion. Hence, at those points at which hydrogen might otherwise be discharged and cause pitting, the hydrogen peroxide is reduced and depolarizes the cathode with respect to hydrogen evolution. The advantage of $\mathrm{H}_{2} \mathrm{O}_{2}$ is that the end-product of 1 ts reduction $1 s$ water, and hence is harmless. Other oxidizing agents that might be employed may leave harmful compounds which may accumulate in the bath: persulfates and permanganates are of this class ${ }^{66}$. 
$4-3-5$ Brighteriers and Levellers

The unique decorative and corrosion-resistant coating that can be obtained with nickel plate underneath a thin, hard, wear-resistant and non-tamishing chromium plate was responsible for the Intensive research that led to the development of modern bright nickelplating. These brighteners have received more attention than those for any othex plating bath, owing to the economic importance of eliminating the expensive hand polishing of dull nickel deposits and the fact that the organic brighteners for nickel are definite compounds and therefore their mode of action could be more accurately studied. It is now possible to classify the brighteners into a few fairly well-defined groups, but on the other hand the function or the mechanism of the various organic compounds is still not fully known although several suggestions have been advanced. ${ }^{75}$ No single theory appears completely to explain all of the observed facts.

The brighteners fall into two classes, class I and class II. In class I nickel brighteners, the aromatic rings to which the sulphur group is attached are generally benzene and naphthalene rings. These brighteners produce almost bright or cloudy bright plate on buffed surfaces but are unable to build higher Iustre with continued plating. they have no critical upper concentration and are used in relatively high concentration $(1-10 \mathrm{~g} / 1)$ without significantly affecting the adhesion and the limiting current density ${ }^{i_{L}}$. They decrease the tensile stress of the deposit.

The brighteners designated as class II nickel brighteners are used together with class I brighteners to obtain a brilliant leveling deposit of increasing lustre with continual plating to the point of highest lustre. Class $\mathrm{I}$ brighteners are unsaturated compounds which 
produce the levelling and increased lustre of the deposit when used in canjunction with class I brighteners.

Most class II brighteners cannot be successfully used alone to obtain bright plate because they produce excessive brittleness and tensile stress.

The levellers act by increasingthe polarization at peaks, as compared to the polarization in the valleys and the current will concentrate in the valley, and levelling is expected. This is due to the incorporation of the levellers in the deposits. The levellers are sulphurfree compounds and conzórin is a good example.

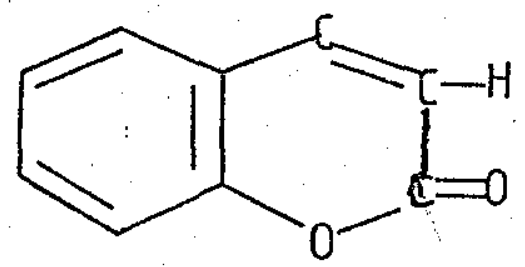

Gardner Foulke ${ }^{76}$ has found that an increase in current density will result in a slower rate of levelling and increase in $\mathrm{pH}$ will increase the levelling while higher temperatures favour better levelling.

\section{$4-3-6$ Solutions used}

(a) Watt Nickel Bath

A simple common solution of nickel sulphate used for heavy nickel deposit. The solution is simple in use and easy to maintain and control. The deposit from this solution is less brittle and shows lower internal stress than the nickel chloride solution ${ }^{77}$. A typical solution contains:

Nickel Sulphate

Sodium Chloride or nickel chloride

Boric Acid

Current Density
140-240 g/1

20-45 g/1

20-30 $\mathrm{g} / \mathrm{I}$

$5 \mathrm{Amp} / \mathrm{dm}^{2}$ 
$\mathrm{pH}$

$$
3.5-4.5
$$

Temperature

$60-65^{\circ} \mathrm{C}$

Sometimes the chloride ions are provided by sodium chloride whtch is cheap and is avallable in a pure state. However, for commerclal application, the sulphate plus chloride solution of the watt type is preferred.

The throwing power of the watts bath is slightly improved by an increase in $\mathrm{pH}$, temperature, and nickel and chloride content ${ }^{78}$. Higher throwing power in acidic nickel bath can be obtained by using low nickel salt concentration, for example 100-120 g/1 nickel sulphate and higher sodiun chloride concentration to $160 \mathrm{~g} / 1$ with $30 \mathrm{~g} / 1$ boric acid, at $\mathrm{pH}$ value 4 with $50-60^{\circ} \mathrm{C}$ and no agitation need to be used. The pII of the solution and the current density has a great effect on the efficiency, at $\mathrm{pH}$ value 5.0 and at $1 \mathrm{Amp} / \mathrm{dm}^{2}$ the cathode efficiency is approximately $99 \%$ and at $5 \mathrm{Amp} / \mathrm{dm}^{2}$ the cathode efficiency is a little higher. At pH value 2.0 for the same solution the cathode efficency is approximately 93\% at $2 \mathrm{Amp} / \mathrm{dm}^{2}$, and about $97 \%$ at $5 \mathrm{Amp} / \mathrm{dm}^{2}$ (See Fig. 11).

(b) All Chloride and High Chloride baths

The solution is used to obtain high-speed bright plating, and is used in barrel-plating operations. The solution is highly conductive with high throwing power and limiting current density. Thick deposits can be obtained but of high tensile stress and the ductility is lower than that obtained by watts solutions ${ }^{79}$. The mechanical properties obtained are thus inferior to those from the watts bath. The solution is more expensive than the sulphate solution and is highly corrosive. . A typical solution is shown here: 
Nickel chloride

Ni clsel sulphate

Boric acid
$150-300 \mathrm{~g} / 1$

$$
0-200 \mathrm{~g} / \mathrm{l}
$$

$20-50 \mathrm{~g} / 1$

The dependence of the solution on the $p H$ variation is not as much as the Watts solution. However, the efficiency is better than the Watts solution.

\section{(c) Nickel Sulphamate Solution}

This solution is used for heavy nickel deposition and electroforming. High rate of deposition with low tensile stress can be obtained from this solution with higher throwing power than the Watts solution ${ }^{80}$, but it is more expensive than the Vatts solution. The limitation has restricted its application for decorative/protective plating. A typical solution of this kind is:

$\begin{array}{llr}\text { Nicke1 sulphanate } & \mathrm{Ni}\left(\mathrm{NH}_{2} \mathrm{SO}_{3}\right)_{2} & 300-450 \mathrm{~g} / \mathrm{I} \\ \text { Nicke1 Chloride } & \mathrm{NiCl}_{2} \cdot 6 \mathrm{H}_{2} \mathrm{O} & 0-15 \mathrm{~g} / 1 \\ \text { Boric Acid } & \mathrm{H}_{3} \mathrm{BO}_{3} & 30 \mathrm{~g} / 1\end{array}$

Boric acid is used as buffer since the solution is operated at pH between 3.5 to 4.5 . Nickel chloride is used to enhance anode dissolution and to prevent compressive stress ${ }^{81}$, and the concentration of the chloride depends on many factors including the type of anode, the nature of the anode bag, the anode current density, the pH value, and the degree of agitation of the solution ${ }^{82}$. The solution can be operated successfully without addition agent, however, organic compounds are added as an antipitting and to modify the intermal stress. The efficiency can be improved by operating at higher . current densities. 


\section{(d) Nickel Fluibotiate Bath}

This solution is easy to operate and used mainly for electro types, barrel plating and heavy nickel plating, but the application is limited by the high cost of chemicals. The solution: is characterised by its high conductivity and high current density can be employed ${ }^{83}$. The throwing power of the solution is inferior to that of the sulphate solution. A typical solution is shown below:

$\begin{array}{llr}\text { Nickel Fuloborate } & \mathrm{Ni}\left(\mathrm{BF}_{4}\right)_{2} & 300-450 \mathrm{~g} / \mathrm{l} \\ \text { Free Fluoborlc Acid } & \mathrm{HBF}_{4} & 5-40 \mathrm{~g} / 1 \\ \text { Free Boric Acid } & \mathrm{H}_{3} \mathrm{BO}_{3} & 2.0-3.5 \mathrm{~g} / 1 \\ \text { Temperature } & & 40-80^{\circ} \mathrm{C} .\end{array}$

Chlorides are added for smooth anode corrosion and the efficiency can be increased by increasing the $\mathrm{pH}$. It has been found that if the $\mathrm{pH}$ is raised from 2.7 to 2.8 (colorimetric) the cathode efficiency rises from about $90 \%$ at $1 \mathrm{Amp} / \mathrm{dm}^{2}$ to approximately $95 \%$ at $5 \mathrm{Amp} / \mathrm{dm}^{2} 77$. E. Rochel and $W$. Wesley ${ }^{83}$ have found that the cathode efficiency can be considered satisfactory since the values of the effictency 1 ie above $90 \%$.

Excellent mechanical properties can be obtained from the flouborate bath $^{83}$. 
C HA P TE R 5

Experimental Work 


\section{$5-1$ Experimental work}

\section{5-1-1 Introduction}

Iron powder A.S.C. 100-29 has been characterized, Table 2,

Fig. 13 and Fig. 14, and particular attention has been paid to the flow rate, apparent density, tap density and particle size distribution. A green density versus, pressure has been drawn, Fig. 15.

Atomized iron powder -was fed into a shaped die

whose wall had been lubricated with stearic acid dissolved in Diethyl ether, Fig. $16, k$ and a pressure applied between the punches. Pressing has carried out on a mechanical press Fig. 17. The relationship between compressibility and green density has been found, Fig. 15. Depending on the density requirement, the pressure applied varies from 190-450 $\mathrm{kN}$. Thus, specimens have been compacted to three different pressures to form three groups of specimens of different densities but all had the same dimensions which were $50 \times 8 \times 4 \mathrm{~mm}$.

The green compacts produced by the pressing operation are mechanically weak and brittle, although they have sufficient strength to withstand normal handling ${ }^{84}$. Even bodies of high density compacted at high pressures may be unable to withstand small applied stresses (other than compressive stresses), because of the limited degree of inter particle bonding ${ }^{16}$. Thus, these specimens are sintered in a reducing atmosphere using a mixture of dry nitrogen $3 \%$ Hydrogen gas. The temperature profile (i.e. temperature vs, distance $p l_{o} t$ ) has been determined (Table 3) to establish the position of the hot zone and the true maximum temperature, Fig. 18.5 pecimens were sintered for $1 / 2 \mathrm{hr}$ at $1373 \mathrm{k} \pm 5$ following the procedure described by $\mathrm{J}$. Turnstall.

The permeability of each specimen has been determined before and after sintering. The specimen is put in a special designed cell, Fig. 20. (See Appendix II). Two rubber gaskets and a brass ring of approximately the same height as the specimen was used to prevent

\section{* J. Tunstall.Ph.D. Thesis. Loughborough University of Tach. 1977.}


leakage of gas from the sides and edges of the specimen. The cell is connected to the Lea and Nurse apparatus, Fig. 21 in order to measure the permeability of the specimens before and after plating. The Lea and Nurse apparatus were built according to the B.S. (4359). The apparatus consists of two monometers, a bed monometer and flow rate monometer. The bed monometer was filled with mercury (Sp. Gr. 13.6) and the flow rate monometer was filled with Di-n-butylphthalate (Sp. Gr. 1.0481) at $20^{\circ} \mathrm{C}$. The monometers were used to measure the pressure drop across the specimen and across the capillary tube used to measure the flow rate. Dry nitrogen was allowed to flow from a gas cylinder through the specimen in the cell and the heights of the liquids in the monometers were recorded and by using the equation provided by the B. s. (4359). The permeability constant was calculated.

The permeability can be measured before and aftex plating for each sample. In order to plate the specimens they were degreased in a degreasing solution to obtain good adhesion, removal of oll, greases and to make the deposit cover all the specimen. The degreasing is carried out in a special solution (see page 77 .)

Etching was accomplished in $15 \% \mathrm{HCl}$ at room temperature. Then the specimens were electroplated.

Samples of similar porosity were plated using different plating solutions, and samples of different level of porosity were plated with the same kind of plating solutions and the same techniques were used. The electrolytes chosen were either from $W$. Canning Company, i.e. Commercial, such as the acld zinc, bright nickel (NiSO1 80), and the' coppex pyrophosphate. The operating condition for the former solutions were chosen according to the condition required, (Table 4) - or the 
electrolytes were prepared according to details given in the if terature unless otherwise stated. For each solution all the operating conditions were held constant and identical for each solution except the time and current density in order to investigate the effect of the thickness on closing the surface pores. The specimens were plated with either a single layer or successive layers. Each specimen after degreasing, etching and plating were thoroughly rinsed in boiling and cold water twice after each process. It has been found that successive rinsing and

is very important, effective and plays an important role in the electroplating of sintered iron; and changing the rinse from cold to hot and (vice versa) pushes the entrapped solution out; decreases the concentration of the entrapped solution inside the pores, and decreases the incidence or "spotting out". Neutralization with $5 \% \mathrm{Na}_{2} \mathrm{CO}_{3}$ is carried out after etching. After plating the specimens were dried in a dryer type(Gallen-kamp) for 20 minutes, and the permeability was checked. One month later the surface characteristics of all the plated specimens were investigated by the scanning electron microscopy as it has a large magnification range, and the optical microscopy (Appendix 1 , F1gs.23-67.), to observe the thickness of the deposit and filling the inside and the surface pores by plating and photomicrographs were taken.

\section{$5-1-2$ Determination of the Flow Rate}

The flow rate is the ability of the powder to flow and fill the dies which is a very important factor in the industry of powder metalIurgy. The flow rate of the powder depends, to a large extent, on the size and shape of particles and on the presence of lubricants moisture and corrosion products, since the presence of these compounds will 
Impede the flow of the powder.

The apparatus used to measure the flow rate is the Hall flow meter and this consists of a highly polished brass funnel and a brass cup. Exactly $50.0 \mathrm{gm}$ of the powder was allowed to flow from the funnel and the time was measured. Flow rate is expressed in seconds. In case of non-standard weight of powder is used, the unit will be g/seconds. The experiment was repeated three times and the average flow rate was reported.

\begin{tabular}{|c|c|}
\hline & Time (secs) \\
\hline Ist run & 34 seconds \\
IInd run & 33.5 seconds \\
IIIrd run & 33.8 seconds \\
\hline
\end{tabular}

The average flow rate $=\frac{34+33.5+33.8}{3}=33.8$ seconds

\section{$5-1-3$ Determination of the Apparient Density}

It is defined as the weight of a unit volume of a loose powder. The value of the apparent density ranging from $20-50 \%$ of the theoretical solid density. The apparent density depends on the thoeretical solid density and particle size and shape. It was determined by weighing an empty cup of capacity $25 \mathrm{~cm}^{3}$. This cup was filled with powder until. it overflowed. The powder in the cup was levelled with a straight edge and the cup tapped gently. The cup and the powder were weighed in order to determine the weight of the powder, which is the difference in weight between the weight of the cup plus the powder and the weight of the empty cup.

This procedure was repeated three times and the mean value of the apparent density reported. 
$P_{a}=\frac{\text { wt. of powder in } \mathrm{ckp} \mathrm{gm}}{25 \mathrm{~cm}^{3}}=\mathrm{g} / \mathrm{cm}^{3}$

\begin{tabular}{|c|c|c|}
\hline $\begin{array}{c}\text { Wt. of powder } \\
\text { In cap cm }\end{array}$ & $\begin{array}{c}\text { volume of powder } \\
\mathrm{cm}^{3}\end{array}$ & $\begin{array}{c}\rho^{\prime} \mathrm{a} \\
\mathrm{g} / \mathrm{cm}^{3}\end{array}$ \\
\hline 79.15 & 25 & 3.164 \\
79.15 & 25 & 3.166 \\
79.00 & 25 & 3.160 \\
\hline
\end{tabular}

$\rho \mathrm{a}=\frac{3.164+3.166+3.16}{3}=3.16 \mathrm{gm} / \mathrm{cm}^{3}$

\section{5-1-4 Determination of Tap Density}

The tap density is the weight per unit volume of powder that has been taped until settling no longer occurs. It is easy to determine by pouring a known weight of powder in a dry clean graduated cylinder and gently tapping $100 \mathrm{gm}$ of powder was poured in a $50 \mathrm{ml}$ measuring cylinder and by using this formula.

$$
\rho t=\frac{100 \mathrm{gm}}{\text { volume occupied by powder }\left(\mathrm{cm}^{3}\right)}
$$

This procedure was repeated three times and the value of the tap density was determined as the mean value.

\begin{tabular}{|c|c|c|}
\hline $\begin{array}{c}\text { Wt of powder } \\
\mathrm{gm}\end{array}$ & $\begin{array}{c}\text { volume oc cupied } \\
\text { by cm }\end{array}$ & $\begin{array}{c}\rho \mathrm{t} \\
\mathrm{gm} / \mathrm{cc}\end{array}$ \\
\hline 100.00 & 29.00 & 3.448 \\
100.00 & 29.00 & 3.448 \\
100.00 & 29.00 & 3.448 \\
\hline
\end{tabular}

$$
p^{t}=\frac{3.448+3.448+3.448}{3}=3.45 \mathrm{gm} / \mathrm{cm}^{3}
$$




\section{$5-2$ Surface Preparation}

\section{5-2-1 Introduction}

The surface cleaning of the substrate to be plated is very important in order to get good adhesion, a complete cover of the substrate, removal of corrosion products and scale, and oil greases etc.

This could be done by using:

(a) Mechanical Methods, e.g. Polishing, Buffing and Brushing. By this method a considerable amount of the metal is removed by grinding then the surface is subjected to a polishing and finally buffing. The surface becomes smooth and free from inclusions

(b) Solvent cleaning: certain solutions are used to dissolve the greases and oils from the substrate. They will not remove rust and scale. This could be done either by:i) vapour degreasing, highly effective method for removing oils and greases by subjecting the metal to be degreased to a non-flammable solutions at its boiling points, it is used for a much greater volume of work being cleaned.

ii) cold cleaning by using a solvent or a mixture of solvent to remove oils and greases. Thls method is used for low-production application and where initial equipment costs are of a major consideration.

(c) Electropolishing: the principle of this method is similar to the mechanical methods, in which a thin layer of the substrate is removed from the surface in order to achieve a smooth surface.

(d) Alkali-Cleaning: the alkali-cleaning is either electro-chemical or chemical. In case of electro-chemical degreasing the metal is either placed on the anode or on the cathode. A suitable voltage and temperature is used. As water decomposes hydrogen and oxygen are 1 iberated and those gases accelerate the removal of the particles from the substrate. 
(e) Oxide Removal: this is a simple immersion operation to remove the oxide and the scale from the surface. One kind of acid or a mixture of them can be used depending on the nature of the oxide to be removed, the substrate, the cost and the thickness.

\section{$5-2-2$ Factors effecting the selction of the Method and the cleaner}

(a) The size and shape of the metal may determine the choice of the cleaning method.

(b) Chemical and physical properties may restrict the method of cleaning, e.g. it is impossible to clean aluminium in alkaline haths since aluminium dissolves rapidy in the alkali solutions. Another example is the changing the lattices of the surface if it is exposed to the polishing and scratching and this might effect the property of the deposit.

(c) Cost Factor and Optimum Finish: The cost of each method (solutions, equipment and operating variables) with respect to the product must be considered in order to achieve an economic plant.

(d) Waste Disposal: cleaner containing organic solvents cannat be discharged into the sewage system unless it is converted to a less harmful form.

\section{$5-2-3$ Process, Solution used and Time}

(a) Each specimen was immersed first in boiling water for 20 seconds, to $\mathrm{fill}$ the pores and make it difficult for the cleaning solution to enter the pores. There by decreasing the concentration of the ingress solution entrapped among the pores.

(b) The specimen was exposed to anodic and cathodic degreasing in a solution as follows: 


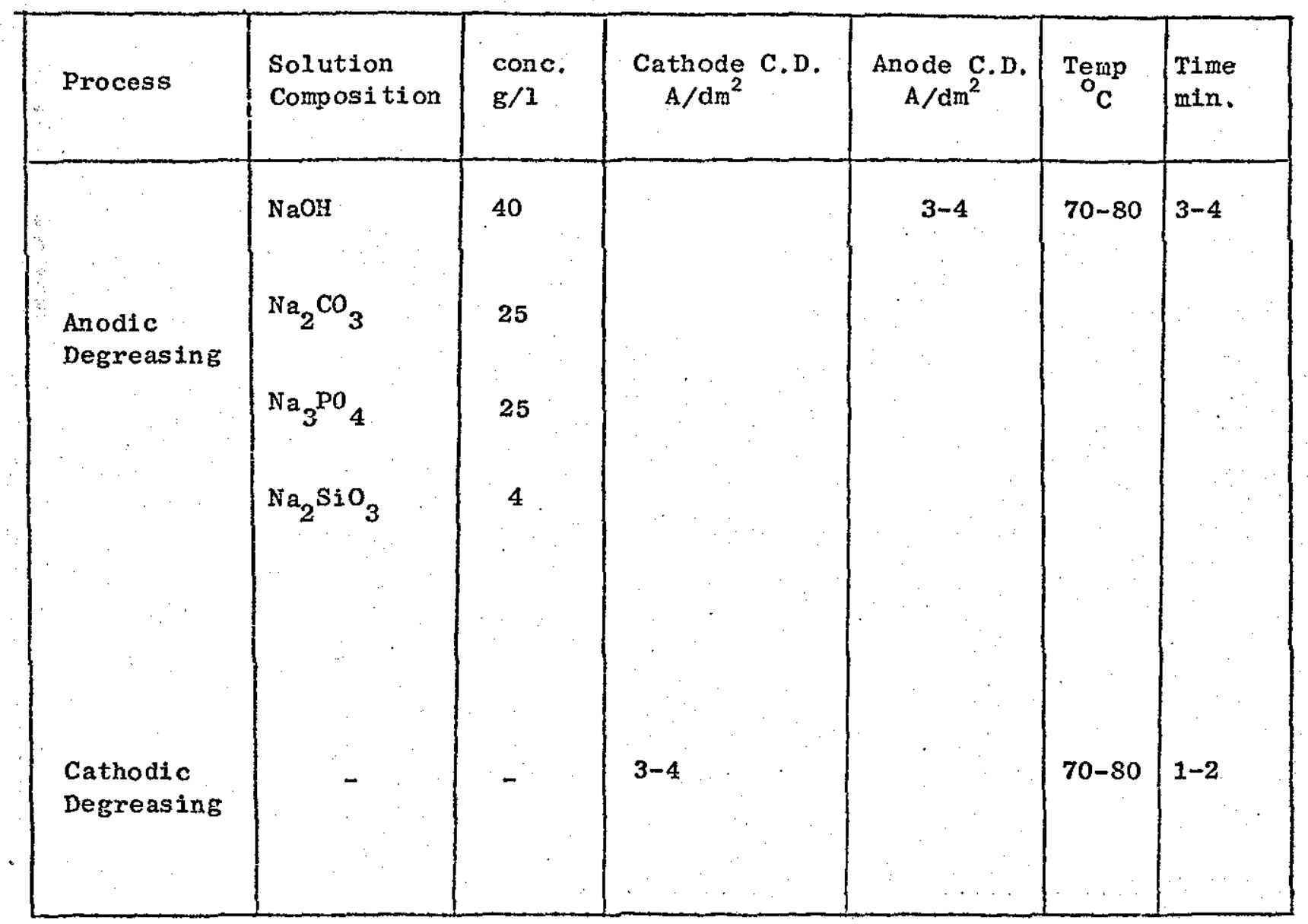

The voltage used $=4 \mathrm{~V}$

Total current/specimen $=4$ Amp.

(c) Cold Rinsing in running water.

(d) Rinsing in boiling water.

(e) Cold rinsing in running water.

(f) Rinsing in boiling water.

These altemate thorough rinsing were used to discharge as much as possible of the entrapped solution by the contraction and expansion of the pores.

(g) Pickling

Hydrochloric acid was used to remove the light rust from the surface and inside the pores, conditions as follows: 


\begin{tabular}{|c|c|c|c|c|}
\hline Process & $\begin{array}{l}\text { Solution } \\
\text { Composition }\end{array}$ & $\begin{array}{l}\text { Conc. } \\
\mathrm{g} / 1\end{array}$ & $\begin{array}{c}\text { Temp. } \\
{ }_{\mathrm{C}} \mathrm{C}\end{array}$ & $\begin{array}{c}\text { Time } \\
\text { min. }\end{array}$ \\
\hline Pickling & $\mathrm{Hcl}$ & $15 \%$ & $22-77$ & $2-3$ \\
\hline
\end{tabular}

(h) Rinsing in cold water.

(i) Rinsing in boiling water

(j) Neutralization with $5 \mathrm{~g} / 1$ of $\mathrm{Na}_{2} \mathrm{CO}_{3}$ by simple immersion.

(ik) Cold rinsing.

(1) Rinsing in boiling water.

(m) Neutralization with $10 \mathrm{~g} / \mathrm{h}$ oxalic acid.

(n) Cold rinsing.

(o) Rinsing in boiling water.

(p) Cold rinsing.

(q) Rinsing in boiling water.

\section{$5-2=4$ Sequence of the Surface Preparation used}

(a) Dipping in boiling water

(b) Anodic degreasing

(c) Cathodic degreasing

(d) Rinsing in cold water

(e) Rinsing in boiling water

(f) Rinsing in cold water

(g) Rinsing in boiling water
20 seconds.

3 minutes.

1 minute.

30 seconds.

30 seconds

30 seconds

30 seconds 

(h) Acid pickling
1-2 minutes
(i) Rinsing in cold water
30 seconds
(j). Rinsing in boiling water
30 seconds
(k) Neutralization with $\mathrm{NaCO}_{3}$ Solution
20 seconds
(1) Rinsing in cold water
30 seconds
(m) Rinsing in boiling water
30 seconds
(n) Neutralization with oxalic acid
30 seconds
(o) Rịsing in cold water
30 seconds
(p) Rinsing in boiling water
30 seconds
(q) Rinsing in cold water
30 seconds
(r) Rinsing in boiling water
30 seconds. 


\section{5 - 3 Plating Procedure with Acid Zinc, Copper Pyrophosphate} and Bright Nickel.

Each specimen after surface preparation has been plated with either acid zinc solution, copper pyrophosphate or bright nickel (NiSOL 80). The specimen was placed in the bath as shown in the Fig. 22 at working temperature. The solutions used were commercial solutions (W. Canning and Company).

The operating conditions for the solutions were followed as shown in Table 4. The cathode was placed equidistant from two identical parallel anodes. The distance between the anode and the cathode was $11.0 \mathrm{~cm}$.

Direct current was used for plating from a power supply and the reading of the current was taken from an ammeter present in the power supply unit itself. Different speciruens of different porosities have been plated in different ways with the different plating solutions. The reason was to study the effect of the different thickness of the deposit formed on the surface on filling and levelling the pores, closing the pores at the surface and providing a protective layer on the surface of each specimen. The surface characteristics of each deposit obtained were examined by the Lea and Nurse apparatus, S.E.M. and the optical microscopy.

The results obtained are reported in tables 5 and 6 .

\section{$5-3-1$ Procedure Us ing Triple Layer Plating}

1. 3 samples of different nominal level of porosities have been surface prepared as in page 77

2. The three samples were plated with certain plating solution of 3 minutes. 
3. The samples were then thoroughly washed in hot boiling and cold running water, dried in the oven at $105^{\circ} \mathrm{C}$, then the weight of each specimen was measured.

4. The permeability of each sample was checked by the Lea and Nurse apparatus after coating with each layer.

5. Each sample was cleaned with $\mathrm{Ca}(\mathrm{OH})_{2}$ solution.

6. Steps 2,3 and 4 were repeated twice so that the total plating time was nine minutes.

7. The procedure above has been followed with:

(a) Acid zinc solution;

(b) copper pyrophosphate solution;

(c) bright nickel (NiSOI 80) solution.

The result was reported in Table 5 .

5 - 3 - 2 Procedure for Microscopical Study of Pore Filling at Increasing Times

1. Three samples of the same nominal level of porosity were taken each time.

2. Plating after surface preparation in certain plating solution but at the various intervals 5,7 and 10 or 5,8 and 12 minutes.

3. After plating each sample was thoroughly washed in hot boiling and cold running water, weighed and the weight of each deposit was measured.

4. The permeability of each specimen was measured with the Lea and Nurse apparatus.

5. Scanning electron microscopy and optical microscopy were used to investigate:

(a) filling the pores at the surface;

(b) thickness of the deposit required to fill and level the pores; 


\section{(c) establishing a corrosion resistance layer at the top of the specimen surface.}

The above procedure has been followed with:

(a) Acid zinc solution;

(b) copper pyrophosphate solution;

(c) bright nickel (NiSOI 80) solution.

The result reported is shown in table 6 .

\section{5 - 4 Plating Procedure with copper Cyanide, Acid copper and Zinc Cyanide Solution}

Each specimen after surface preparation has been plated either with copper cyanide, acid copper, zinc cyanide or a combination of the three kinds of plating solution. The operating conditions for each solution were followed as shown in table 7 .

The same power supply was used as with the non cyanide solutions. The reason for using the cyanide was the ability of the cyanide solution to throw well.

The results of the plated specimens were reported in tables 8 and 9 .

\section{$5-5$ Scanning Electromicros copy}

The instrument is used to examine the characteristics of surface since it has a wide magnification range, large depth of focus and high resolution presented on a cathode ray oscilloscope.

The advantage of the S.E.M. is in the speed and ease of viewing metallic samples, where no surface preparation is required for them.

The specimen was stuck on a special holder using colloidal graphite 
solution between the specimen and the holder to ensure good electrical contact. All examinations were carried out using a CAMBRIDGE S.E.M. $\operatorname{maxk} \mathrm{S} 2 \mathrm{~A}$.

\section{5-6 Optical Microscopy}

Al1 the observatiors by the optical microscopy have been accomplished on one made by Cooke Troughton \& Simms Limited.

The optical microscopy has been used to observe the thickness of the deposit and filling the inside and the surface pores by plating. This has been carried out by taking a portion from the specimen by cutting and mounting, using a thermosetting epoxy resin with vacuum impregnation. The resins used were Araldite MY 753, together with HY 951 Araldite hardner, both liquids were mixed in a ratio of 10:1 by weight and after mixing the mixture was placed in a dessicator which was connected to a single stage rotary vacuum pump to remove the air from the mixture, the time used was 15 minutes. Curing at room temperature for 48 hours produced a hard transparent mount. The mounting moulds. were made from $32 \mathrm{~mm}$ diameter and $7 \mathrm{~mm}$ light steel rings. The plated portions were placed in the centre of the moulds. The moulds and the contents were then subjected to a vacuum. This process was to remove the air from the resin and to allow the resin to permeate the specimen pores. The mounts were rough due to the cutting. Thus the specimen was ground by hand using four grades of grinding paper $240,320,400$ and 600 . Then the mount was polished by using a rotating wheel polishing machines using $6 \mu \mathrm{m}$ diamond polishing compound as a lubxicant. The aim was to remove as much as possible all the scratches from the cross-section and to obtain a highly polished surface.: After polishing the surface, the mount was etched by $5 \% \mathrm{Nital}$ ( $5 \%$ by volume 
$\mathrm{HNO}_{3}+95 \%$ by volume methanol) at room temperature for $10-15$ seconds. The examination of the polished cross-sectional area was carried out on the optical microscope and photo micrographs were taken. 
$\begin{array}{lllllll}C & \text { H A P } & \text { T E } & R & 6\end{array}$

Results 


\section{6-1 Results}

The results obtained from the experimental work are of two kinds. Firstly, the quantitative measurements are given in Tables 5-9 which cover the following data:

Table 5: Permeability results for acid solution yielding single layer deposits.

Table 6: Permeability result.s for acid solution yielding single deposits.

Table 7: Specification for cyanide copper, acid copper, and cyanide zinc solution.

Table 8: Specification for layer thicknesses of each sample subjected to single and multi-layered coating.

Table 9: Permeability results for cyanide solution yielding single and multi-layered coating.

Secondly, the micrographs using scanning electron techniques as well as classical light optical microscopy are given in Figs. 23-67.

Figs. 23-34: Micrographs for sintered samples with 5\% porosity. Figs. 35-47: Micrographs for sintered samples with 10\% porosity. Figs 48-67: Micrographs for sintered samples with 15\% porosity. 
C H A P T E R 7

Discussion 


\section{$1-1$ Discussion}

\section{7.- 2 Introduction.}

The production of powder metallurgy components has been rising rapidly in the last twenty years owing to the many advantages that it has over the other conventional method of fabrication. In the first place it has the ability to produce a very complicated shape by the relatively fow production steps. Secondly, it is cheaper for these intricate shapes despite the use of expensive metal powder as the raw material. In terms of properties of the finished components the pores of the sintered products are the major drawbacks, since they provide a large and reactive surface for corrosion. Therefore, many surface finished processes are considered for the powder metallurgy products but they rarely fill all the required specification requirements. Impregnation with oil or with wax cannot solve the problem of getting good decorative finish. Steam treatment gives a good protection against corrosion, but at the same time blocks the surface pores. Thus preventing good lubrication for the articles. Electroplating can find wide applications as a finish for the powder metallurgy parts since the electroplating can protect the substrate from corrosion and inprove the appearance of the products giving decorative appeal.

Three electro-deposits were chosen for investigation; they are: zinc, copper and nickel. The reason for selecting them may be summarized as follows:

(a) Relatively cheap cost;

(b) they are available in different kinds of solutions with different characteristics;

(c) easy to control and maintain and technology is well known;

(d) a lot of information is available about each solution;

(e) solutions and process is already available in most plating shops. 
Single or multi successive layers have been used with various combinations of the deposits to protect sintered iron substrates. The zinc is anodic to the iron, therefore it protects iron from corrosion by sacrificing itself and dissolving in preference to iron. Bright zinc can easily be obtained directly by electrodeposition and this layer can give both protection and decorative finish. Passivating of: the zinc deposit by chrondc acid solution can add further to the ability of the zinc deposit to protect against corrosion; besides which a good appearance can be obtained. Copper is cathodic to iron and it is primarily used as a basis for other plating. The copper deposit can easily be polished to a high brilliance.

Nickel is used largely as a decorative finish and sometimes used because of its high mechanical strength. It is resistant to oxidation by air, and it is resistant to some chemicals which attack iron easily, such as Hcl. Nickel can be deposited bright, semi-bright or dull, each kind of deposit has its own characteristics against corrosion and a combination of the bright and semi-bright nickel deposit gives a fairly good protection against corrosion and can protect iron and divert the corrosion to take place on the double nickel deposit.

In judging the quality of the deposit produced experimentally the following factors have been taken into consideration.

(a) The ability to fill the inside and the surface pores and covering all the surface and the pores by building up layers connected with each other and blocking the channels and decreasing the amount of solution entrapped between the pores.

(b) The ability to provide a protective layer against corrosion and prevent corrosion on the surface and inside of the products. 
contd (b) The thiciness of the protective layer is of great importance to close the pores and prevent condensed water to entrap between the pores and propagate corrosion.

(c) The ability to improve the appearance by providing a decorative finish and retailing the lustres of the deposit for a long time without any alteration because of the reaction with the entrapped solution due to an even closing of the surface and the inside pores.

(d) The incidence of spotting out phenomenon by observation the surface of the object after plating and recording any alteration on the surface.

(e) The achievement of a decrease in permeability of the component which indicates that the pores were closed because of the building of the deposit over the surface and blocking the channels and the inside pores.

The above are the considerations which have been borne in mind in assessing the various coating systems which have been used in this investigation.

\section{1 - 3 Discussion of the Compacts Plated with Copper Cyanide Solution}

\section{7-3-1. Plating with Copper Cyanide Solution for compacts with}

\section{5\% Porosity}

1. Inspite of the presence of a few holes on the surface of the copper deposited by the cyanide solution, they were not connected to the substrate pores. They resulted from the use of a high current density $2 \mathrm{Amp} / \mathrm{specimen}\left(8 \mathrm{Amp} / \mathrm{dm}^{2}\right)$. Appendix 3 . Decreasing the current density eliminated pores from the surface. This result explained by the sample 220 (Fig. 33 and sample 213 of 
$5 \%$ porosity, Thble 9) for which 0.5 Amp/spectmen has been used so that the result was better than samples $1,2,3,4) 5 \% \varepsilon$.

2. PIating for five minutes at a C.D. of $0.5 \mathrm{Amp} / \mathrm{specimen}$ was not enough to fill the surface pores. Increasing the plating time was shown very effective at low current density. Prolonged time was detrimental as long as short time, this was due to the penetration of the plating solution inside the pores by diffusion.

3. In general, for plating powder metallurgy part with copper cyanide solution, the closing of the surface pores and the inside pores depends on the intensity of the pores near the surface. The more pores near the surface the greater the difficulty in closing them.

\section{7-3-2 Plating with copper cyanide solution for Compacts with} $10 \%$ Porosity.

1. The pores have been filled completely by plating the specimen for 10 and 15 minutes of samples $10 \% \varepsilon$.closing the pores was the best between the $15 \% \varepsilon$ and the $5 \% \varepsilon$ for the same time of plating and current density. The 15 minutes plated sample is better than the 10 minutes sample.

2. Filling the pores has been achieved by decreasing both the time of plating and the current density, this is due to the good throwing power of the cyanide copper plating solution used.

3. There was no "spotting out" due to the closure of pores at the substrate therefore the appearances of the plated specimens were very good and the brightness of the copper deposit lasted for a long time before it tarnished.

4. There was a great decrease in the permeability of the plated specimens and this was due to the closing of the pores at the surface and the inside of the specimen. 


\section{7-3-3 Plating with. Copper. Cyanide Solution for Compacts with 15\%'Porosity}

1. Although there were holes on the copper deposit for samples 1 and 2 $15 \% \varepsilon$, but htese holes were not connected to the substrate as it has been observed from the optical microscopy observation and from the visual examination before and after drying.

2.: Varying the time (thickness) and the current density has a great effect on closing the pores. plating at different current density shows that as the current density decreases the time required to fill the pores should increase in order to get a thick deposit on the surface.

3. Best results are obtained by reducing the current density and increasing the plating time, Table 9 , this is due to getting uniform deposit free from nodules.

1 - 4 Comparison between the Plating of the Three Nominal Porosity Level Plated by Copper Cyanide Solution

It shows that the $10 \% \varepsilon$ specimens plated with copper cyanide has the best result among the other specimens and this is due to the moderate porosity level and sufficient plating time and good current density used.

For low porosity level increasing the thickness of the deposit by increasing the current density is more efficient than by increasing the plating time, since prolonged exposure of the specimen to the plating solution allows solution to be entrapped in the pores by diffusion and causes defects.in the deposits (samples 3 and $4-5 \% \varepsilon$ ). However, for high porosity filling the surface pores by amono layex can be done either by increasing time or current density, or by both, (samples 1 and $2,10 \% \varepsilon$ ). 


\section{1 - 5 Plating by Copper-Pyrophosphate Solution}

1. The deposit of copper obtained from a copper pyrophosphate solution filled the pores successfully with a great reduction in the permeability of the specimens and the best result was obtained with porosity Ievel $10 \%$ - Table 9.

2. There was no "spotting out" since the surface pores of both the substrate and the copper deposit have been closed by the good deposit of copper. Thus, the appearance of the plated specimens were very good and lasted for a long period before it changed its lustre due to the atmospheric corrosion.

3. The corrosion resistance of the specimens plated by the copper pyrophosphate was very good and there were no traces of any corrosion on the sintered iron specimens.

1-6 Comparison between the cyanide, acid and pyrophosphate Copper Solution

1. The Cyanide Solution is the best of the three solutions since it has a good throwing power and a good penetration action, but on the other hand, it has its disadvantages and amongst them are its toxity, hydrogen embrittlement and low micro-throwing power. The pyrophosphate solution can be used successfully in plating powder metallurgy products but the disadvantages are the immersion action with iron and the same with the acid solution.

It is clear that no single solution can close the pores entirely. unless a thick deposit is produced. It is better to use a combination of any two of these solutions because this helps to fill the pores 
due to the change in the growth of the deposits.

2. Copper deposits provide a good base for subsequent top anodic coating for corrosion protection purposes since it has a good conducting characteristic and already most of the pores and the channels have been closed.

\section{1 - 7 Discussion of the Compacts Plated with Zinc Cyanide}

7-7-1. Plating with Zinc Cyanide Solution for the Compacts with 5\% Porasity

1. The thiclness of the zinc layer produced form the zinc cyanide solution was not sufficient to fill the pores. But, on the other hand the inside pores have been filled due to the high throwing power of the solution. Thus, the speicmens were no longer permeating gas. The appearance was very good after plating and drying. It has been found that the thickness was quite satisfactory to protect the specimens from corrosion or by "spotting out".

2. Decreasing the time of plating (thickness) and the current density gives bigger holes at the surface, and does not even give a protection against corrosion as corrosion product has appeared on the surface. Increasing the plating time at low current density improves the appearance and fills the pores (sample 218), due to building up the I ayer of zinc.

\section{7-7-2 Plating with Zinc Cyanide Solution for the Compacts $10 \%$ Porosity}

1. The time of plating $(10,15$ minutes) was not sufficient to produce a deposit to fill the pores. Increasing the time cincreasing the thickness of the deposit) is very useful to close both the surface 
pores and the inside pores.

2. Decreasing the current density gives the same iesult since the thickness of the deposit will not be sufficient to fill and close the pores.

3. Increasing the current density is necessary to fill the pores and gives a protective deposit against coxrosion, but too high a current density must not be used.

4. Increasing the time of plating is more beneficial than increasing the current density since by increasing the current density nodules will form with some pores in it and these pores will be connected to the surface pores and enhance corrosion. On the other hand, increasing time of plating at moderate current density produce a uniform, thick and nodules free deposit.

5. The time of plating depends on the specification of the plating solution, i.e. depends on the equivalent amper-hour of the metal to be deposited.

7-7-3 plating with Zine Cyanide Solution for Compacts with $15 \%$ Porosity

As the discussion of the $10 \% \varepsilon$ samples plated with zinc cyanide solution only.

\section{I - 8 Comparison between the Samples of different Level of Porosity} Plated with Zinc Cyanide Solution

1. From the many investigations on the specimens of different level of porosities plated with the zinc cyanide solution it is seen that the plating time was insufficient to fill the pores completely and more time needs to be used at the current density of one Amp/specimen in order to achieve a good result.

2. The result obtained by plating with zinc cyanide were inferior to 
the result obtained by plating with copper cyanide solution, although the same current density and time had been used. The difference was due to the thickness of the deposit at the 10 minutes and 15 minutes plating time, as the electrochemical equivalent of copper cyanide is about twice the electrochemical equivalent of zinc.

5. The deposit obtained from the cyanide solution after 10 and 15 minutes Was sufficient to protect the sintered iron specimen as the appearance was good and could be expected in the industry.

\section{$I-9$ Plating with Nickel (Bright) Solution}

1. The appearance of the $\mathrm{Ni}$ deposit was very bright, whether it is directly deposited on the sintered iron specimens or as a top deposit on many other base layers.

2. Inspite of the fact that the nickel deposit did not fill all the surface pores when it was used alone, nickel deposit kept its good appearance which means that there was no spotting out and suggest the use of nickel plated specimens in a dry environment without any risk of corrosion. Therefore, if nickel deposit was a top deposit there is no restriction on the application of the powder metallurgy product.

3. The best appearance obtained from all the samples were by using the nickel deposit as a top coat due to its brightness and good leveliing of the deposit.

\section{1-joplating with Double Layer of Copper Coating}

The appearance of the samples after plating with the cyanide and the acid coppex layer was good and bright and the best result obtained 
was at the low porosity $(5 \% \varepsilon)$. Although there were holes at the surface of the top deposit (acidic) at the $10 \%$ and $15 \% \varepsilon$, but it seems that these holes have no action on the plating since the bright appearance of the acld copper deposit lasts for a long period before It tarnished due to the atmospheric corrosion. The acid copper thickness was small due to a short plating time. It is clear that increasing the time of plating with the acid copper solution is very useful in order to close the surface pores and to build up over the copper deposit from the cyanide coppex solution. The acid copper deposit closed the pores in the copper deposit from the cyandie solution.

\section{1 -11 Comparison between the mono layer and the double layer coating}

It has been found that the double layer coating is more effective than the mono layer coating and the combination of copper deposit from different types of plating solution which having different metallurgical structure and particle orientation improves the filling of the surface and inside pores. The use of the acid copper solution is very important since the hydrogen co-deposition is negligible and the hydrogen could not evolve at the powder metallurgy parts during plating and causes hydrogen embrittlement besides the copper can furnish a good base for other plating purposes.

\section{7 - 12 Plating with the Triple Layers}

1. From both the S.E.M. and the optical microscopy it has been found that the surfaces were free from pores and the substrate pores have been filled and levelled successfully and each layer has filled the rematning pores from the previous deposit. 
The top deposit for the specimens plated with a triple layer was different. This leads to che possibility of plating the powder metallurgy parts by different kinds of plating solution depending on the purposes and the finishing of the plating required.

From the corrosion point of view the three layexs can provide a good proteciton against corrosion. The top deposit will protect the product from the atmospheric corrosion or by the attack from the environment, while the inner layer protects the powder metallurgy product from the inside attack by the solutions entrapped between the unfilled pores and preventing the "spotting out".

The economic factor is very important since triple plating requires many stages of thorough rinsing, but this drawback is offset by the benefits gained from plated powder metallurgy products.

\section{7:-13 Comparison Between Single, Double and Triple Layers Plating}

Table 9 shows that the best results were obtained in case of triple plating since triple plating provides a deposit which can asily fill the surface and inside pores and provide a very good finish for the powder metallurgy parts.

The S.E.M. for the triple plated specimen shows that there were no defects on the top layer whatsoever.

The appearance of the specimens plated with the triple 1 ayer were far better than the other specimens and this is due to the presence of a levelled, good contact electrically of the substrate ( the second deposit).

It is clear that increasing the number of the deposits used the better the plating becomes, thus the double layer is better than the single layer plating. 
7 -14 Plating with quadriple Layers

Four layer plating should be very beneficial due to closing the pores but it would not be economic due to the cost of both the plating and the rinsing. Triple layer can fill all the pores at lower cost.

7 - 15 Comparison between the Plating of Sintered and Unsintered Specimens

Fig. 60 shows that the penetration depth of the plating solution is great because of the size of the pores and the channels near the surface. Thus the amount of deposit in the pores is greatex than that in any other sintered specimen. Fig. 61 shows that the surface pores have been filled well.

The disadvantages of plating before sintering are thai the phase changes during sintering and the difference in the melting points of the various deposits used to plate the specimens would require different and possibly unacceptable heat treatment cycles to be specified in each case. Furthermore, the coating might completely diffuse into the sintered compact (e.g. zinc melting at $418^{\circ} \mathrm{C}$ deposited on iron sintered at $1120^{\circ} \mathrm{C}$ for half-an-hour), or be vapourized and the effective coating protection virtually lost.

\section{$1-36$ Effects of the Operating Conditions}

At higher current density nodulus formed on the surface of the deposit and these nodules enhance channelling to the substrate pores. and to the inside pores. Low current density was found not sufficient enough to fill the pores. Moderate current density is recommended for 
plating powder metallurgy products.

The temperature of the plating solution has no unique action on the plating and its effect is similar to its effect on the plating of non-porous materials.

Agitation was found very useful since it changes the concentration of solution near the cathode.pH has a similar effect as the temperature. 
$\begin{array}{llllllll}C & \text { H A } & \text { P } & \text { T E } & \text { R } & 8\end{array}$

Conclusion 


\section{CONCLUSIONS}

1. It has been found that the powder metallurgy product that is to be plated for the different purposes of plating influences both the choice of the coating and also possibly the method by which they are applied. The optinum characteristics of the deposit depends on the experience in plating a certain product. Prolonged time of plating is as harmful as too short a plating time.

2. From the S.E.M. and the Lea and Nurse measurements, it has been found that the surface of the sintered iron compact has been closed if different 1 ayers of deposit are used one over the other due to the differences in growth mode of each deposit. closing the pores at the surface depends on the thickness of the deposit and on the characteristics of the solution (i.e. macro and micro throwing power, levelling action and coverage power). Thorough rinsing and using hot and cold rinses were found to be very useful to decrease the concentration of the entrapped solition in the pores, thus decreasing the "spotting-out" and the "drag-out". Satisfactory appearance has been obtained in each case.

3. Multi layers were found to be very helpful in closing the pores. Each layer filled the uncovered pores by the previous deposit. When mult layers are used, it is advantageous to use levelled zinc as the first layer of the system in order to maintain good mechanical properties since the corrosion will start on the zinc in preferential to the iron.

4.) Closing the surface pores depends on the roughness of the surface to be plated. The greater the roughness of the surface the greater the thickness of the deposit required. The thickness required also depends on the porosity level (i.e. number of holes on the surface. 
5. It is very useful in closing the pores to use a copper cyanide solution since the electrochemical equivalent of copper is high, besides which the throwing power of the solution is very good.

6. Plating powder metallurgy products requires a great deal of attention and especially to estimate approximately the surface failure to do

area to be plated, sincehthis will lead to a bad appearance, espectally in dealing with bright solutions and when the appearance is of great importance.

7. Optimum plating has been obtained by using bright nickel solution. This is due to the levelling action of the solution and a bright deposit has been obtained irrespective of whether nickel deposit was a top deposit or was directly on the substrate. The grains of the nickel deposit were uniform in size and there were no holes or nodules on it. Although the nickel deposit has not filled in some specimens the surface pores entirely as it is seen from (n) But there were no traces of "spotting-out" besides the appearance was very good. This suggests the possibility to use the powder metallurgy parts plated with $\mathrm{Ni}$ in the dry envixonment only in order to avoid the corrosion hazards.

Satisfactory appearance was obtained by using copper deposit particularly when duplex copper has been used and the lustre of the deposit lasted for a long time. The thin zinc deposit does not protect the specimen because of the considerable "spottingout" in the case of thin layer (i.e. Insufficient time of plating). 


\section{Recommendation for Further Work}

1. Use of solutions giving crack-free deposits is recommended.

2. Attempts to decrease the porosity of the deposit to the minimum should be made.

3. The proportion of the pores filled by plating should be measured:

4. The relation between the thickness and the pores to be filled should be determined. 
1. B.A. Borok

2. J.S. Hirschhorn
Researches in Powder Metallurgy, A special Research Report, translated from Russian, 1966.

Introduction to Powder Metallurgy, Colonial Press, INC, 1969.

3. A. Yu. Valldikivi Puginn and Mozberg,

Poroshkovager Met., 7, 76, 1978.

4. C.G.GoetzeI

Treatise on Powder Metallurgy, Interscience, New York, 19. 1950.

5. H.D. Kipling Powdex Metallurgy, 19 (1), 8, 1976.

6. R. Anger and Y. Trudel

International J. P/M., 10 (2), 111,1974

7. W. D. Kingery

Introduction to Ceramics, John Wily and Sons, Inc., 4th Printing, 1966.

8. R. Haynes

One Week Course Notes on $\mathrm{P} / \mathrm{M}$. , Loughborough University of Technology, 1975.

9. Michael Besterici

\& Pavel Petrik Metal Abstract, 10 (7), 1398, 1977.

10. Ivan Atonasov Metal Abstract, 9(6), 1081, 1976.

11. F.L. Sands and Powder Metallurgy Practice and Application, C. R. Shakespeare London, George Newnes Ltd., 1966.

12. Z.Zembura,

W. Glodzinska \&

Y.Haranczyk Arch. Huntn., 20 (3), 405, 1975.

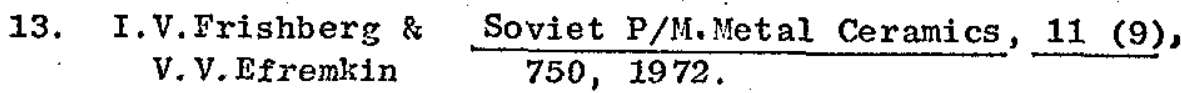


14. A.S.Grintsov,

A. B.Medvedovskii Metal Abstract, 10 (4), 430, 1977

15. Sands and

Shakespeare

Powder Metallurgy Practice and Application, London, George Newnes J td., 1966, P.5.

16. S.A.Tsukerman Powder Metallurgy, Pergamon Press, 1965.

17. Metal Powder Report 32 (8), August, 299, 1977.

18. A. Maps tone, Product Finishing, November, 37, 1973.

19. P.Schwarzkopf International J. P/P , 2 (4), 3, 1966.

20. M. Stevanovic

\& V.Petrovic P/M International, 2 (2), 36, 1970 .

21. M.J.Donachie

\&.M.F. Burr Journal of Metals, 15, 849, 1963.

22. M. C.Kostelnk

F.H. Kludt \&

J.K. Beddow

International J. P/M, 4 (4), 19, 1968.

23. M.Yu. B.ûshin Vestnik Metallo Prom. 18, 124, 1938.

24. I. Shapiro $\%$
I.M. Kolthoff
J. Phys. Colloid Chem. 51, 483, 1947.

25. R.W.Hecke1

Trans, Metall.Soc. Aime., 221, 1001, 1961.

26. A. Duffield \& P.Grootenhuis

$\frac{\text { Iron and Steel Institute Symposium on } P / M}{\text { P. } 96,1954 \text {, }}$

27. C. Torre, Berg-: Monatsh Monton, Hochshule, Leoben, 93, Hüttenmann $62,1948$.

28. G. Bockstiegel International J. P/M, 2 (4), 13, 1966. 
29. G.Bockstiegei

Modem Development in Powder Metallurgy, Volume I, Plenum Press, New York, 1966.

30. E. Du d rova \& J.Kubelik

$P / M$ International $, 3(4), 183,1971$.

31. M.K. Carlson \&

J.S. Hirschhorn

Internationál. J, P/M 6 (1), 39, 1970.

32. A. Sal ak \&

E. Dudrova

33. H.H. Hausner

34. J.kotanic,

P. O. Povic \&

V. Petrovic

35. Vaclav Prochazka

and Al zbeta

Durisinova

36. R. Marger \&

M. Eudier

37. A. Joshi,

J. Wil demuth

\& D.F. Stein

38. Yoj, Awano \&

Takashi Kimura

39. H.H. Hausner

40. M. Eudier

41. M.J. Xoczak \&

A. Lawley

P/M Int. , 4 (4), 186, 1972.

Physic. Sint., 5 $(2,2), 95,1973$.

Physic. Sint., $5(2,2) 95,1973$.

$\underline{p / M}, \underline{12}, 17,1963$. of Metals, 1970.

P/M. , 9, 278, 1962 .
Second Intermational Conference on Mechanical Behaviour of Materials, American Society of Metals, 1756 - 1760, 1970

International J. P/M, 11 (2), 137, 1975.

J. Japan Soc. P/M, 20 (2), 37, 1973.

Second Intermational Conference on Mechanical Behaviour of materials, American society 
42. R. Haynes

43. D. G. McAdam

44. C. G. Goetzel

45. R. Haynes

46. C. G. Goetzel

47. S.M.Kaufman: \& S. Mocarski

48. R. Haynes

49. I. Jenkins

50. 0, Hotfman

51. G.C.Kuczynski

52. A. Squire

53. L.L.Siegle

54. Koloty Rikn

55. D. R. Gabe

56. A. Mapston

57. R. Rushbrook
P/M. , 14 (27), 64, 1971.

J. Iron and Steel Inst., 168, 346, 1951.

Treatise on $\mathrm{P} / \mathrm{M}$, Volume II, Interscience, New York. 1950.

$\underline{P} / M_{.}, 1(17), 17,1977$

Treatise on $P / M .$, Volume $I I$, Interscience, New York, P. 338. 1950.

Interrational'J. Powder Met. $7(3), 19,1971$.

P/M. $, 13(26), 465,1970$.

$\underline{\mathrm{P} / \mathrm{M}}, \underline{7}, 68,1964$.

Anti-corx, Meth. Mat., 16 (8), 16, 1969 .

$\underline{\mathrm{P} / \mathrm{M}}, \underline{12}, 1,1963$.

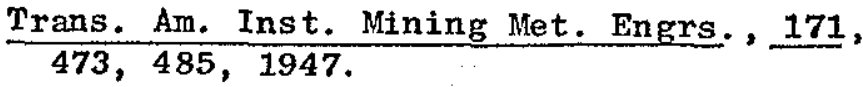

Kinetics of High Temperature Process, John Wiley and sons, New York, 1959.

Corrosion-National Association of Corrosion Engineering No. 8, 261, 1963.

Powder Metalluxgy, 4, 227, 1977.

Product Finish. Nov., 33, 1973.

$\frac{\text { Electroplating and Met. Fin }, 7 \text { (3) }}{93,1954}$ 
58. G. Bock

stiegel

Powder Met. , (10), 171, 1962.

59. M. T. Matty \&
J. Mathews
Powdex Met., 16, 270, 1965.

60. G.H. Jenner \&

T.P. Hoars

Trans. Inst. Met. Fin., 34, 253, 1957.

61. "Brand Mech. Plating" 3 Ms. Company.

62. W. Dingley,
J. Bednar \&
R. Rogers
Plating, 53, 602, 1966.

63. F.A.Lowenheim Modern Electroplating. John Wiley \& Sons, 1974.

64. A.K.Graham

Electroplating Engineering Handbook, V.N.R. New York, 3rd Edition, 1971.

65. S.Field \&

A. D. Weill,

Electroplating, Sir Isaac Pitman \& Sons, Ĺondon, 1961.

66. W.BI um \&

G.B. Hogaboom

Principles of Electroplating. Micro Hill 1949.

67. F. Nobel \&
B.D.Ostrow
P1ating, $41(8), 892,1954$.

68. R. L. Sands \& Powder Metallurgy Practice and Application, C. R. Shakespeare London, George Newnes Ltd., 1966, P.22.

69. F. Passal

Plating, 46, 628, 1959.

70. E.H. Lyons

Trans. Electro. Chem Soc., 80, 387, 1941.

71. H. Geduld

Met. Fin. $73 \quad$ (3) $, 27,1976$.

72. M.B.Diggin

Metal Fin., (41), 277, 1943. 
73. H. Ge dul d

74. J.K. Dennis \& T.E. Such

75. R.J.Kendrick

76. D.G.Gardner Foulk

77. R. Brugger

78. P. Spiro

79. J.K. Dennis T.K. Such

80. S.A.Watson

81. 0.J.Klengnmair

82. R.A.F.Hammond

83. I. Rochel and W. Wesley

84. D.F. Berry
Met. Fin., 73 (1), 41, 1976.

Nickel and Chrome Plating, P. 58, London, George and Newnes Ltd., 1972:

Plating, October, 1099, 1961.

Met. Fin., (54), 52, 1956.

Nickel Plating, Robert Drugger Ltd. , 1970.

Electroforming, Robert Draper Ltd., 1971.

Nickel and Chrome Plating, P. 59, London George Newnes Litd., 1972.

Trans. Inst. Het. Fitr. $37,28,1960$.

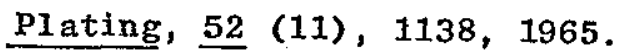

Met. Fin. J., 16 (6), 169, 1970.

P1ating, 37, 142, 1950.

Copper Development Association, Dec. 1972 .

85. Canning Handbook on electroplating, Twenty First Edition, 1970. 


\section{APPENDIX 1}

\section{Observations on Individual Specimens}

Sample No. $1 \quad 5 \% \varepsilon$

The surface pores have been successfully filled with a copper deposit and the result was in agreement with the scanning electron microscopy, (S.E.M) Fig. 23, which shows that there were few holes on the surface of the deposit.

Sample No. $25 \% \varepsilon$ as Sample No. $4 \quad 5 \% \varepsilon$

Sample No. $3 \quad 5 \% \varepsilon$

The surface pores have been filled completely but the solution penetration was great. The plating solution filled the inside pores quite satisfactorily, but the holes which vere observed by the scanning electron microscopy were not connected to the substrate.

Sample No. $4 \quad 5 \% \varepsilon$

From Fig. 24(0.M) all the surface pores have been filled completely, sealing the inside pores with copper deposit. The grain boundaries have been plated with copper and the interconnected pores have been closed with copper deposit too.

Sample No. $6 \quad 5 \% \varepsilon$

The appearance of the specimen was good after plating. The double layer of copper has filled the surface and the inside pores successfully with great penetration of the plating solution. The S.E.M. observation shows that there were no holes on the surface of the copper deposit. 
Sample No. $7 \quad 5 \% \varepsilon$

It has been found by the Lea and Nurse method that the smaple was still permeable and this result was in agreement with the scanning electron microscopy, S.E.M. Fig. 25. But from the optical microscopy observations (Fig. 26 O.M.) it is clear that all the surface pores have been filled, besides which the top layer (zinc) has filled the unfilled pores of the copper deposits.

Sample No. $8 \quad 5 \% \varepsilon$

The optical microscopy observations showed that the thickness of the deposit was not sufficient to fill the surface pores in the deposit which are connected to the surface pores. Increasing the thickness of the deposit will help to close the surface pores.

Sample No. $9 \quad 5 \% \varepsilon$

The deposit has filled most of the surface pores but not all the pores, and there was a confirmation between the scanning electron microscopy and the optical microscopy, S. E.M. Fig. 28.

Sample No. $10 \quad 5 \% \varepsilon$

All the surface pores have been filled quite satisfactorily and the copper deposit has sealed the pores near to the surface very satisfactorily. The inside pores have been closed by the zinc and copper deposits very well. 
Sample No. $115 \% \varepsilon$

Excellent closing of the inside and surface pores has been achieved by the different plated deposits with good levelling action by the copper deposits, (Fig. 29 0.M.). From the scanning electron microscopy it was found that all the surface pores have been closed entirely.

Sample No. $12 \quad 5 \% \varepsilon$

Most of the surface pores have been filled by the deposits from the different plating solutions. There were a few holes on the surface of the nickel deposit which were responsible for permeating the gas in the Lea and Nurse apparatus, S.E.M. Fig. 30. Although the penetration of the plating solutions inside the sample was great, it has been found by the optical microscopy observations that all the interconnected pores has been filled.

Sample No. $14 \quad 5 \% \varepsilon$

All the surface pores have beenc closed by the copper deposit with good penetration and sealing of the inside pores. The top coat (zinc) has sealed the porosity in the copper deposit very satisfactorily, (FIg. 31, S.E.M.).

Sample No. $216 \quad 5 \% \varepsilon$

Most of the surface pores have been filled as well as the pores near the surface, as it has been found by the optical microscopy. The S.E.M. observation shows that there were holes like channels connected to the substrate pores. 
Sample No. $219 \quad 5 \% \varepsilon$ as Sample No. $2165 \% \varepsilon$

Sample No. $2175 \% \varepsilon$ as Sample No. $2165 \% \varepsilon$

Sample No. $211 \quad 5 \% \varepsilon$

Fig. 32, (S.E.M.) shows that there are big holes in the copper deposit and from the optical microscopy observation it has been. found that these holes are connected to the substrate pores.

The inside pores have been filled quite satisfactorily so that the spectmen was not permeating gas as examined by the Lea and Nurse apparatus and the result of the permeability was zero.

Sample No. $212 \quad 5 \% \varepsilon$ as Sample No. $220 \quad 5 \% \varepsilon$

Sample No. $213 \quad 5 \% \varepsilon$

The (S.E.M.) observation shows that there are holes on the copper deposit. From the optical microscopy observation it has been found that not all the surface pores have been filled and there were still some pores uncovered by the copper deposit, but it has been found that the penetration of the plating solution was very good.

Sample No. $218 \quad 5 \% \varepsilon$ as Sample No. $212 \quad 5 \% \varepsilon$

Sample No. $220 \quad 5 \% \varepsilon$

Fig. 33, (S.E.M), shows that there were no holes on the copper deposit. The optical microscopy observation confirms with the S.E.M. and the observation shows that all the surface pores and the inside pores have been filled very well. 
Sample NO. $5 \quad 5 \% \varepsilon$

From the S.E.M. observation it has been found that the surface of the zinc deposit was free from holes. From the optical microscopy observation it has been found that all the surface pores have been filled with a great deposition of zinc inside the specimen.

\section{Sample No. $13 \quad 5 \% \varepsilon$}

Fig. 34, (S.E.M) shows that there are no holes on the surface of the copper pyrophosphate deposit, besides that the grains are similar in shape and size. From the optical microscopy observation of the cross section of the plating it has been found that all the surface pores have been filled completely with good filling of the inside pores by the copper deposit. The appearance of the plated specimen was quite satisfactory.

Sample No. $15 \quad 5 \% \varepsilon$

The nickel layer has filled most of the holes on the surface with good levelling at the holes at the surface. The interconnected pores near the surface have been filled and levelled. Nickel deposit has been found everywhere inside the specimen. Since the inside pores have been filled very well the specimen does not permeate gas through the examination by the Lea and Nurse apparatus.

The S.E.M. observation confirms with the optical microscopy result and a lot of holes were present on the nickel deposit at the surface. 
Sample No. $1 \quad 10 \% \varepsilon$

Fig. 35 (S.E.M.) shows that the surface pores have been filled entirely, but the permeability measurement shows that the specimen isstili permeable ( $T a b l e ~ 9)$ al though there is clearly a great improvement in the permeability. For the observation by the optical microscopy it was cleax that the surface pores were closed quite satisfactorily with a good penetration for the plating solution inside the specimen.

Sample No. $2 \quad 10 \% \varepsilon$

The surface pores have been filled completely with the layers from the plating solutions and the penetration of the copper and zinc cyanide solutions has been found to be very good. The permeability measurement shows that the permeability for the specimen is zero.

Sample No. $14 \quad 10 \% \varepsilon$

From Fig. 36 (S.E.M.) it is seen that there is a hole in the deposit which is connected to the substrate surface and this hole must be responsible for permeating the gas throughout the specimen (Table 9).. From the observation of optical microscopy it was seen that all the surface pores have been filled by the double copper layers besides which the penetration of the solution was found to be very good.

Samples No. 4 and $12 \quad 10 \% \varepsilon$

Figure 37 shows that all the surface pores have been filled with a copper deposit, and from the observation by the optical microscopy, Fig. 38, it was clear that the deposit of the copper has filled all 
the pores at the surface. Moreover, the penetration of the solution was very good. These results were in agreement with the permeability measurement (Table 9).

Samples No. 16 and $17 \quad 10 \% \varepsilon$

Fig. $39(0 . M)$ shows that all the surface pores have been filled by the three layers with a good penetration for the solutions inside the specimen. The above result is confirmed with the permeability measurements (Table 9).

Sample NO. $20 \quad 10 \% \varepsilon$

Both the pores at the surface and the interconnected ones have been filled by the plating solution, Fig. 40. From the S.E.M. Fig. 41, it was observed that the surface is pore free.

These results are confirmed by the permeability measurement, Table 9 .

Sample No. $21 \quad 10 \% \varepsilon$

Most of the surface pores have been filled by the four layers but it was seen by optical microscopy that the zinc cyanide deposit has not filled the surface and there was a penetration of copper solution inside the pores. The presence of the double copper layer helped to fill and close the surface pores and the inside pores.

The result obtained by scanning electron microscopy (F1g. 42 S.E.M.) has shown that there was one hole in the area scanned and this result confirms with the permeability measurement, (Table 9). 
Sample No. $19 \quad 10 \% \quad \varepsilon$

The plating time was not sufficient to fill the surface pores (Fig. 43 S.E.M. Table 9) and there were some holes on the surface of the deposit which were connected to the inside pores, although the penetration of the solution was very good.

The permeability measurement result (Table 9) confirms with the result obtained by the scanning electron microscopy.

Sample No. $18 \quad 10 \% \quad \varepsilon$

The result obtained by looking at the cross section of the sample by optical microscopy has shown that the deposit of the zinc was not sufficient to fill the surface pores and there were some areas which were not filied. This observation was in agreement with both the scanning electron microscopy. (Fig. 44 S.E.M.) and the permeability measurement, (Table 9).

Sample No. 5 10\%ع as sample No. $5 \cdots 15 \% \varepsilon$

Sampie No. $6 \quad 10 \% \varepsilon$

The appearance of the nickel deposit was excellent but it had holes which were connected to the substrates as it has been shown by the optical microscopy observation. Also, it can be seen that all the pores near the surface were filled with nickel deposit so that the specimen was no longer permeating gas, (Table 9). 
Sample No. $7 \quad 10 \% \varepsilon$

The thickness of the deposit was not sufficient to fill the surface pores since there were still some holes in the surface of the specimen unfilied by the nickel deposit.

Sample No. $810 \% \varepsilon$ as sample No. $6 \quad 10 \% \varepsilon$

Sample No. $9 \quad 10 \% \quad \varepsilon$

Fig. 45 (S.E.M.) shows that there are big holes on the surface of the copper deposit. From the optical microscopy observation it has been found that filling the surface pores was not good, and there was no copper deposition inside the sample. It is clear that 5 minutes of copper pyrophosphate deposit was not sufficient to fill the surface and inside pores satisfactorily.

Sample No. $10 \quad 10 \% \varepsilon$

Good filling of both the surface and the inside pores has been reached by the copper pyrophosphate deposit, but the appearance of the deposit was not satisfactory.

Sample No. $11 \quad 10 \% \varepsilon$ as sample No. $13 \quad 15 \% \varepsilon$

Sample No. $1310 \% \varepsilon$ as sample No. $1315 \% \varepsilon$

Sample No. $1510 \% \varepsilon$ as sample No. $715 \% \varepsilon$ 
Sample No. $311 \quad 10 \%$ a as sample No. $312 \quad 10 \% \varepsilon$

Sample NO. $312 \quad 10 \% \Xi$

Al though the specimen did not permeate gas as it was examined by the Lea and Nurse method, but the S.E.M. and the optical microscopy has shown that the specimen has a lot of pores on the deposit surface and not all the substrate pores have been closed by the zinc deposit and the thickness was not enough to fill the surface pores.

Sample No. $315 \cdot 10 \% \varepsilon$

All the surface pores have been filled with copper deposit with a good depth of penetration of the plating solutions as it has been observed by the optical microscopy. The permeability measurement shows a confirmation with the optical microscopy and the S.E.M.

Sample No. $31610 \% \varepsilon$ as sample No. $31510 \% \varepsilon$

Sample No: $317 \quad 10 \% \quad \varepsilon$

Fig. 46 (O.M.) shows that not all the surface pores have been filled successfully although the plating time was 20 minutes at current density of $0.5 \mathrm{amp} / \mathrm{specimen.} \mathrm{The} \mathrm{S.E.M.} \mathrm{(Fig.} 47$ S.E.M.) shows that there are some holes on the surface of the deposit which are permeating gas as indicated by the result obtained by the Lea and Nurse method. Table 9 . 


\section{Sample No. $1 \quad 15^{\circ} \varepsilon$}

The appearance was good after plating with copper cyanide solution for 15 minutes.

From Fig. 48 (S.E.M.) it can be seen that the deposit contains some pores within it and some of these pores connected to the - Surface of the substrate.", are responsible for "spotting-out" and makes the specimen permeable (Table 9). On the other hand, most of the pores are not connected to the substrate.

Increasing the time of plating is beneficial in case of depositing one layer on a powder metallurgy part in order to close the pores and protect the substrate.

\section{Sample No. $2 \quad 15^{\circ} \varepsilon$}

1. The appearance was good after plating with copper cyanide for 10 minutes.

2. After drying at $105^{\circ} \mathrm{C}$ for 20 minutes the surface was not as good as before drying. The reason was the "spotting-out". solution emerging from the pores and dispersing on the surface of the copper deposit. (Table 9).

3. From Fig. 50 (S.E.M.), it is clear that the number of pores in sample No. 2 are greater than the number of pores in sample No. 1 and that was due to the difference in thickness of the deposits on both samples. Besides, the pores in the deposit on sample No. 2 are 1 arge and connected to the surface of the substrate and this was the reason for changing the condition of the surface after drying. Thus, increasing the time of plating (thickness. of deposit) is very important if one layer is deposited on the surface of powder metallurgy parts if the aim is to close the 
pores. Besides, a good throwing power solutions must be chosen in order to get a uniform deposit on the substrate.

\section{Sample No. $3 \quad 15 \% \varepsilon$}

1. The appearance after plating was very good.

2. After drying the appearance was still good, which shows that it is necessary to plate with acid copper after copper cyanide, although the time of plating with acid copper is short. (5 minutes).

Fig. 50 (S.E.M.) shows that the surface is free from pores, cracks and the deposit was fully levelled.

Sample $4^{\cdots} 35 \%^{\circ} \varepsilon$

The appearance was good and bright but after drying there was a white uniform film on the surface of the zinc.

From Fig. 51 (S.E.M.) the deposit appears very good, it was levelled and the pores appeared not to be connected to the substrate, the grains were large, which can lead to a good corrosion protection. From Table 9 , it is clear the specimen is not permeable which means that al1 the pores have been closed by the successive layers.

Sample No. $12 \quad 15 \% \varepsilon$

The appearance after plating with copper cyanide solution, acid copper and bright nickel was excellent.

After drying there was a small change in the appearance but in general the appearance was still good. 
Fig. 52 (S.E.M.) shows that the nickel layer was fully levelled, with no cracks and holes inside the deposits. It was found that the grain sizes were a mixture of large and small sizes and the grain boundaries became much more clear besides which the nickel Iayer can provide a decorative deposit for powder metallurgy parts.

The results obtained by the permeability measurements showed that the surface is no longer permeable.

Fig. $53\left(0 . \mathrm{M}_{.}\right)$shows that the penetration of the double copper layers were very good and the nickel deposit closed all the pores present on the surface of the copper deposit.

Sample No. $14 \quad 15 \%$ as Sample No. 12

Sample No: 16'15\%'

The appearance after palting was very good, but after drying the appearance was not as good as it was before drying. The holes present on the surface, which are shown by Fig. 54 (S.E.M.), are not connected to the substrate surface as shown in Fig. $55\left(0 . M_{0}\right)$ and Table 9 .

It was observed that the copper deposit obtained by the solution at the experimental working conditions are not sufficient to close the pores, and since zinc deposit has been found inside the specimen (which means the penetration depth of both solutions are great).

Sample No. $17 \quad 15 \% \varepsilon$

1. The appearance was good after plating and drying.

2. The zinc deposit alone at this thickness was not sufficlent to close the pores.

The surface contains a few holes which are responsible for per- 
meating the gas throw the specimen, (Table 9).

Fig. 56 (0.M.) shows that the depth of the penetration of zinc cyanide solution is quite satisfactory, but the time of plating is not enough to fill all the surface pores fully although the present layer can give a satisfactory protection against corrosion.

\section{Sample $18 \quad 15 \%$ same as sample No. $17 \quad 15 \% \varepsilon$}

\section{Sample NO. $19 \quad 15 \% \quad \varepsilon$}

1. The appearance was very good.

2. No holes have been noticed after examining with the $0 . M$.

Fig. $57(0 . M)$ and the result is confirmed on Table 9 .

Sample No: $20 \cdots 15 \%$

1. The appearance was very good.

2. From Fig. 58 (S.E.M.) it has been found that the surface was free from holes and the grain size of the zinc was very 1 arge and uniform. It was clear that all the substrate pores have been closed due to the thickness of the four layers of different kinds. Fig. 59 (0.M.) shows that the pores inside the specimen have been filled and levelled by the plating solutions, there is no channeling to the surface shape. It has been observed from Fig. 59 ( $\left.0 . M_{.}\right)$ that the deposit from the zinc cyanide solution has filled the inside pores and most of the surface pores, but it is clear that the thickness of the zinc deposit is not enough to fill all the. surface pores. Thus, the duplex copper layers have filled most of the surface pores and provided a base for the zinc layer 
from the acid zinc solution to protect the specimen from corrosion.

Sample No. $102 \quad 15 \%, \varepsilon$

The surface pores have not closed totally by the copper deposit; but most of the pores near the surface have been closed.

The S.E.M. observation shows that there were holes in the copper deposit and the 5 minutes plating was not sufficient to fill the surface pores.

Sample No. $103 \quad 15 \% \quad \varepsilon$

Most of the surface pores have been closed with the copper deposit by 10 minutes of plating. The solution penetration was great and copper deposit has been found inside the specimen.

Holes on the copper deposit have been seen by the S.E.M. which are connected to the substrate holes.

Sample No. $105 \quad 15 \% \varepsilon$ As sample No. $317 \quad 10 \% \varepsilon$

Sample No. $40 \quad 15 \%$ (unsintered sample)

Fig. 60 (0.M.) shows that closing the surface pores was not as good as the sintered samples with no deposition was shown inside the specimen. From the scanning electron microscopy observation, Fig. 61 (S.E.M.) it is clear that the number of holes on the surface of the deposit is small and the elucidation for the uncovered holes by plating is the presence of a great pores on the surface of the compact, so that the zinc deposit could not cover them at the plating time. 
Sample No. $5 \quad 15 \% \varepsilon$

The appearance of the deposit was very good. Fig. 62 (0.M.) shows that all the surface pores have been closed entirely with a great depth of the plating solution. All the interconnected pores near the surface have been sealed with zinc deposit. Zinc deposit has been found inside the specimen.

Sample No. $6 \quad 15 \% \quad \varepsilon$

The appearance of the deposit was good. From the optical microscopy observation it has been found that the nickel deposit has not filled all the surface pores and there were still some pores uncovered with the nickel deposit. The thickness of the nickel deposit was not sufficient to fill and level the surface pores. On the other hand, the penetration of the nickel solution was very good and nickel deposit has been found inside the specimen: The S.E.M. observation confixms with the above result and with the permeability measurement, Table 9 .

Sample No. $7 \quad 15 \% \varepsilon$

The appearance was very good.

Fig. 63 (O.M.) shows that all the surface pores have been filled and levelled with a single nickel deposit. The penetration of the plating solution was very good and all the pores near the surface have been filled with nickel deposit.

The permeability measurement Table 9 shows that the specimen was no longer permeating gas, besides the S.E.M. observation confirms with the above result and no holes connected to the substrate were observed on the nickel deposit. 
Sample No. $8 \quad 15 \% \varepsilon$ as sample No. $7 \quad 15 \% \varepsilon$

But the nickel deposit inside the specimen was more than the nickel deposit in Sample No. $7,15 \% \varepsilon$, and the nickel deposit at the surface more levelled than sample No. $7,15 \% \varepsilon$, (See Fig. 64, (S.E.M.).

Sample NO. $9 \quad 15 \% \quad \varepsilon$

The appearance of the specimen after plating was excellent. From the optical microscopy observation it has been found that the surface pores have been filled with a good deposition of copper inside the specimen. But from the S.E.M. observation, it has been observed, holes in the copper deposit, it is clear that these holes were not connected with the substrate.

Sample No. $10 \quad 15 \% \varepsilon$ As sample No. $13 \cdots 15 \%$ E

Sample No. $11 \quad 150^{\prime} \varepsilon$

The appearance of the plated sample was not good. Fig. 65 (S.E.M.) shows that there are many holes in the copper deposit and these holes are connected to the substrate as shown from the monometer reading, Table 9 . Fig. 66 (0.M.) shows that not all the surface holes have been. filled, al though the time of plating was 15 minutes.

Copper deposit has been found filling most of the inside pores.

Sample No: $13: 15 \% \varepsilon$

The appearance of the plated specimen was very good. As it has been seen from the optical microscopy observation that the surface 
pores have been filled with great depth of penetration of the plating solution. The interconnected pores near the surface have been filled with copper deposit. Copper deposit has been found filling the inside pores.

Sample No. $15 \quad 15 \%$ \& As Sample No. $7 \quad 15 \% \quad \varepsilon$

Sample No. $101 \quad 15 \% \quad \varepsilon$

The optical microscopy has shown that the deposit thickness was not enough to fill the substrate pores, moreover, corrosion product has been seen on the iron surface. The S.E.M. observation shows that there were big holes on the zinc deposit. The permeability measurement confirms with the above result and shows that the specimen is still permeating gas.

Sample No. $106 \quad 15 \% \varepsilon$

The optical microscopy observation shows that in some places the zinc deposit has filled the big pores and in other places the deposit did not manage to close the surface pores. Corrosion product has been found on the iron surface. The S.E.M. observation shows that there were still holes on the surface of the zinc deposit.

Sample No: $108 \quad 15 \% \quad \varepsilon$

Fig. 67 (O.M.) shows that no deposit on the surface of the specimen or inside the sample. 


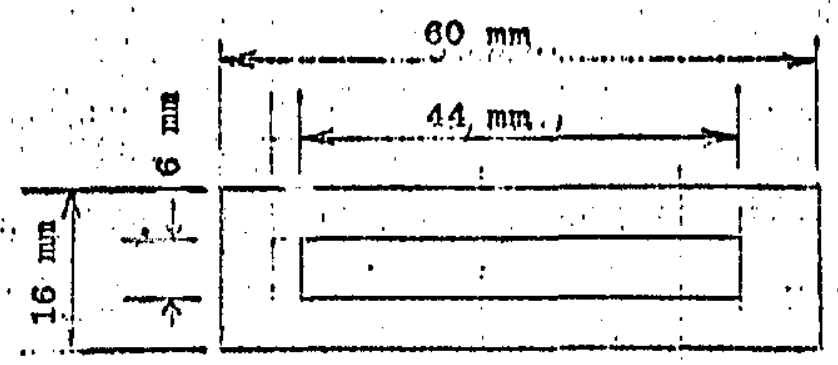

Rubber Washer

Quantity $=2$

Scale $1 / 1$

影
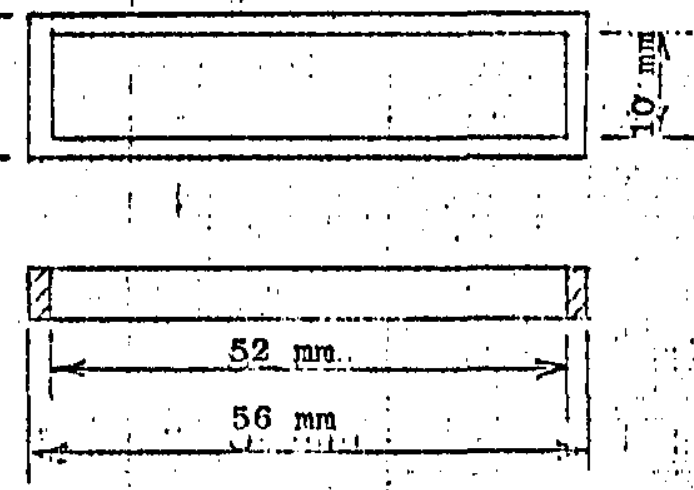

Brass or Copper rings

Quantity $\equiv 2 \quad$ Scale $1 /$

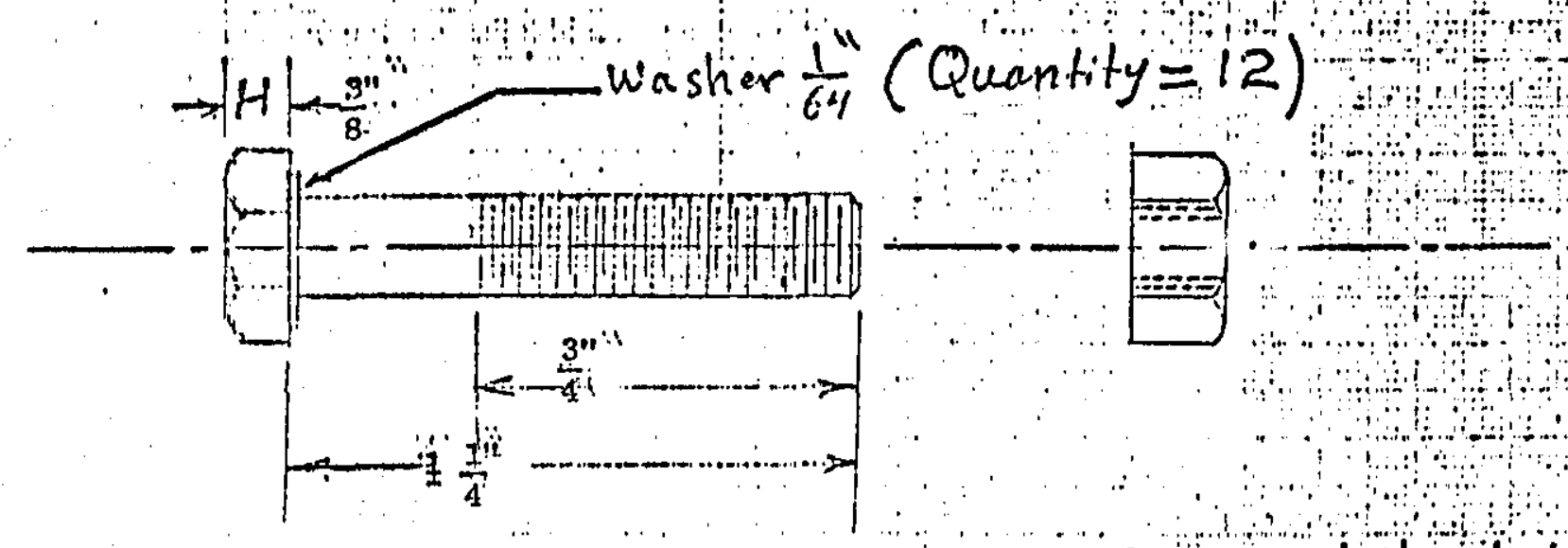

Hexagonal Standard Bolt Copper Or Brass With Nuts Nominal Size $\frac{\text { III Thered/in }=20}{4}$ 
Calculation of the surface area of the specimen.

The approrimate dimensiors of each specimen are:

length $=0.51 \mathrm{dm}$
width $=0.08 \mathrm{dm}$
height $=0.0404 \mathrm{dm}$

The area $\left(\mathrm{dm}^{2}\right)=(0.08+0.51) 2 \times 0.0404+2(0.51 \times 0.08)$

$=0.129 \mathrm{dm}^{2}$

$\cong 0.13 \mathrm{dm}^{2}$

Since the specimen is porous and the actual surface area is double or more, the calculated surface area is approximated to $0.25 \mathrm{dm}^{2}$ to simplify the calculation. 
Cumulative Particle Size Distribution in Iran Powder ASC 100-29

\begin{tabular}{|c|c|c|c|}
\hline $\begin{array}{c}\text { Size range } \\
\text { Micron }\end{array}$ & Weight \% & $\begin{array}{c}\text { Mass Fraction } \\
\text { Coarser }\end{array}$ & $\begin{array}{l}\text { Mass Fraction } \\
\text { Finex }\end{array}$ \\
\hline 212 & 00.00 & 00.00 & 100.00 \\
\hline 180 & 01.00 & 1.23 & 99.00 \\
\hline 150 & 05.80 & 7.03 & 93.20 \\
\hline 125 & 05.42 & 13.45 & $86: 78$ \\
\hline 106 & 12.40 & 25.85 & 74.38 \\
\hline 90 & 05.37 & 31.22 & 69.01 \\
\hline 75 & 14.64 & 45.86 & 54.37 \\
\hline 63 & 12.31 & 58.17 & 42.06 \\
\hline 53 & 09.10 & 67.27 & 32.96 \\
\hline 45 & 07.73 & 75.00 & 25.23 \\
\hline 38 & 08.00 & 83.00 & 17.23 \\
\hline & 17.00 & $100.00 \cong$ & $0.00 \cong$ \\
\hline
\end{tabular}


Temperature Profile in the sintering Furnace

\section{Table 3}

\begin{tabular}{|c|c|c|c|}
\hline$\underset{\mathrm{cm}}{\text { Distance in }}$ & $\begin{array}{l}\text { Reading of Poten- } \\
\text { tiometer cold } \\
\text { junction at } \\
0^{\circ} \mathrm{CM} \text {. V. }\end{array}$ & $\begin{array}{c}\text { Reading of } \\
\text { Potentiometer } \\
\text { M.V. }\end{array}$ & $\begin{array}{l}\text { Temperature } \\
\text { Corresponding } \\
\text { to the Read- } \\
\text { ing }{ }^{\circ} \mathrm{C}\end{array}$ \\
\hline-5 & 7.78 & 8.78 & 216 \\
\hline 0 & 24.55 & 25.55 & 615 \\
\hline 5 & 37.34 & 38.34 & 924 \\
\hline 7 & 40.12 & 41.12 & 995 \\
\hline 10 & 42.70 & 43.70 & 1062 \\
\hline 14 & 43.92 & 44.92 & 1095 \\
\hline 15 & 44.14 & 45.14 & 1100 \\
\hline 18 & 44.17 & 45.17 & 1101 \\
\hline 20 & 43.96 & 44.96 & 1096 \\
\hline 21 & 43.94 & 44.96 & 1095 \\
\hline 23 & 43.57 & 44.57 & 1085 \\
\hline 25 & 43.00 & 44.00 & 1070 \\
\hline 30 & 40.64 & 41.64 & 1008 \\
\hline 34 & 33.44 & 34.44 & 828 \\
\hline 40 & 11.14 & 12.14 & 298 \\
\hline 45 & 3.80 & 4.80 & 117 \\
\hline 50 & 0.68 & 1.68 & 42 \\
\hline
\end{tabular}


$\underline{T}^{\text {Table } 4^{85}}$

Operating Conditions for the Non-Cyanide Solutions

\begin{tabular}{|c|c|c|c|c|c|}
\hline $\begin{array}{c}\text { Plating } \\
\text { Solution Used }\end{array}$ & $\begin{array}{c}\text { Temperature } \\
\text { or }\end{array}$ & $\begin{array}{c}\text { Current } \\
\text { Density } \\
\text { Amp/dm }\end{array}$ & $\begin{array}{c}\text { Voltage } \\
\text { Volt }\end{array}$ & pH & $\begin{array}{c}\text { Type of } \\
\text { Agitation }\end{array}$ \\
\hline $\begin{array}{c}\text { Acid Zinc } \\
\text { Solution }\end{array}$ & $15-28$ & $1-4$ & $2-2,5$ & $4-4,5$ & No Agitation \\
\hline $\begin{array}{c}\text { Copper Pyro- } \\
\text { phosphate }\end{array}$ & $50-55$ & $3.5-5$ & $2-3$ & $8.6-9.2$ & No Agitation \\
\hline $\begin{array}{c}\text { Bright Nickel } \\
\text { (NiSOL 80) }\end{array}$ & $50-50$ & $4-6$ & $1.5-2$ & $3.6-4.2$ & $\begin{array}{c}\text { Air and } \\
\text { Mechanical1y }\end{array}$ \\
\hline
\end{tabular}


Permeability Results for Multi-Layered coatings

\begin{tabular}{|c|c|c|c|c|c|c|c|c|c|c|c|c|c|}
\hline $\begin{array}{l}\text { Sampie } \\
\text { Number }\end{array}$ & $\begin{array}{l}\text { Nominal } \\
\text { Porosity } \\
\text { Level \% }\end{array}$ & $\begin{array}{l}\text { Kind of } \\
\text { Deposit }\end{array}$ & $\begin{array}{c}\mathrm{h}_{2} \\
\text { Before } \\
\text { p1ating } \\
\mathrm{cm}\end{array}$ & $\begin{array}{c}\mathrm{h}_{2} \\
\text { After } 3 \\
\text { mins. Plat } \\
\text { ting cin }\end{array}$ & $\begin{array}{l}\text { Wt, of } \\
\text { first } \\
\text { Deposit } \\
\text { gm }\end{array}$ & $\begin{array}{c}\mathrm{h}_{2} \\
\text { After Ano- } \\
\text { ther } 3 \text { min } \\
\mathrm{cm}\end{array}$ & $\begin{array}{c}\text { Wt. of } \\
\text { Second } \\
\text { Deposit } \\
\text { gm }\end{array}$ & $\begin{array}{l}\quad h_{2} \\
\text { after } \\
\text { Further } \\
3_{\mathrm{cmins}} .\end{array}$ & $\begin{array}{c}\text { Wt. of } \\
\text { Third } \\
\text { Deposit } \\
\text { gm }\end{array}$ & $\begin{array}{l}\text { Current } \\
\text { Density } \\
\text { Amp/Spe- } \\
\text { cimen }\end{array}$ & $\left|\begin{array}{c}\text { Wt. of } \\
\text { Total } \\
\text { Deposit } \\
\mathrm{gm}\end{array}\right|$ & $\stackrel{1}{1}_{\mathrm{cm}^{2}}$ & $\begin{array}{c}\lambda \\
2 \\
\mathrm{~cm}^{2}\end{array}$ \\
\hline 5 & $15 \%$ & $\begin{array}{l}\text { Acid } \\
\text { Zinc }\end{array}$ & 37.5 & 2.5 & 0.040 & 0.00 & 0.052 & 0.00 & 0.048 & 1.0 & 0.140 & 0.0151 & Zero \\
\hline 5 & $10 \%$ & $\begin{array}{l}\text { Acid } \\
\text { Zinc }\end{array}$ & 1.5 & 0.2 & 0.046 & 0.00 & 0.052 & 0.00 & 0.046 & 1.0 & 0.144 & 0.01471 & Zero \\
\hline 5 & $5 \%$ & $\begin{array}{l}\text { Acid } \\
\text { Zinc }\end{array}$ & 0.1 & 0.00 & 0.040 & 0.00 & 0.048 & 0.00 & 0.046 & 1.0 & 0.134 & 0.01695 & Zero \\
\hline 13 & $15 \%$ & $\begin{array}{l}\text { Copper } \\
\text { Pyrophos } \\
\text { phate }\end{array}$ & 36.6 & 1.00 & 0.093 & 0.40 & 0.042 & 0.00 & 0.038 & $\begin{array}{l}2.0 \\
\therefore\end{array}$ & 0.173 & 0.0153 & Zero \\
\hline 13 & $10 \%$ & $\begin{array}{l}\text { Cu Pyro- } \\
\text { Phosphate }\end{array}$ & 8.7 & 0.9 & 0.081 & 0.30 & 0.033 & 0.00 & 0.051 & 1.0 & 0.165 & 0.01428 & Zero \\
\hline 13 & $5 \%$ & $"$ & 0.8 & 1.8 & 0.045 & 0.00 & 0.045 & 0.00 & 0,046 & 1.0 & 0.136 & 0.01676 & Zero \\
\hline 15 & $15 \%$ & $\begin{array}{l}\text { Bright } \\
\text { Nickel }\end{array}$ & 40.6 & 1.0 & 0.022 & 0.00 & 0.021 & 0.00 & 0.025 & 1.0 & 0.068 & 0.01539 & Zero \\
\hline 15 & $10 \%$ & $"$ & 3.8 & 0.5 & 0.012 & 0.00 & 0.19 & 0.00 & 0.021 & 1.0 & 0.052 & 0.01443 & Zero \\
\hline 15 & $5 \%$ & $"$ & 2.7 & 0.00 & 0.017 & 0.00 & 0.02 & 0.00 & 0.02 & 0.057 & & 0.01137 & Zero \\
\hline
\end{tabular}




\begin{tabular}{|c|c|c|c|c|c|c|c|c|c|}
\hline $\begin{array}{l}\text { Sample } \\
\text { Number }\end{array}$ & $\begin{array}{l}\text { Nominal } \\
\text { Porosity } \\
\text { Level o }\end{array}$ & $\begin{array}{l}\text { Kind of } \\
\text { Deposit }\end{array}$ & $\begin{array}{l}\text { Plating } \\
\text { Time } \\
\text { min. }\end{array}$ & $\begin{array}{l}\quad h_{2} \\
\text { Before } \\
\text { Plating } \\
\text { cm }\end{array}$ & $\begin{array}{l}\quad h_{2} \\
\text { After } \\
\text { Plating } \\
\end{array}$ & $\begin{array}{l}\text { Current } \\
\text { Density } \\
\text { Ampl.men } \\
\text { spectme }\end{array}$ & $\begin{array}{l}\text { Weight } \\
\text { of } \\
\text { Deposit } \\
\text { gm }\end{array}$ & $\mathrm{c}^{\frac{\lambda}{\mathrm{m}^{2}}} \times 10^{8}$ & $\underset{\mathrm{cm}^{2}}{\lambda} 10^{8}$ \\
\hline 1 & 2 & 3 & 4 & 5 & 6 & 7 & 8 & 9 & 10 \\
\hline 9 & $15 \%$ & $\begin{array}{l}\mathrm{Cu}-\text { Pyro } \\
\text { phosphate }\end{array}$ & 5.0 & 34.1 & 0.00 & 1.0 & 0.086 & 0.01513 & 0.00 \\
\hline 10 & $15 \% \varepsilon$ & $\begin{array}{l}\text { Cu-py ro- } \\
\text { phosphat }\end{array}$ & 8.0 & 37.6 & 0.00 & 1.0 & 0.138 & 0.0151 & 0.00 \\
\hline 11 & $15 \%$ & $"$ & 12.0 & 40,0 & 0.4 & 1.0 & 0.211 & 0.0152 & 0.01583 \\
\hline 9 & $10 \%$ & $"$ & 5.0 & 1.9 & 0.00 & 1.0 & 0.067 & 0.01431 & 0.00 \\
\hline 10 & $10 \%$ & $"$ & 8.0 & 0.7 & 0.00 & 1.0 & 0.104 & 0.01457 & 0.00 \\
\hline 11 & $10 \%$ & $"$ & 12.0 & 1.2 & 0.00 & 1.0 & 0.146 & 0.01438 & 0.00 \\
\hline 6 & $15 \%$ & $\begin{array}{l}\text { Bright } \\
\text { Niclrel }\end{array}$ & 5.0 & 44.5 & 0.50 & 0.6 & 0.031 & 0.01501 & 0.0161 \\
\hline 7 & $15 \%$ & $"$ & 7.0 & 41.2 & 0.50 & 0.6 & 0.065 & 0.014 .99 & 0.0158 \\
\hline 8 & $15 \%$ & $"$ & 10.0 & 35.1 & 0.50 & 0.6 & 0.089 & 0.01508 & 0.0154 , \\
\hline
\end{tabular}


Table 6 - (Continued)

\begin{tabular}{|c|c|c|c|c|c|c|c|c|c|}
\hline 1 & 2 & 3 & 4 & 5 & 6 & 7 & 8 & 9 & 10 \\
\hline 6. & $\begin{array}{c}10 \% \\
\vdots\end{array}$ & $\begin{array}{c}\text { Bright } \\
\text { Nicke1 }\end{array}$ & 5 & 1.00 & 0.00 & 1.00 & 0.082 & 0.0143 & 0.00 \\
\hline 7 & $10 \%$ & $"$ & 7 & 11.2 & 0.5 & 1.00 & 0.101 & 0.01438 & 0.0152 \\
\hline 8 & $10 \%$ & $n$ & 10.0 & 53.2 & 1.2 & 1.0 & 0.143 & 0.01448 & 0.01430 \\
\hline
\end{tabular}


operating Conditions for the Cyanide Solutions

Table 7

\begin{tabular}{|c|c|c|c|c|c|}
\hline $\begin{array}{c}\text { Plating Solution } \\
\text { Used }\end{array}$ & $\begin{array}{l}\text { Tempera- } \\
\text { ture oc }\end{array}$ & $\begin{array}{l}\text { Current } \\
\text { Density }\end{array}$ & $\begin{array}{c}\text { Voltage } \\
\text { Volt }\end{array}$ & $\mathrm{pH}$ & $\begin{array}{l}\text { Type of } \\
\text { Agitation }\end{array}$ \\
\hline $\begin{array}{c}\text { Copper Cyanide } \\
\text { Solution }\end{array}$ & $76-82$ & $3.0-4.5$ & $1.5-3.0$ & $11.5-12.5$ & $\begin{array}{l}\text { Stirring \& } \\
\text { Mechanical }\end{array}$ \\
\hline $\begin{array}{l}\text { Acid Copper } \\
\text { Solution }\end{array}$ & $15-40$ & $6-10^{\circ}$ & $1.5-4.0$ & & $\begin{array}{l}\text { Stirring-\& } \\
\text { Mechanical }\end{array}$ \\
\hline $\begin{array}{r}\text { Zinc Cyanide } \\
\text { Solution }\end{array}$ & $30-40$ & $3-6.5$ & $3.0-5.0$ & & $\begin{array}{l}\text { Stirring \& } \\
\text { Mechanical }\end{array}$ \\
\hline
\end{tabular}




\begin{tabular}{|c|c|c|c|c|c|c|c|c|c|}
\hline \multirow{2}{*}{$\begin{array}{l}\text { Sample } \\
\text { Number }\end{array}$} & \multirow{2}{*}{$\begin{array}{l}\text { Nominal } \\
\text { porosity } \\
\text { Level }\end{array}$} & & & & & & & & \\
\hline & & $\begin{array}{l}\text { First } \\
\text { Layer }\end{array}$ & $\begin{array}{l}\text { Time } \\
\text { Mins. }\end{array}$ & $\begin{array}{l}\text { Second } \\
\text { Layer }\end{array}$ & $\begin{array}{l}\text { Time } \\
\text { Mins. }\end{array}$ & $\begin{array}{l}\text { Third } \\
\text { Layer }\end{array}$ & $\begin{array}{l}\text { Time } \\
\text { Mins. }\end{array}$ & $\begin{array}{l}\text { Fourth } \\
\text { I ayer }\end{array}$ & $\begin{array}{l}\text { Time } \\
\text { Mins. }\end{array}$ \\
\hline 1 & 2 & 3 & 4 & 5 & 6 & 7 & 8 & 9 & 10 \\
\hline 1 & $5 \%$ & $\begin{array}{l}\mathrm{Cu}^{\prime \prime} \\
\text { Wi thout } \\
\text { A.A. }\end{array}$ & 10.0 & . & & & & & \\
\hline 2 & $5 \%$ & $\begin{array}{l}\text { Cu' ' } \\
\text { Without } \\
\text { A.A. }\end{array}$ & $\begin{array}{l}10.0 \\
\therefore\end{array}$ & . & & & . & & \\
\hline 3 & $5 \%$ & $\mathrm{Cu}^{\prime \prime}$ & 10.0 & & & & & & \\
\hline 4 & $5 \%$ & $\mathrm{Cu}^{\prime \prime}$ & 10.0 & . & . & & & . & \\
\hline 5 & $5 \%$ & $\mathrm{Zn}$ & 3.0 & $\therefore \mathbf{Z n}$ & 3.0 & $\operatorname{Zn}$ & 3.0 & & \\
\hline 6 & $5 \%$ & $\mathrm{Cu}^{*}$ & 10.0 & $\mathrm{Cu}$ & 5.0 & & & 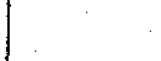 & \\
\hline 7 & $5 \%$ & $\mathrm{Cu}^{\prime}$ ? & 10.0 & $\mathrm{Cu}$ & 5.0 & $\mathrm{Zn}+\cdots$ & 10.0 & . & \\
\hline 8 & $5 \%$ & $\mathrm{Zn} \cdots$ & 10.0 & & & & & . & \\
\hline 9 & $5 \%$ & $7 n: 1$ & 15.0 & & & & & & . \\
\hline 10 & $5 \%$ & $\ln \cdot$ & 10.0 & $\mathrm{Cu}^{\prime}$ & 10.0 & $\mathrm{Cu}$ & 5.0 & $\begin{array}{c}\mathrm{N} 1 \\
\mathrm{Br} \pm \mathrm{ght}\end{array}$ & 10.0 \\
\hline
\end{tabular}




\begin{tabular}{|c|c|c|c|c|c|c|c|c|c|}
\hline 1 & 2 & 3 & 4 & 5 & 6 & 7 & 8 & 9 & 10 \\
\hline 11 & $5 \%$ & $Z_{n x} "$ & 10.0 & $\mathrm{Cu}^{+}{ }^{+}$ & 10.0 & $\mathrm{Cu}$ & 5.0 & Zn & 10.0 \\
\hline 12 & $5 \%$ & $\mathrm{Cu}^{\prime \prime}$ & 10.0 & $\mathrm{Cu}$ & 5.0 & $\begin{array}{c}\mathrm{Ni} \\
\text { Bright }\end{array}$ & 10.0 & & \\
\hline 13 & $5 \%$ & $\mathrm{Cu}^{\prime}$ & 3.0 & $\mathrm{Cu}^{\prime}$ & 3.0 & $\mathrm{Cu}^{\prime}$ & 3.0 & $:$ & \\
\hline 14 & $5 \%$ & $\mathrm{Cu}^{\prime+}$ & 10.0 & $\mathrm{Cu}$ & 5.0 & $\mathrm{Zn}+1$ & 10.0 & & \\
\hline 15 & $5 \%$ & $\begin{array}{c}\text { Ni } \\
\text { Bright }\end{array}$ & 3.0 & $\frac{N i}{\text { Bright }}$ & 3.0 & $\begin{array}{c}\mathrm{Ni} \\
\text { Bright }\end{array}$ & 3.0 & & \\
\hline 216 & $5 \%$ & $\mathrm{Zn} \cdot !$ & 5.0 & & . & & & & \\
\hline 217 & $5 \%$ & $\mathrm{zn}$ ' & 10.0 & & & & & & \\
\hline 218 & $5 \%$ & $\mathrm{Zn}{ }^{\prime \prime}$ & 15.0 & & & & & & \\
\hline 219 & $5 \%$ & $7 n=1$ & 20.0 & & & & & & \\
\hline 211 & $5 \%$ & Cu'." & 5.0 & & & & & & \\
\hline
\end{tabular}




\begin{tabular}{|c|c|c|c|c|c|c|c|c|c|}
\hline 3 & 2 & 3 & 4 & 5 & 6 & 7 & 8 & 9 & 10 \\
\hline 220 & $5 \%$ & $\mathrm{Cu}$ '" & 10.0 & & & & & & \\
\hline 213 & 5 & $\mathrm{Cu}^{\prime \prime}$ & 25.0 & & & & & & \\
\hline 212 & $5 \%$ & $\mathrm{Cu}^{\prime \prime}$ & 20.0 & & & & & & \\
\hline
\end{tabular}


Specification of plating of Each Sample with $10 \%$ Porosity

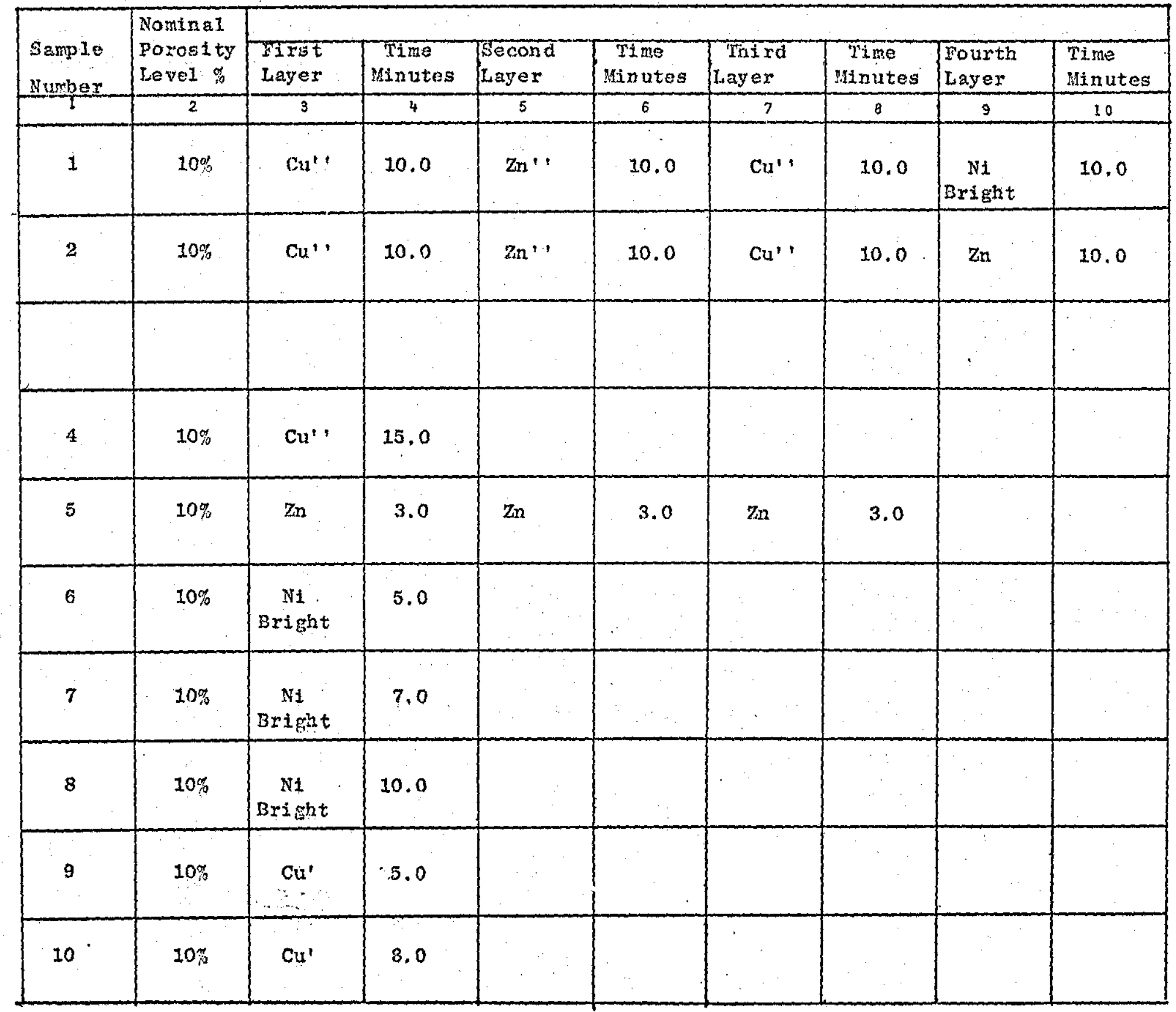




\begin{tabular}{|c|c|c|c|c|c|c|c|c|c|}
\hline 1 & 2 & 3 & 4 & 5 & 6 & 7 & 8 & 9 & 10 \\
\hline 11 & $10 \%$ & $\mathrm{Cu}^{\prime}$ & 12.0 & & & & & & \\
\hline 12 & $10 \%$ & $\mathrm{Cu}^{\prime \prime}$ & 10.0 & & & & & & \\
\hline 13 & $10 \%$ & $\mathrm{Cu}$. & 3.0 & $\mathrm{Cu}^{\prime}$ & 3.0 & $\mathrm{Cu}^{\prime}$ & 3.0 & & \\
\hline 14 & $10 \%$ & $\mathrm{Cu} \cdot '$ & 10.0 & $\mathrm{Cu}$ & 5,0 & & . & & ' \\
\hline 15 & $10 \%$ & $\begin{array}{c}\mathrm{Ni} \\
\text { Bright }\end{array}$ & 3.0 & $\begin{array}{c}\mathrm{Ni} \\
\text { Bright }\end{array}$ & 3.0 & $\stackrel{N i}{\text { Bright }}$ & 3.0 & & \\
\hline 16 & $10 \%$ & $\mathrm{Cu} \mathbf{u}^{\prime \prime}$ & 10.0 & $\mathrm{Cu}$ & 5.0 & $\mathrm{Zn}$ & 10.0 & & \\
\hline 17 & $10 \%$ & $\mathrm{Cu}$ ' & 10.0 & $\mathrm{Cu}$ & 5.0 & $\begin{array}{c}\text { N1 } \\
\text { Bright }\end{array}$ & 10.0 & & \\
\hline 18 & $10 \%$ & $\mathrm{Zn}$ "' & 15.0 & & & & & & \\
\hline 19 & $10 \%$ & $\mathrm{Zn}{ }^{\prime \prime}$ & 10.0 & & & & & & \\
\hline 20 & $10 \%$ & $\mathrm{Zn} "$ & 10.0 & $\mathrm{Cu}{ }^{\prime \prime}$ & 10.0 & $\mathrm{Cu}$ & 5.0 & $\begin{array}{l}\text { N1 } \\
\text { ight }\end{array}$ & 10.0 \\
\hline
\end{tabular}




\begin{tabular}{|c|c|c|c|c|c|c|c|c|c|}
\hline 1 & 2 & 3 & 4 & 5 & 6 & 7 & 8 & 9 & 10 \\
\hline 21 & $10 \%$ & $7 n^{\prime \prime}$ & 10.0 & $\mathrm{Cu}^{\prime \prime}$ & $I 0.0$ & $\mathrm{Cu}$ & 5.0 & $9 \mathrm{nn}$ & 10.0 \\
\hline 312 & $10 \%$ & $\operatorname{Zn}+1$ & 10.0 & & & & & & \\
\hline 311 & $10 \%$ & $7 n^{\prime \prime}$ & 15.0 & & & & & & \\
\hline 313 & $10 \%$ & $\mathrm{Cu}^{\prime \prime}$ & 5.0 & & & & & & \\
\hline 315 & $10 \%$ & $\mathrm{Cu}^{\prime \prime}$. & 10.0 & & & & & & \\
\hline 316 & $10 \%$ & $\mathrm{Cu}$ & 15.0 & & & & & & \\
\hline 317 & $10 \%$ & $\mathrm{Cu}+1$ & 20.0 & & & & & & \\
\hline
\end{tabular}


Specification of Plating of Fach Sample with $15 \%$ Porositif

\begin{tabular}{|c|c|c|c|c|c|c|c|c|c|}
\hline \multirow{2}{*}{$\begin{array}{l}\text { Samole } \\
\text { Number }\end{array}$} & \multirow{2}{*}{$\begin{array}{l}\text { Nominal } \\
\text { Porosity } \\
\text { Level \% }\end{array}$} & & & & & & & & \\
\hline & & $\begin{array}{l}\text { Nirst } \\
\text { Layer }\end{array}$ & $\begin{array}{l}\text { Time } \\
\text { Min. }\end{array}$ & $\begin{array}{l}\text { Second } \\
\text { Layer. }\end{array}$ & $\begin{array}{l}\text { Time } \\
\text { Min. }\end{array}$ & $\begin{array}{l}\text { Third } \\
\text { Layer }\end{array}$ & $\begin{array}{l}\text { Time } \\
\text { Min. }\end{array}$ & $\begin{array}{l}\text { Fourth } \\
\text { I.ayer }\end{array}$ & $\begin{array}{l}\text { Time } \\
\text { Min }\end{array}$ \\
\hline 1 & 2 & 3 & 4 & 5 & 8 & $\therefore 7$ & 8 & 9 & 30 \\
\hline 1 & $15 \%$ & $\mathrm{Cu}+\mathrm{t}$ & 15.0 & & & & & & \\
\hline 2 & $15 \%$ & $\mathrm{Cu}^{\prime \prime}$ & 10.0 & & & & & & \\
\hline 3 & $15 \%$ & $\mathrm{Cu}$ & 10.0 & $\mathrm{Cu}$ & 5.0 & & & & \\
\hline 4 & $15 \%$ & $\mathrm{Cu}^{\prime \prime}$ & 10.0 & $\mathrm{Cu}$ & 5.0 & Ran & 10.0 & & \\
\hline 5 & $15 \%$ & $\mathrm{zn}$ & 3.0 & $\mathrm{gn}$ & 3.0 & $z n$ & 3.0 & & \\
\hline 6 & $15 \%$ & $\begin{array}{l}\text { Ni } \\
\text { Bright }\end{array}$ & 5.0 & & & & & & \\
\hline 7 & $15 \%$ & $\begin{array}{l}\text { Ni } \\
\text { Bright }\end{array}$ & 7.0 & & & & & & \\
\hline 8 & $15 \%$ & $\begin{array}{l}\mathrm{Ni} \\
\text { Bright }\end{array}$ & 10.0 & & & & $\because$ & & \\
\hline 9 & $15 \%$ & $\mathrm{Cu}^{\prime}$ & 5.0 & & & & & & \\
\hline 10 & $15 \%$ & Cu' & 8.0 & & & & & & \\
\hline
\end{tabular}




\begin{tabular}{|c|c|c|c|c|c|c|c|c|c|}
\hline I & 2 & 3 & 4 & 5 & 6 & 7 & 8 & 9 & 10. \\
\hline 11 & $15 \%$ & $\mathrm{Cu}^{\prime}$ & 12.0 & & & & & & \\
\hline 12 & $15 \%$ & $\mathrm{Cu}$ '" & 10.0 & $\mathrm{Cu}$ & 5.0 & $\begin{array}{c}\mathrm{Ni} \\
\text { Bright }\end{array}$ & 10.0 & . & \\
\hline 13 & $15 \%$ & $\mathrm{Cu}^{\prime}$ & 3.0 & $\mathrm{Cu}^{\prime}$ & 3.0 & $\mathrm{Cu}^{\prime}$ & 3.0 & & \\
\hline 14 & $15 \%$ & $\mathrm{Cu}^{\prime \prime}$ & 10.0 & $\mathrm{Cu}$ & 5.0 & $\mathrm{Cu}^{\prime \prime}$ & 10.0 & Brifht & 10.0 \\
\hline 15 & $15 \%$ & $\begin{array}{c}N i \\
\text { Bright }\end{array}$ & 3.0 & $\begin{array}{c}N i \\
\text { Bright }\end{array}$ & 3.0 & $\begin{array}{c}N i \\
\text { Bright }\end{array}$ & 3.0 & & \\
\hline 16 & $15 \%$ & $\mathrm{Cu}{ }^{\prime}$ & 10.0 & $\mathrm{Zn} \cdot$ & 10.0 & $\mathrm{Cu}^{\prime \prime}$ & 10.0 & $\mathrm{Zn}{ }^{\prime \prime}$ & 10.0 \\
\hline 17 & $15 \%$ & $z n^{\prime}$ & 15.0 & & & & & & $\therefore$ \\
\hline 18 & $15 \%$ & $\mathrm{Zn} \cdot$ & 10.0 & & & & & & \\
\hline 19 & $15 \%$ & $7 n^{\prime \prime}$ & 10.0 & $\mathrm{Cu}^{\prime \prime}$ & 10.0 & $\mathrm{Cu}$ & 5.0 & $\begin{array}{c}N i \\
\text { Bright }\end{array}$ & 10.0 \\
\hline 20 & $15 \%$ & $z_{n} \cdot$ & 10,0 & $\mathrm{Cu}^{\prime \prime}$ & 10.0 & $\mathrm{Cu}$ & 5.0 & $\mathrm{Zn}$ & 10.0 \\
\hline
\end{tabular}




\begin{tabular}{|c|c|c|c|c|c|c|c|c|c|}
\hline 1 & 2 & 3 & 4 & 5 & 5 & 7 & 8 & 9 & 20 \\
\hline 21 & $15 \%$ & $\mathrm{Cu}^{\prime \prime}$ & 5.0 & & & & & & \\
\hline 101 & $15 \%$ & Zn' & 5.0 & & & & & & \\
\hline 106 & $15 \%$ & Zn'" & 10.0 & & & & & & \\
\hline 108 & $15 \%$ & $7 \mathrm{n} \cdot$ & 15.0 & & & & & & \\
\hline 102 & $15 \%$ & $\mathrm{Cu}^{\prime}$ ? & 5.0 & & & & & & \\
\hline 103 & $15 \%$ & ru' ' & 10.0 & & & & & & \\
\hline 104 & $15 \%$ & $\mathrm{Cu} !$ & 15.0 & & & & & & \\
\hline 105 & $15 \%$ & $\mathrm{Cu}_{1} !$ & 20.0 & & & & & & \\
\hline
\end{tabular}


Permeability Results for Ciganide Solution 'for Samples with $5 \%$ Porosity

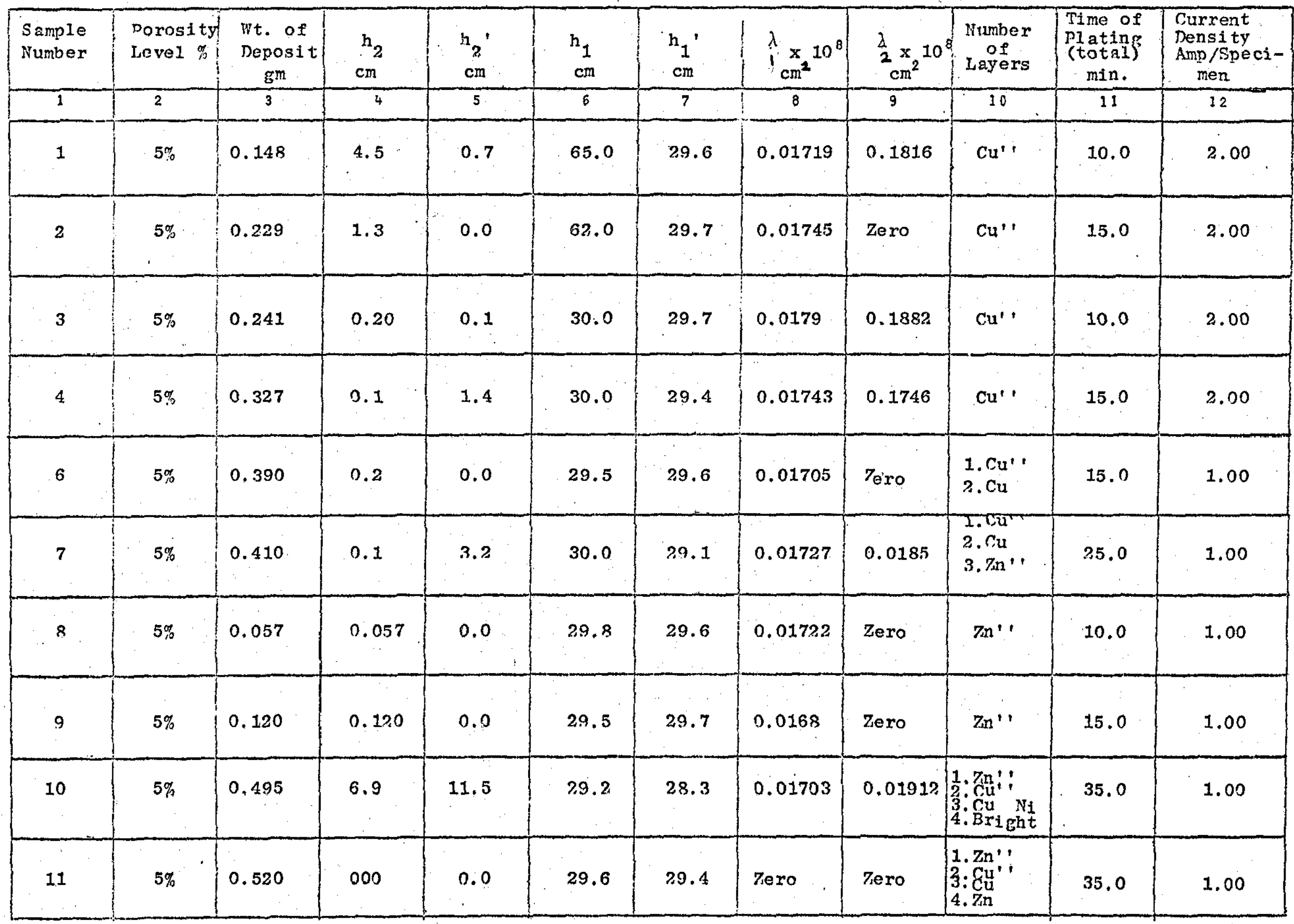




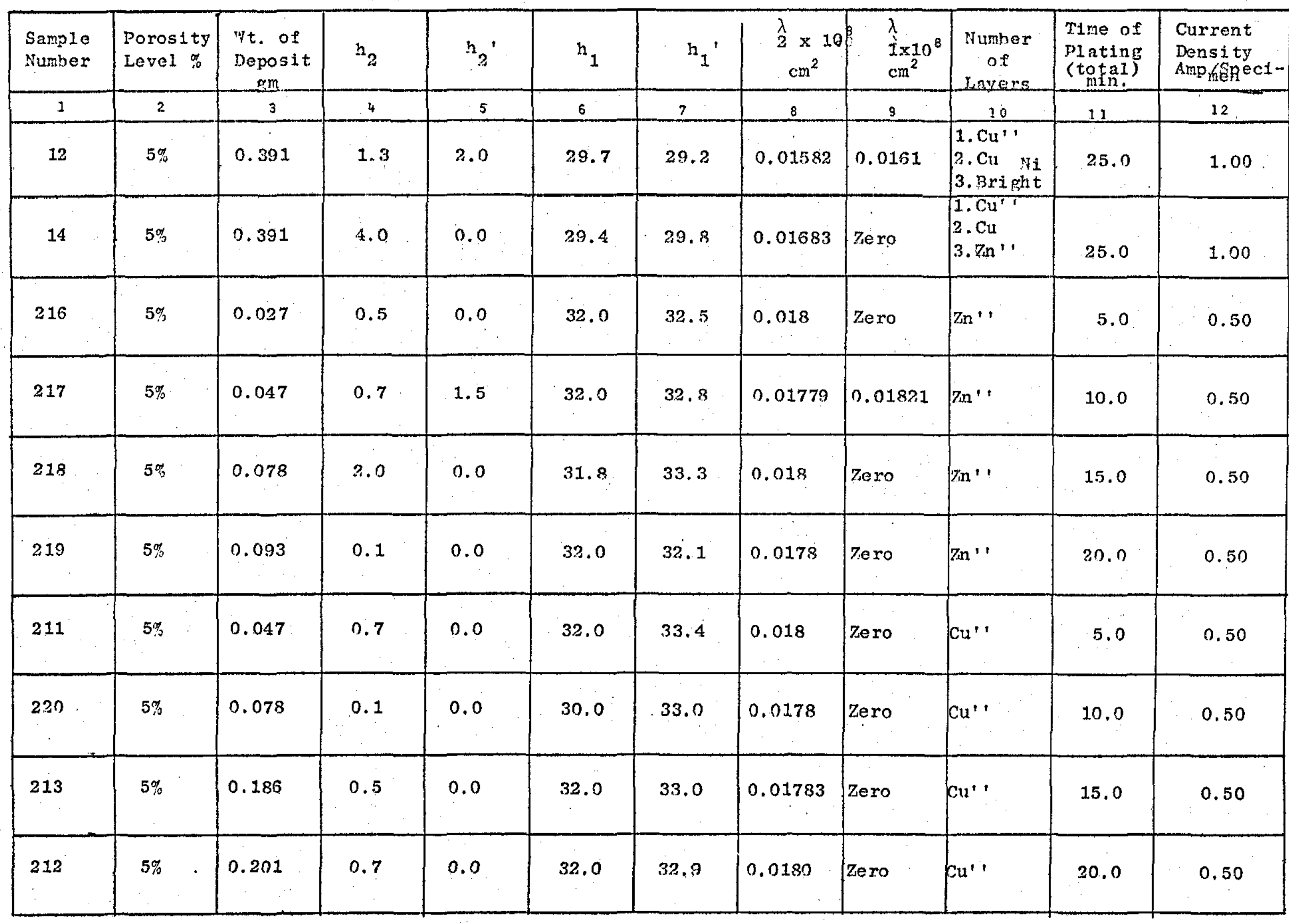


Permeability Results for Cyanide Solution for Samples with $10 \%$ Porosity

\begin{tabular}{|c|c|c|c|c|c|c|c|c|c|c|c|}
\hline $\begin{array}{l}\text { Sample } \\
\text { Number }\end{array}$ & $\begin{array}{l}\text { Porosity } \\
\text { Level } \%\end{array}$ & $\begin{array}{l}\text { Wt. of } \\
\text { Deposit }\end{array}$ & $\begin{array}{l}h_{2} \\
\mathrm{~cm}\end{array}$ & $\begin{array}{c}\mathrm{h}_{2}{ }^{\prime} \\
\mathrm{cm}^{\prime}\end{array}$ & $\begin{array}{l}\mathrm{h}_{1} \\
\mathrm{~cm}\end{array}$ & $\mathrm{~h}_{1}^{\prime}$ & ${ }_{10^{8}}^{8}$ & $\begin{array}{r}2 \\
\times 10^{8} \\
\end{array}$ & $\begin{array}{c}\text { Number } \\
\text { of } \\
\text { Layers }\end{array}$ & $\begin{array}{l}\text { Time of } \\
\text { plating } \\
\text { min }\end{array}$ & $\begin{array}{l}\text { Current } \\
\text { Density } \\
\text { Amp/Speci- }\end{array}$ \\
\hline 1 & 2 & 3 & 4 & 5 & 6 & 7 & $B$ & 9 & & 11 & 12 \\
\hline 2 & $10 \%$ & 0.563 & 24.5 & 0.00 & 52.00 & 29.60 & 0.0151 & Zero & $\begin{array}{l}1 . \mathrm{Cu} \\
2 . \mathrm{Zn} \cdot \\
3, \mathrm{Cu} \\
4 . \mathrm{Zn}\end{array}$ & 40.00 & 1.00 \\
\hline 4 & $10 \%$ & 0.281 & 1.0 & 0.00 & 29.70 & 29.80 & 0.01449 & Zero & $\mathrm{Cu}$ "' & 15.00 & 1.00 \\
\hline 12 & $10 \%$ & 0.183 & 0.6 & 0.00 & 29.6 & 29.5 & 0.01510 & Zero & $\mathrm{Cu}^{\prime \prime}$ & 10.60 & 1.00 \\
\hline 14 & $10 \%$ & 0.199 & 3.3 & 0.90 & 29.6 & 29.3 & 0.01427 & 0.152 & $\begin{array}{l}\text { 1.Cu' } \\
2 . \mathrm{Cu}\end{array}$ & 15.00 & 1.00 \\
\hline 16 & $10 \%$ & 0.284 & 2.0 & 0.00 & 29.6 & 29,7 & 0.01431 & Zero & $\begin{array}{l}\text { 1. Cu' } \\
\text { 2. Cu } \\
\text { 3. } \mathrm{zn}^{\prime},\end{array}$ & 25.00 & 1.00 \\
\hline 17 & $10 \%$ & 0.382 & $\begin{array}{r}1.2 \\
.\end{array}$ & 0.00 & 30.0 & 29.7 & 0.01427 & Zero & $\begin{array}{l}1 . \mathrm{Cu} \\
2 . \mathrm{Cu} \sqrt{\mathrm{Ni}} \\
3 . \mathrm{Bright}\end{array}$ & 25.00 & 1.00 \\
\hline 18 & $10 \%$ & 0.033 & 5.2 & 1.00 & 29.2 & 29.7 & 0.01435 & 0.154 & $\mathrm{Zn} \cdot$ & 15.00 & 0.50 \\
\hline 19 & $10 \%$ & 0.023 & 2.0 & 0.40 & 29.80 & 29.5 & 0.01437 & 0.1621 & $7 n+1$ & 10.00 & 0.50 \\
\hline
\end{tabular}




\begin{tabular}{|c|c|c|c|c|c|c|c|c|c|c|c|}
\hline 1 & 2 & 3 & 4 & 5 & 6 & 7 & 8 & $g$ & 10 & II & 12. \\
\hline 21 & $10 \%$ & 0.329 & 23.5 & 1.00 & 24.2 & 29.5 & 0.01399 & 0.1567 & $\begin{array}{l}\text { 1. } \mathrm{Zn}: ' \\
2 . \mathrm{Cu} \cdot \\
3 . \mathrm{Cu} \\
4 . \mathrm{Zn}\end{array}$ & 35.00 & 1.00 \\
\hline 312 & $10 \%$ & 0.027 & 0.5 & 0.00 & 32.1 & 32.1 & 0.0131 & Rero: & $\mathrm{Zn}{ }^{\prime}$ & 10.00 & 0.5 \\
\hline 311 & $10 \%$ & 0.060 & 1.6 & 0.20 & 32.0 & 32.5 & 0.01481 & 0.142 & $7 n+1$ & 15.00 & 0.5 \\
\hline 313 & $10 \%$ & 0.059 & 0.1 & 0.00 & 31.0 & 32.5 & 0.0136 & Zero & $\mathrm{Cu}^{\prime \prime}$ & 5.0 & 0.75 \\
\hline 315 & $10 \%$ & 0.146 & 1.00 & 0.00 & 32.0 & 32.6 & 0.0142 & zero & $\mathrm{Cu} \cdot '$ & 10.0 & 0.75 \\
\hline 316 & $10 \%$ & 0.156 & 0.10 & 0.00 & 32.0 & 32.5 & 0.0139 & Zero & $\mathrm{Cu}+'$ & 15.0 & 0.75 \\
\hline 317 & $10 \%$ & 0.346 & $4.0 n$ & 0.20 & 31.6 & 31.9 & 0.0148 & $0.014 \mathrm{~T}$ & $\mathrm{Cu}+'$ & 20.0 & 0.75 \\
\hline
\end{tabular}


Permeability Results for Cyanide Solution for Samples with $15 \%$ Porasity

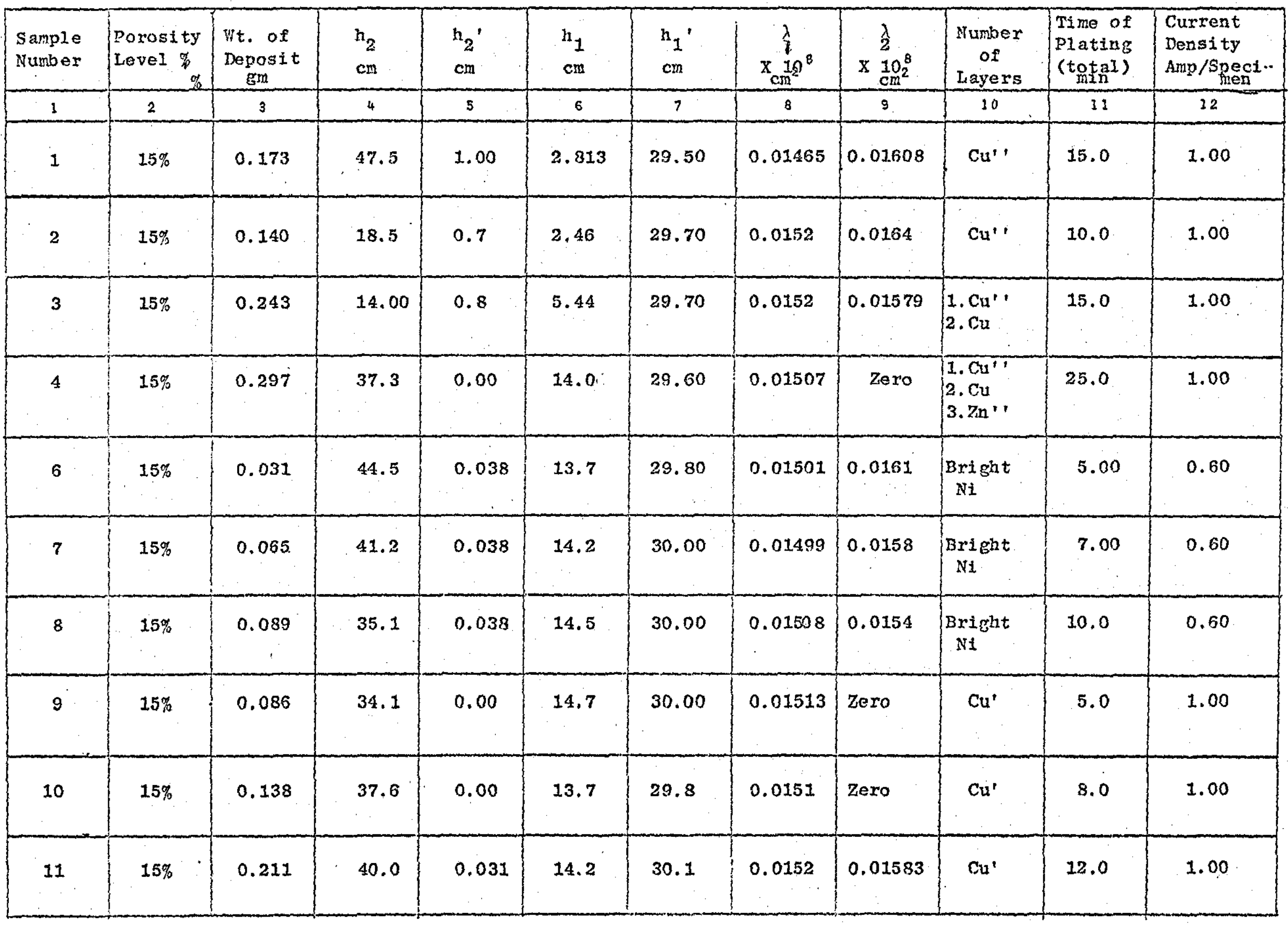




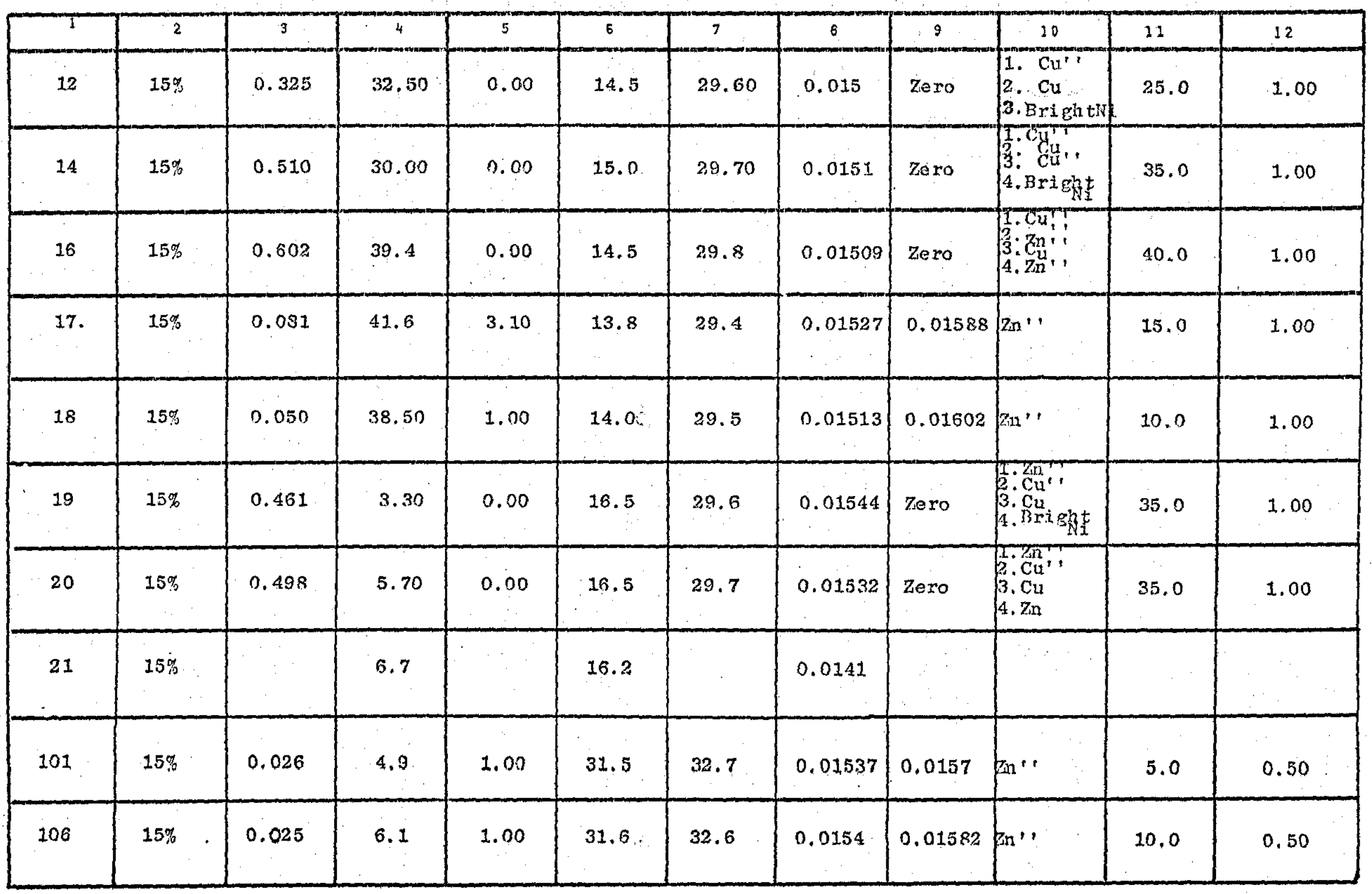




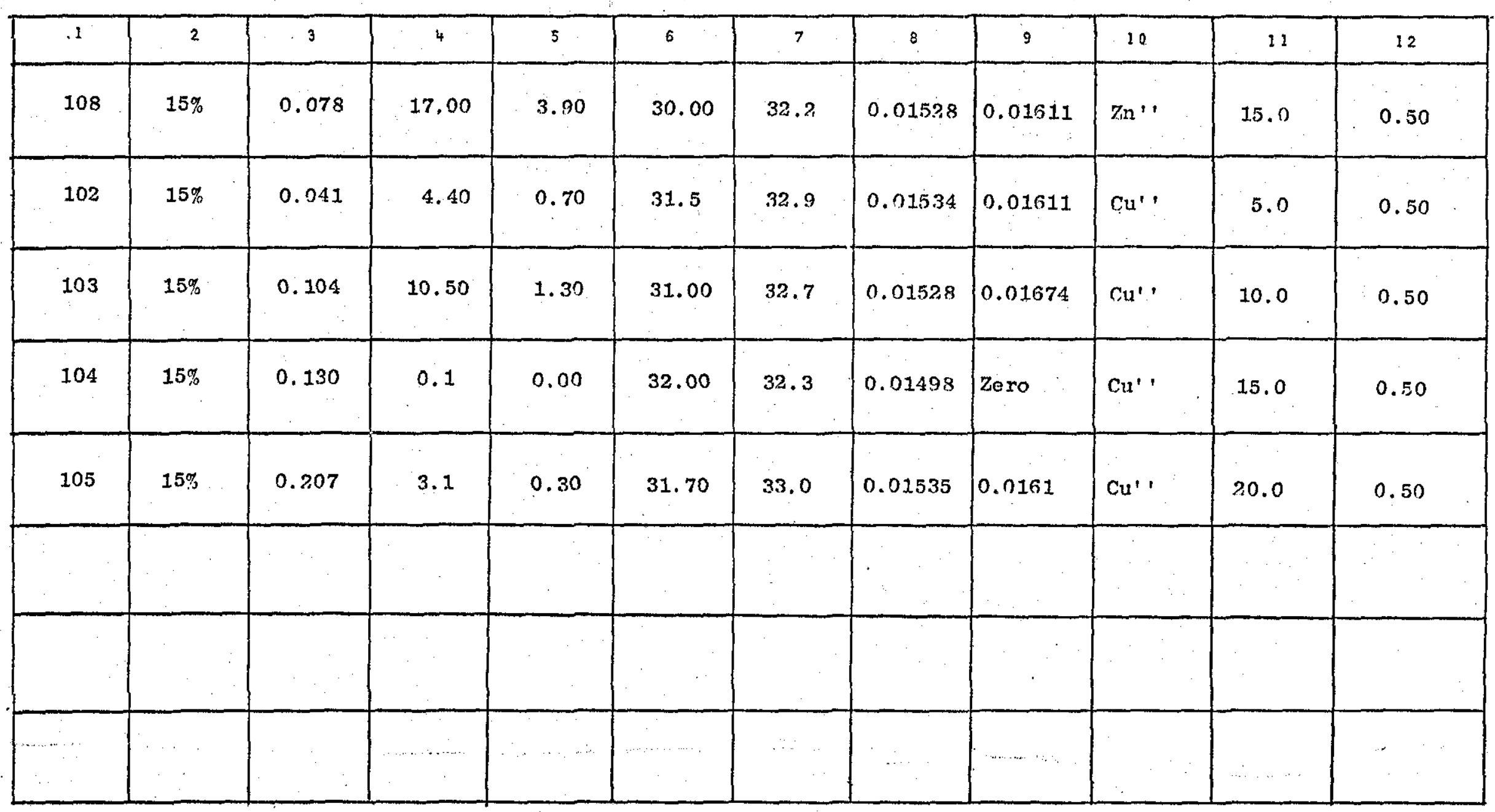


FIGURES 


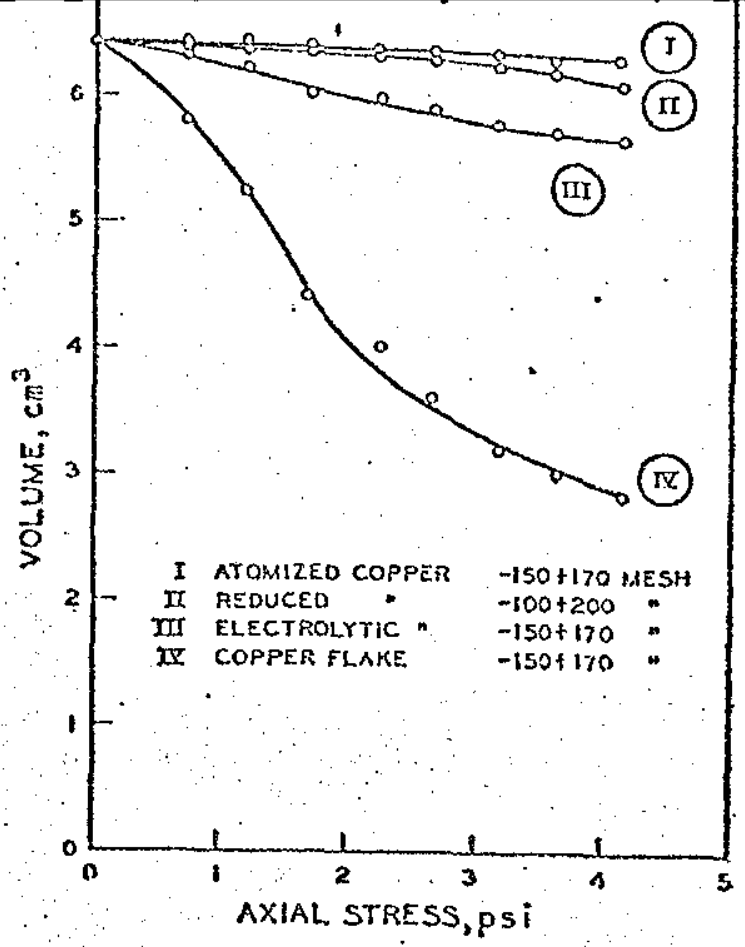
ercune 1 The Effect Of Particle Shape On The Volume-Pressure Curves For Copper
Powder
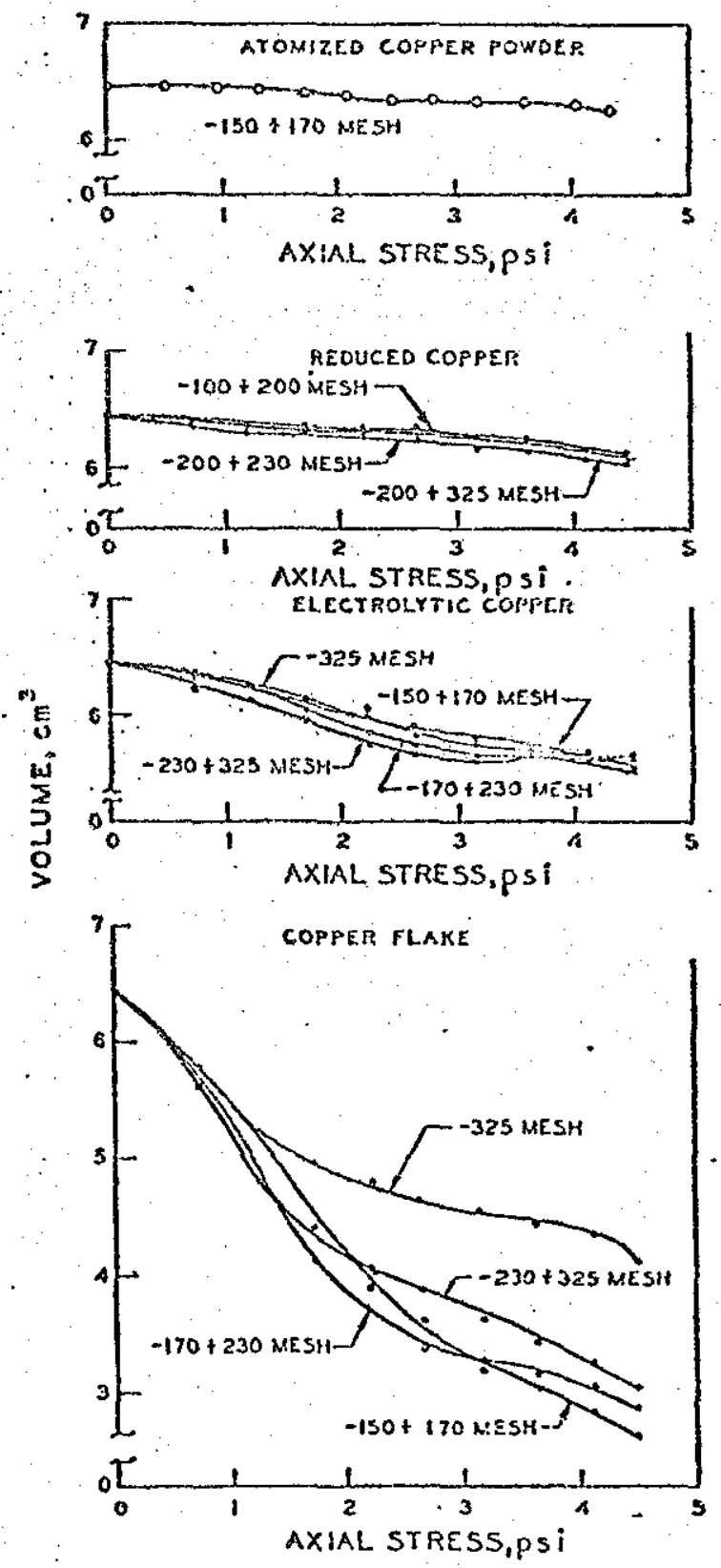

nucure 2 The Effect Of Particle Size On The Volume-Pressure Curves For Copper Powder of Various Shapes. 


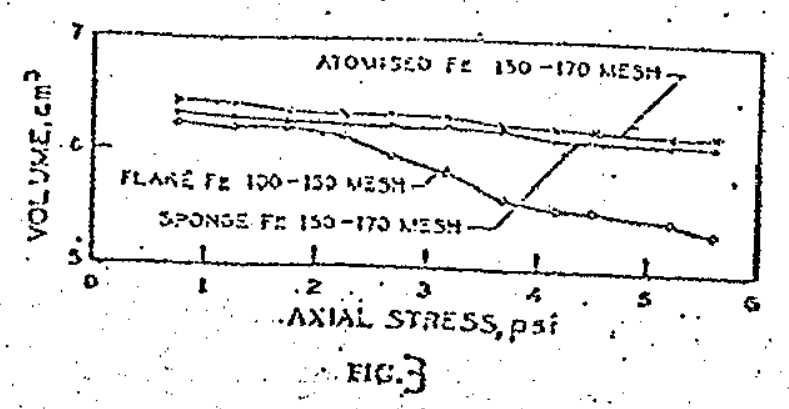

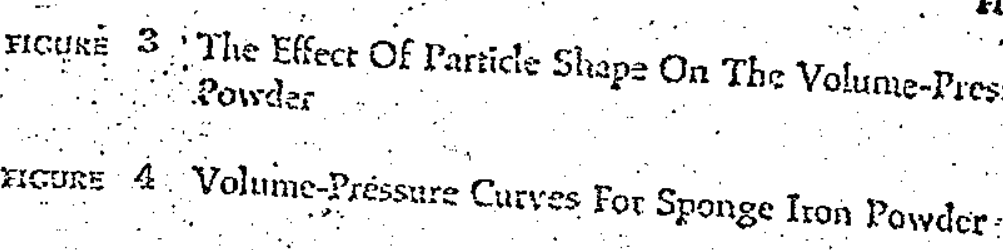

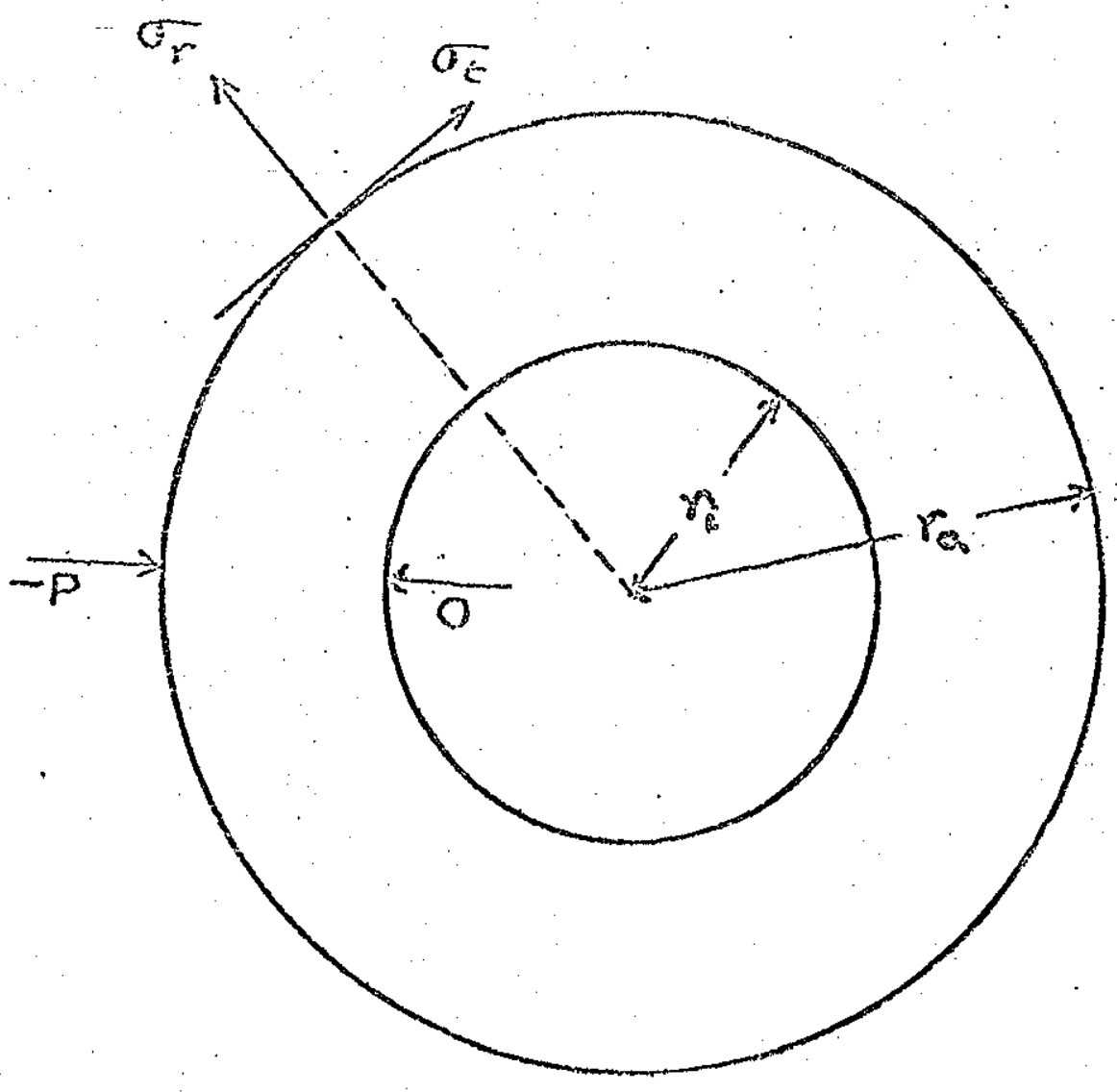

Fig. 5

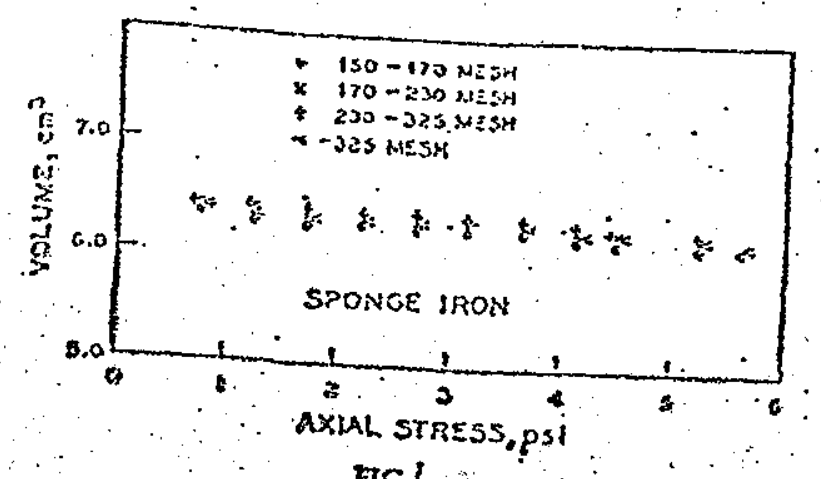

ne. 4 . 


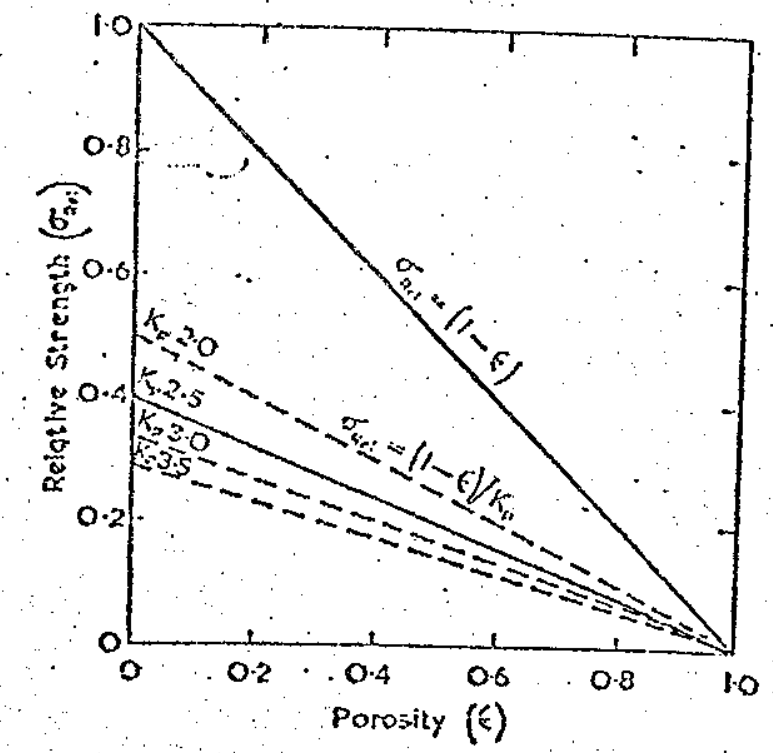

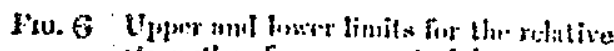

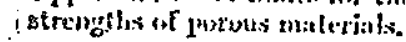
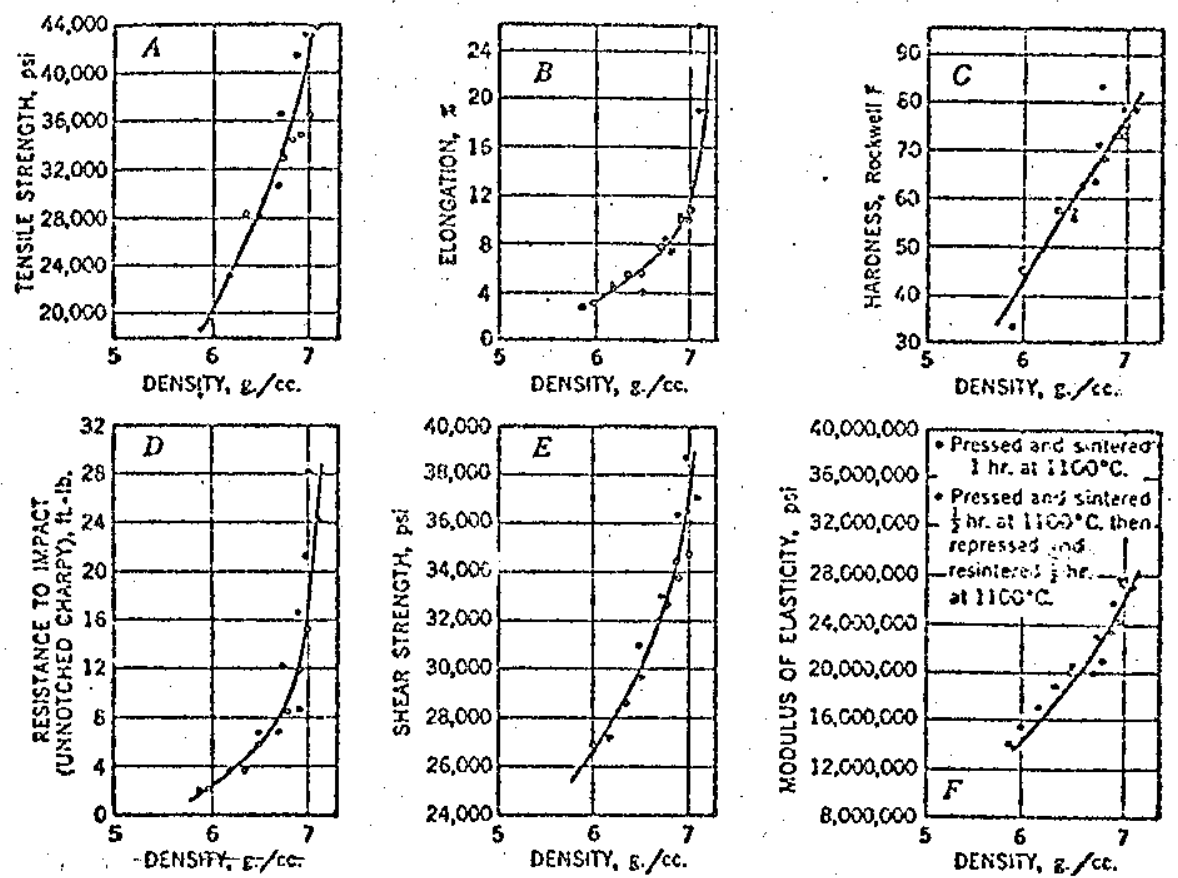

FIG.7 Efiect of repressing and resintering on the physical properties of iron powder compacts (according to Squire ${ }^{b 4}$ ): $A$, relation between tensile strength and density; $B$, relation between elongation and clensity; $C$, relation between hardness and density; $D$, relatign between impact strength and density; $E$, relation between shear strength and density; nad $F$, rehation between modulus of elasticity and density. 


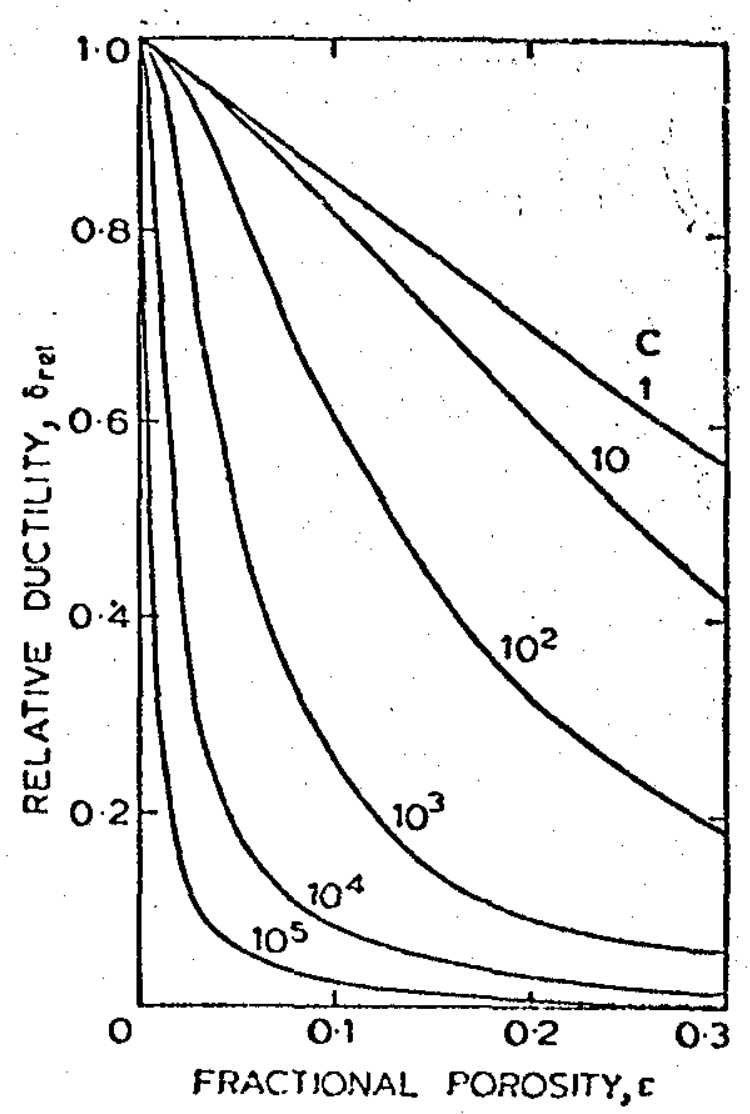

Fig. 8 fffect of vilue of constant $C$ on form of ducility/porositycontent: chive. 


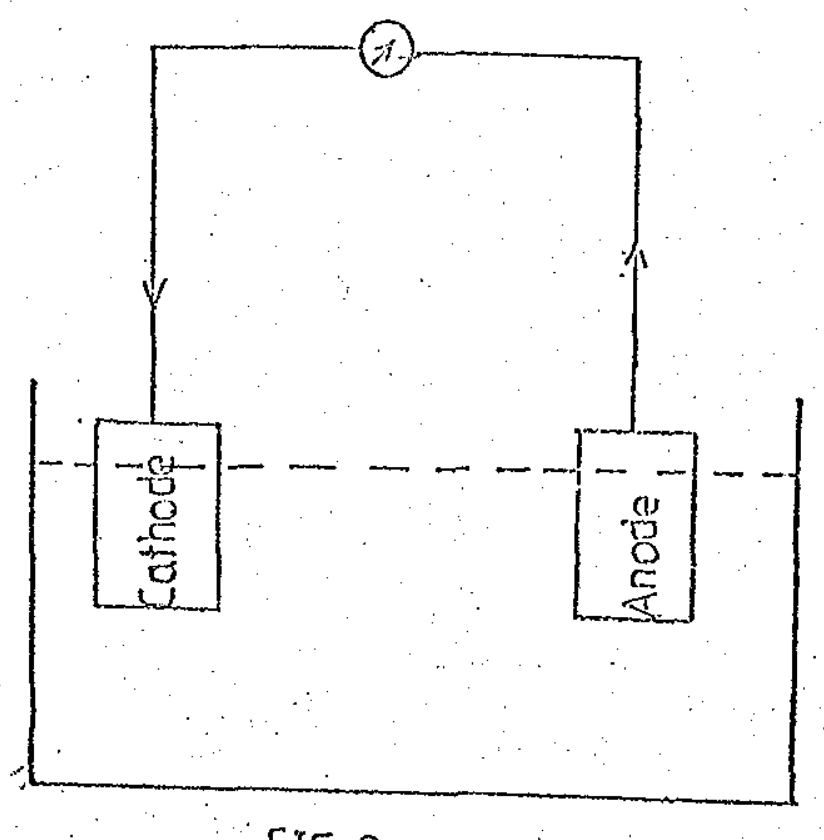

FIS. 9

The electro chemical corrosion circuit.

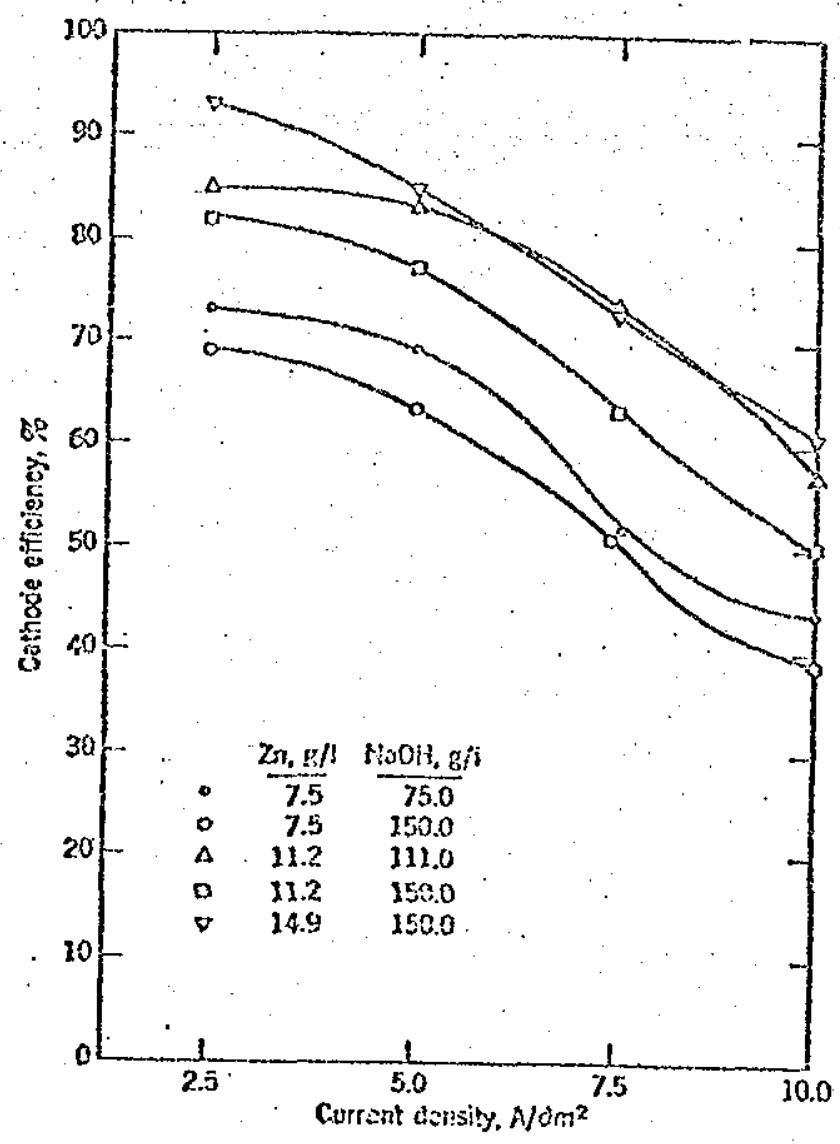

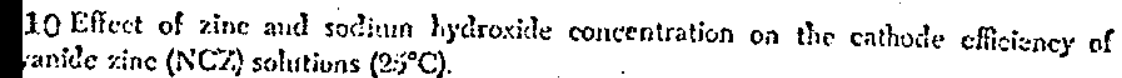

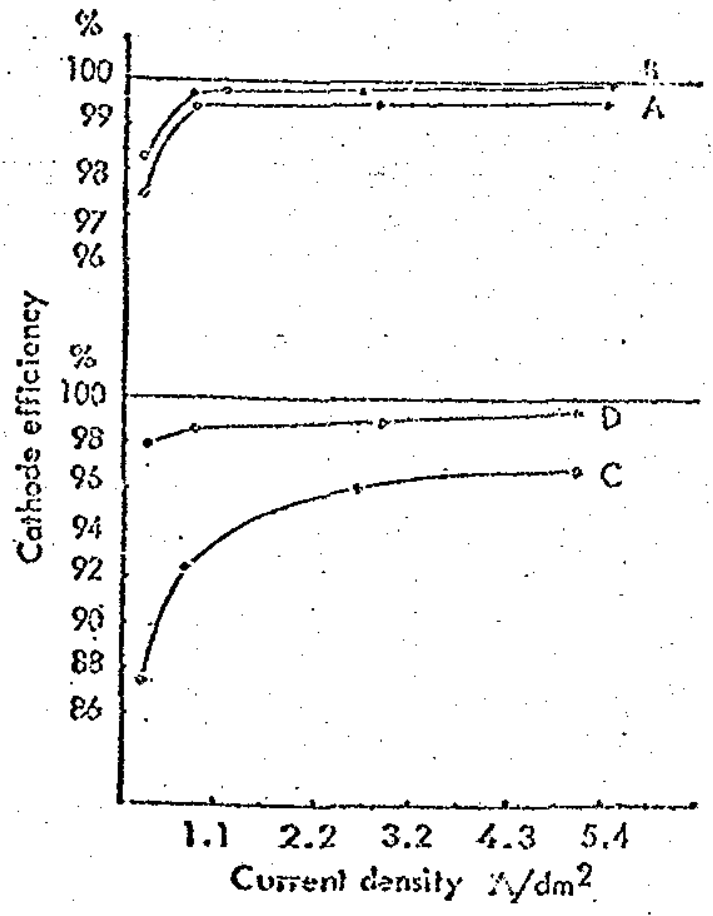

Fig $1 \mathrm{j}$ Caikode eficiency of sulplate and chlosicic nickel flating solutions (afuer W"csley. - and (arey)

A. Sulplate lath at pis 5

B. Chloride ba!k at jill 5

C. Sulphate bath at pH 2

D. Chlorisle berin al. $\mathrm{pH} 2$ 


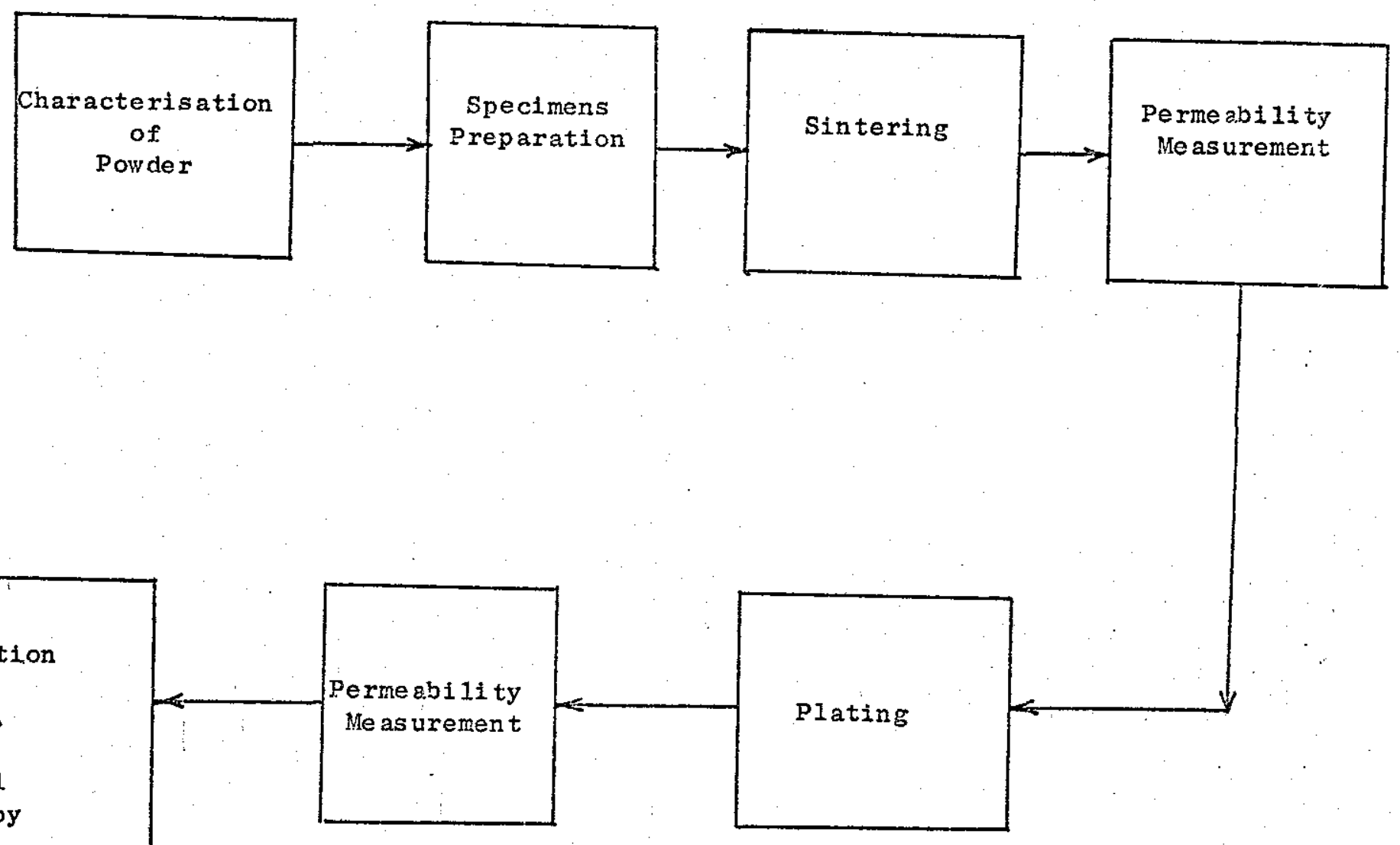

FIg. 12

Schernatic diagran for the plating of sintered iron powder 


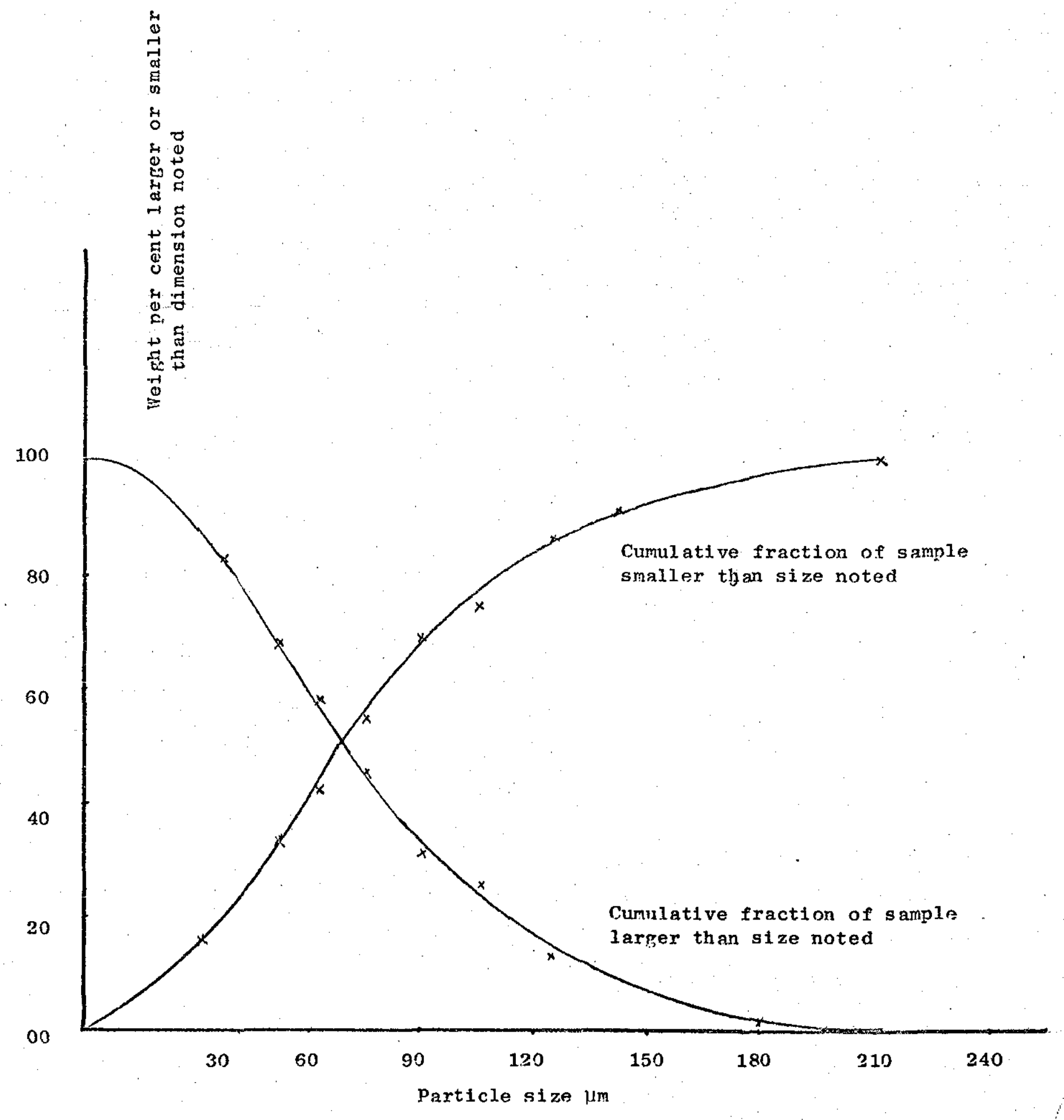

Fig. 13 Cumulative distribution plat for screen analysis of Table 2 . 


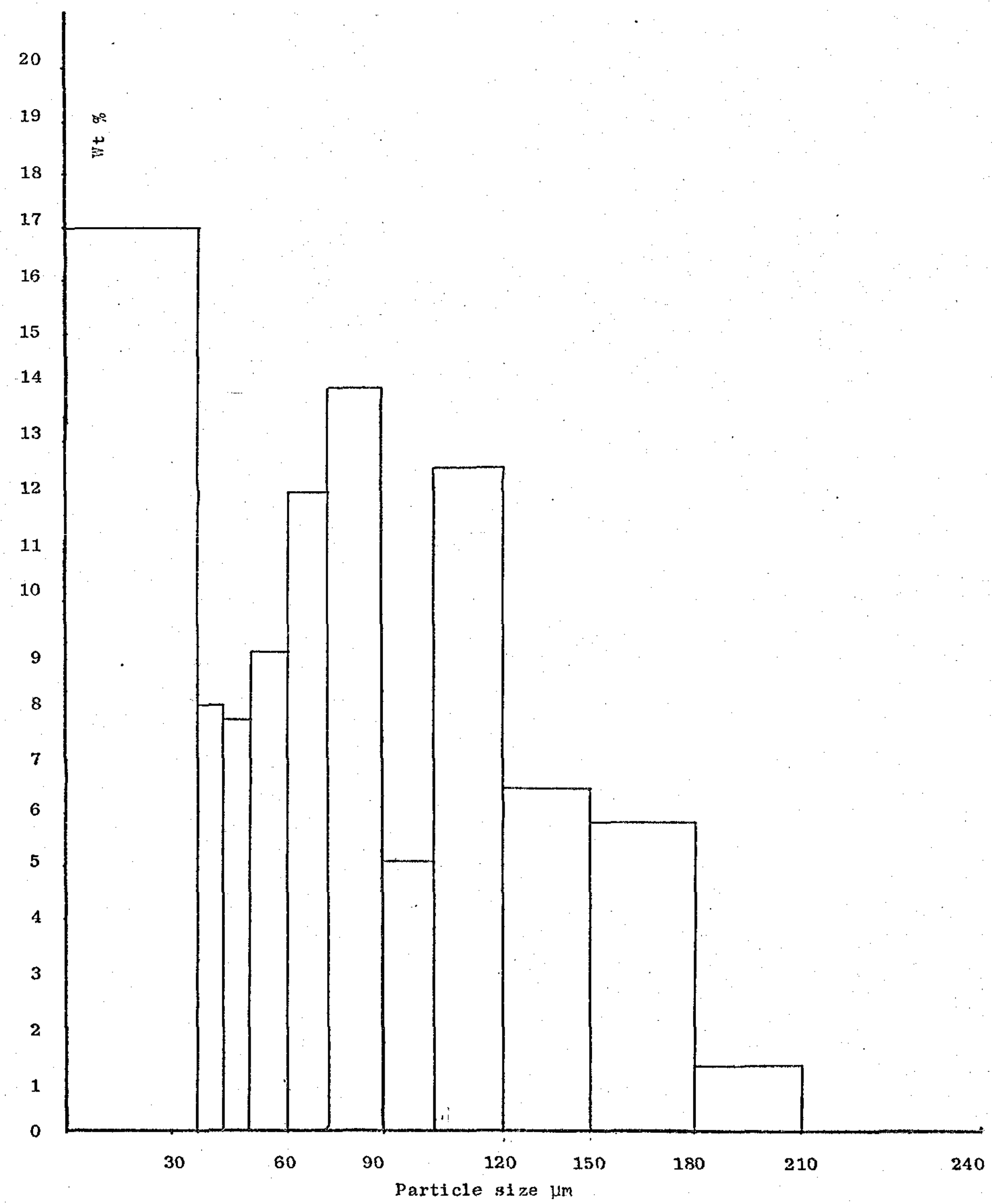

Fig. 14

Histogram presentation of screen analysis of Table 2 


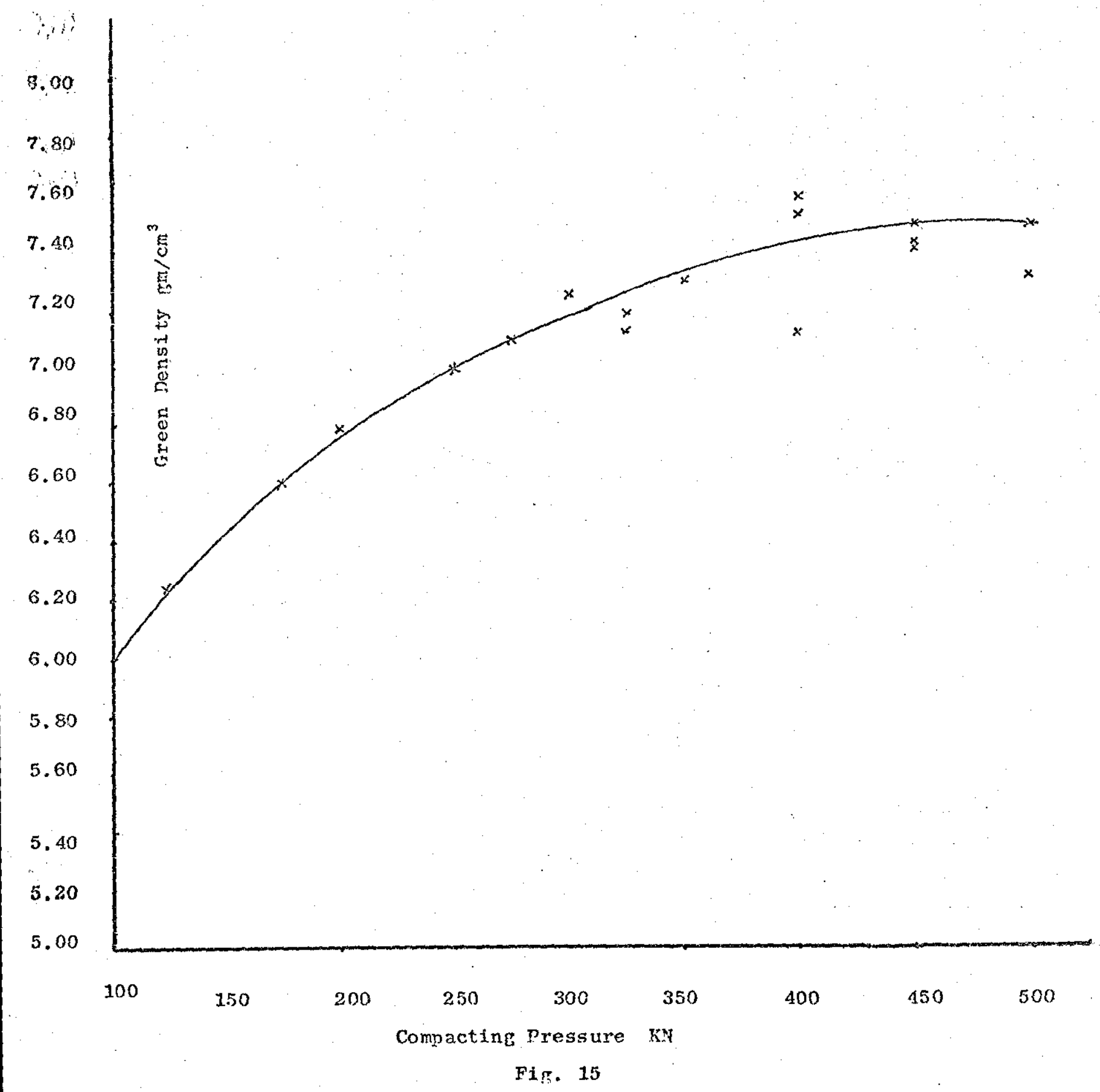

Relationship between green density and compacting pressure 
Fig. 16

Compaction Die for Manufacture of Specimens

Fig. 17

Tensile Testing Machine used in Compacting the Specimens 

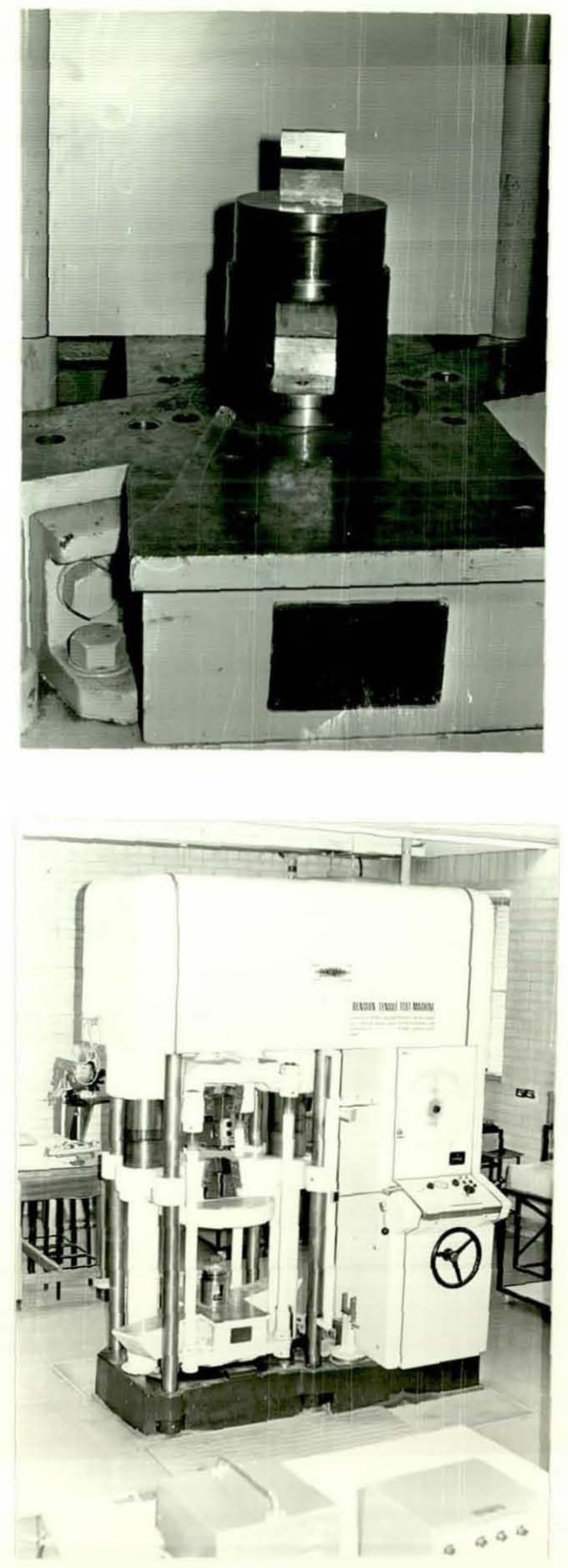


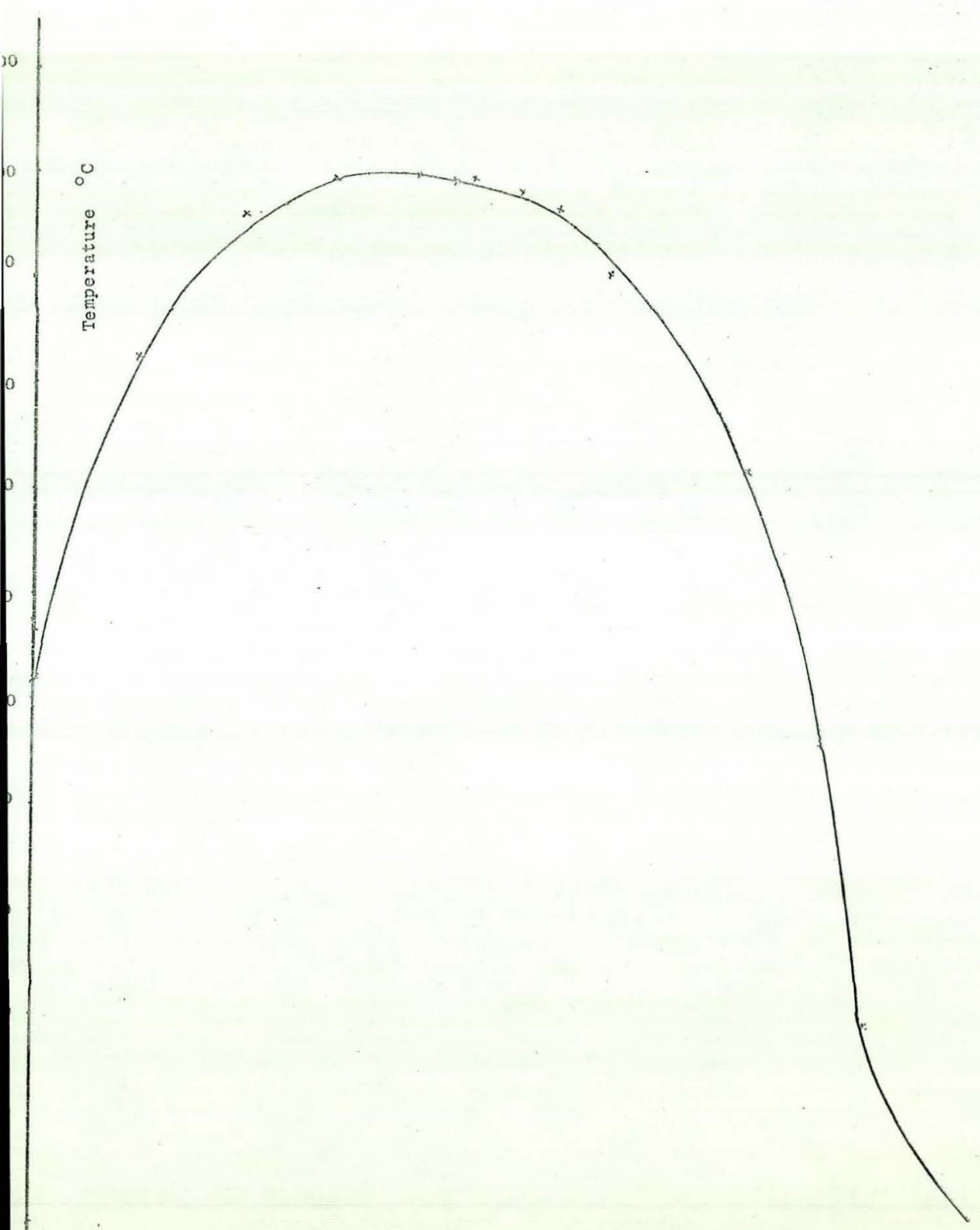




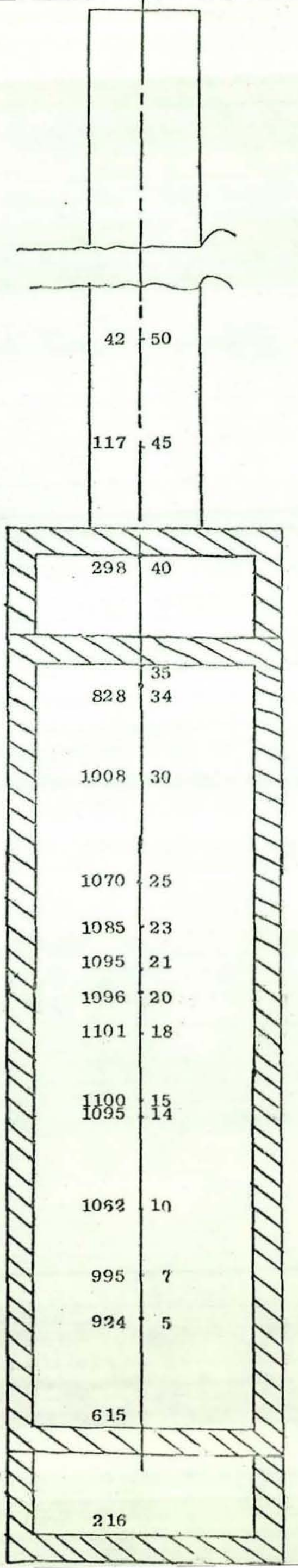


Fig. 20

Cell for the Measurement of Permeability of Sintered Compacts

Fig. 21

Lea and Nurse Permeability Apparatus 

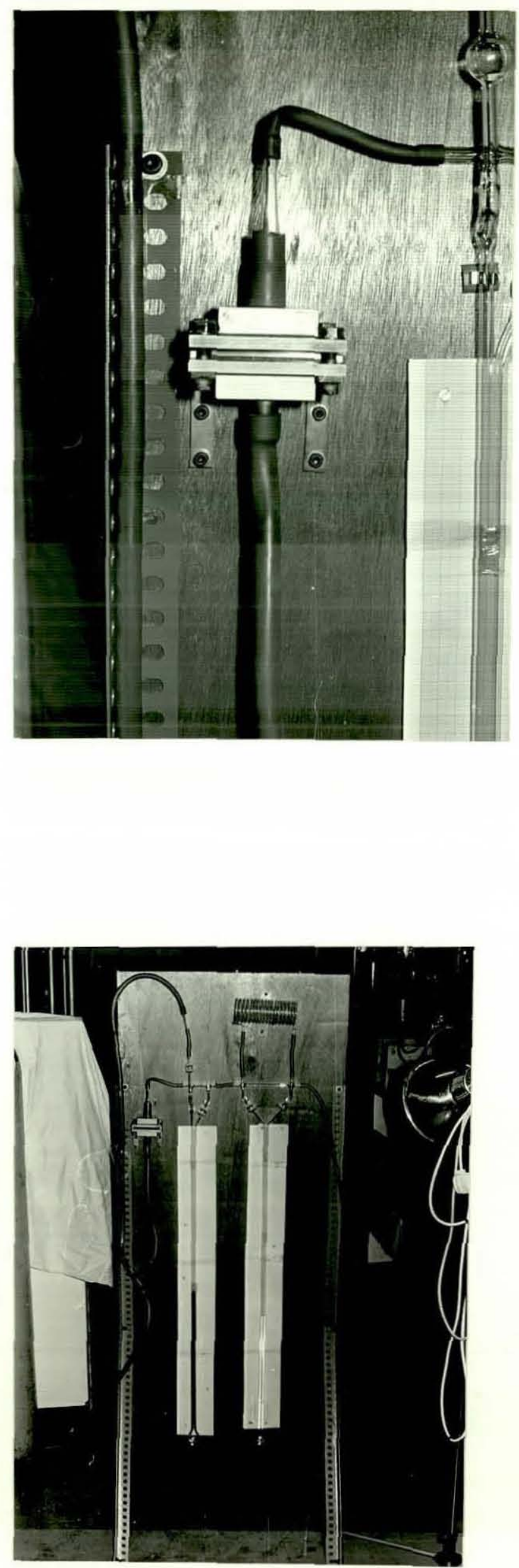
To Power Supply

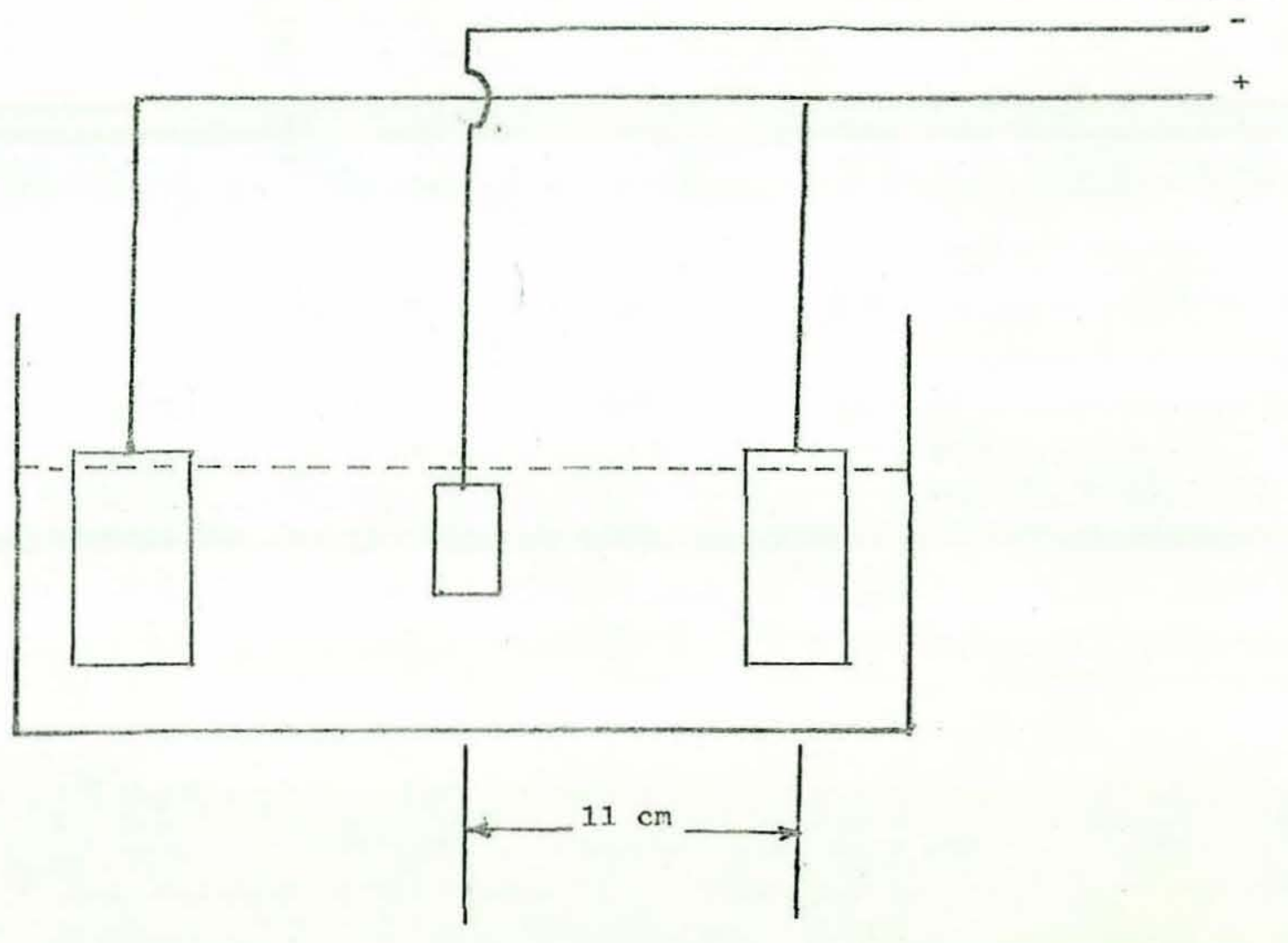

Fig. 22

Schematic diagram of plating system 
Fig. 23

Copper Deposit on Compact with 5\% Porosity (S.E.M.) $x 240$

Fig. 24

Cross-Section of Compact with 5\% Porosity. As Polished (Optical) x 64 . 

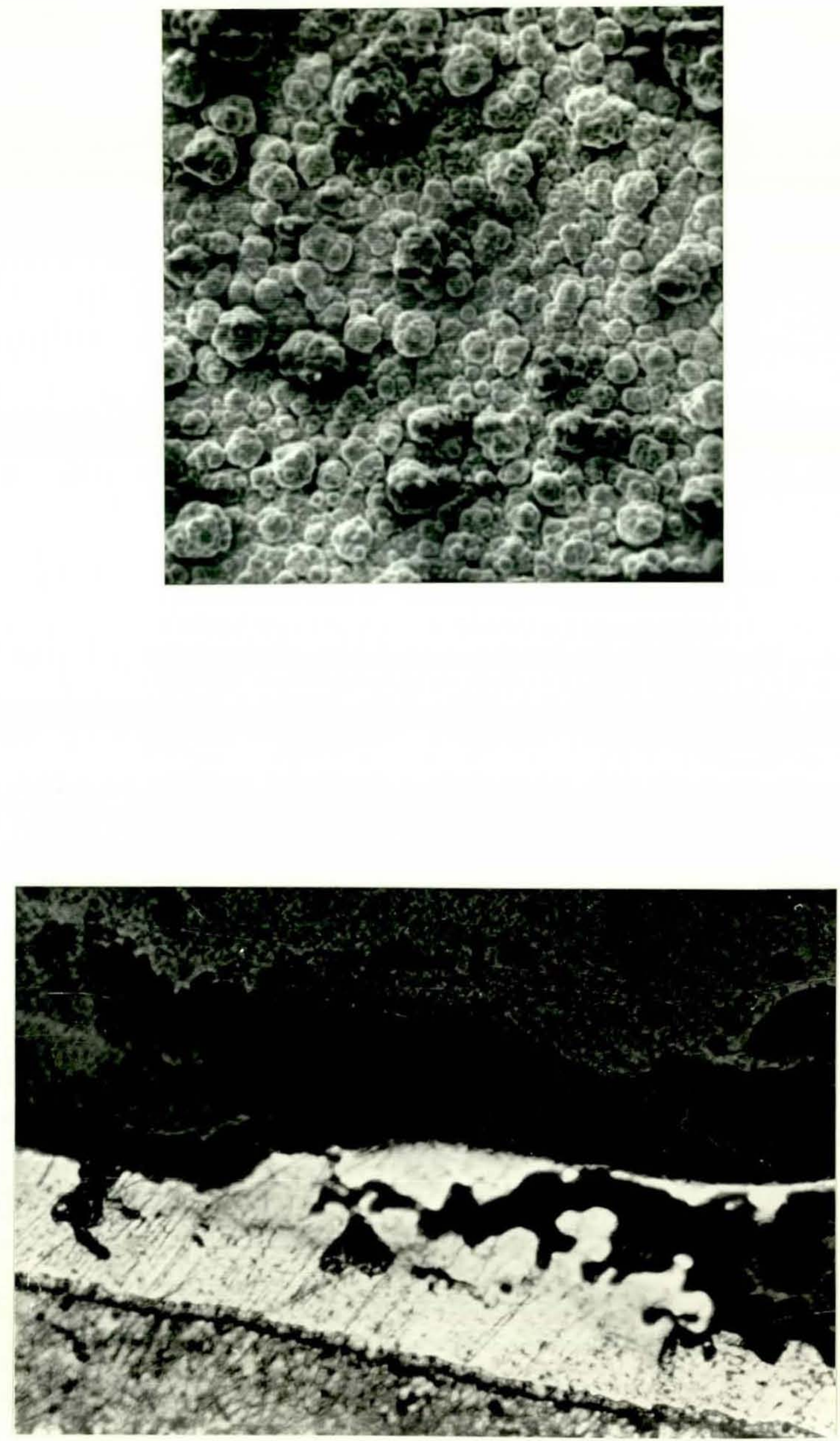
Fig. 25

Triple Deposit (Zn-Deposit from the Cyanide Solution in the Top) on Compact with $5 \%$ Porosity. (S.E.M.) $\times 250$.

Fig. 26

Cross-Section of the Triple Deposit on a Compact with 5\% Porosity. As Polished x 160 . 

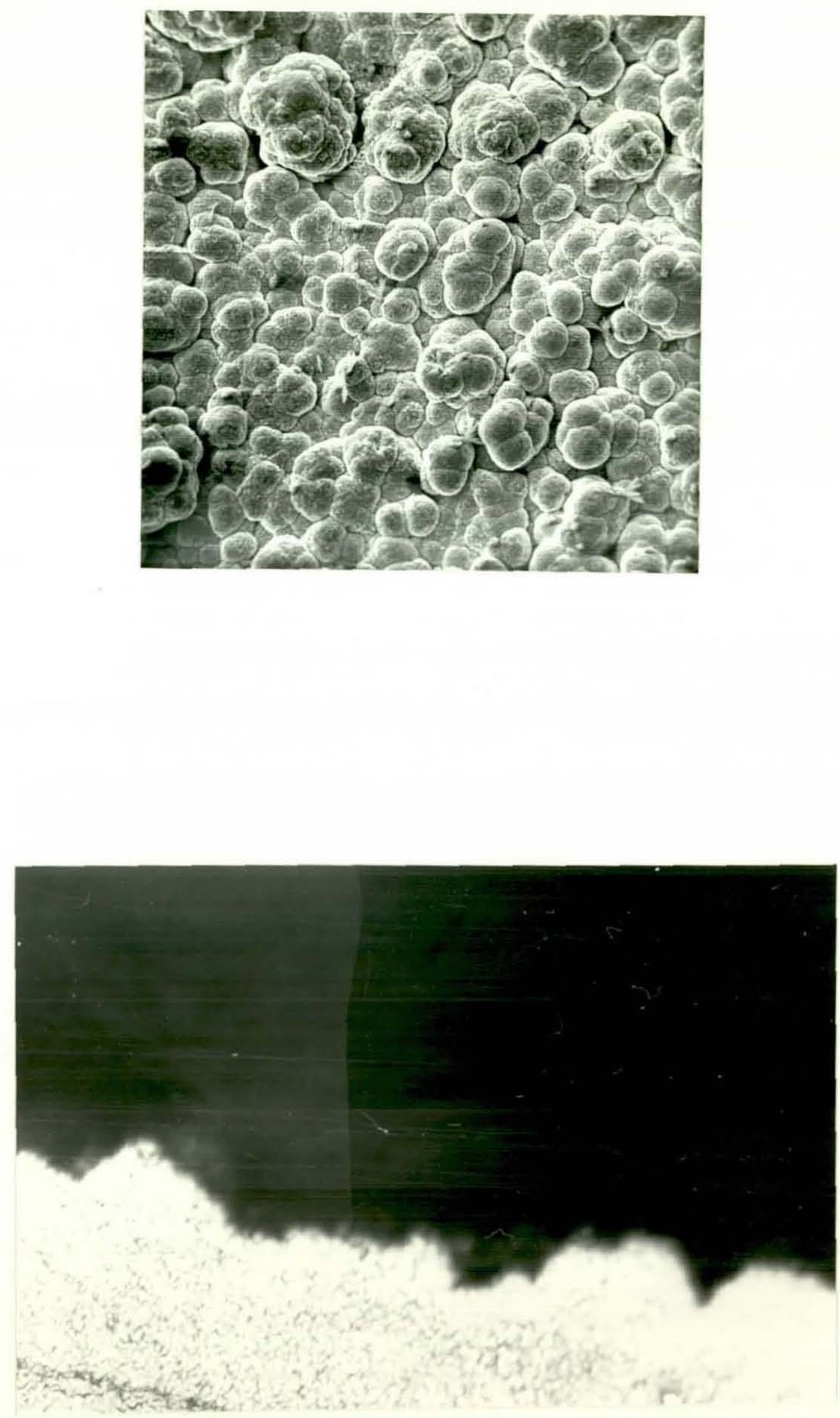
Fig. 27

Zinc Deposit (10 min. Deposition) on Compact with 5\% Porosity (S.E.M.) $\times 575$.

Fig. 28

Zinc Deposit (15 min. Deposition) on compact with 5\% Porosity (S.E.M.) x 575 . 

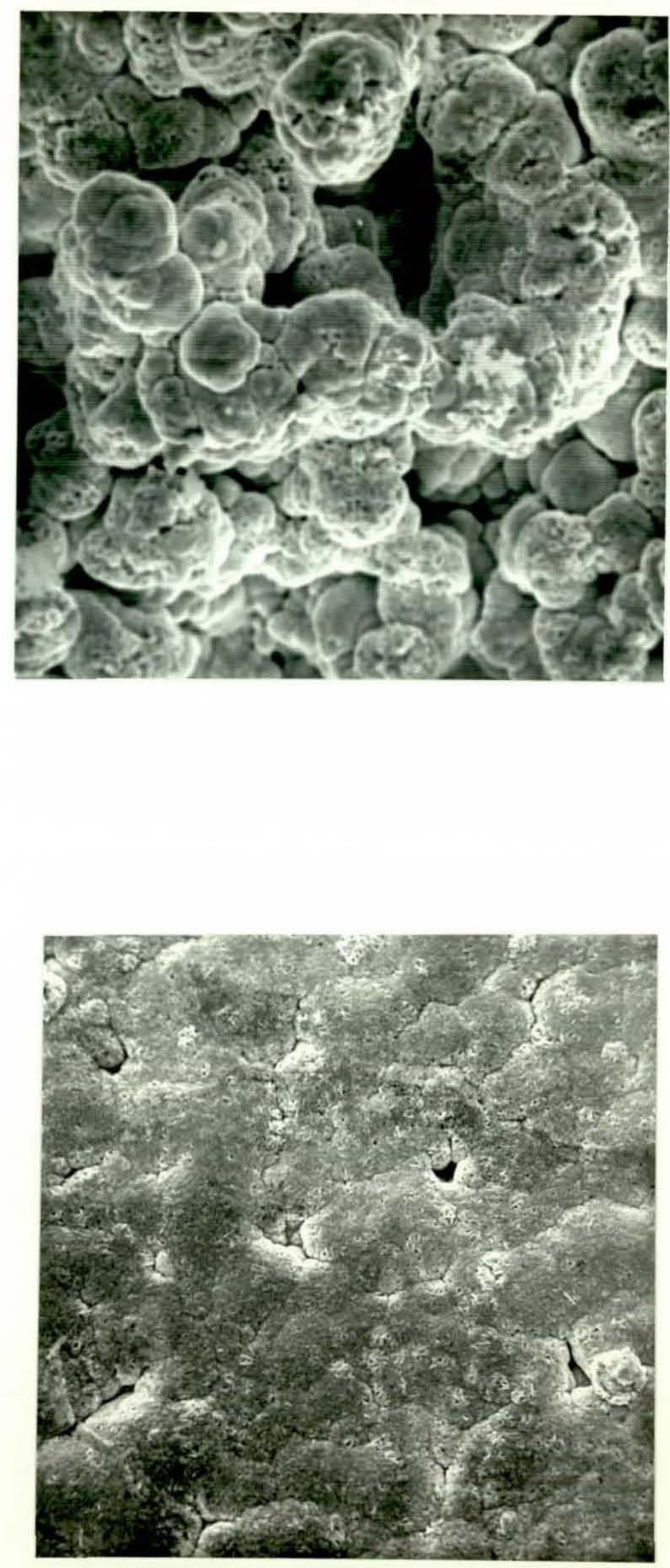
Fig. 29

Cross-Section of a quadruple Deposit on a Compact with $5 \%$ Porosity. As Polished x 64 .

Fig. 30

Triple Deposit (Bright Nickel is the top Deposit) on a Compact with 5\% Porosity (S.E.M.) $\times 600$. 

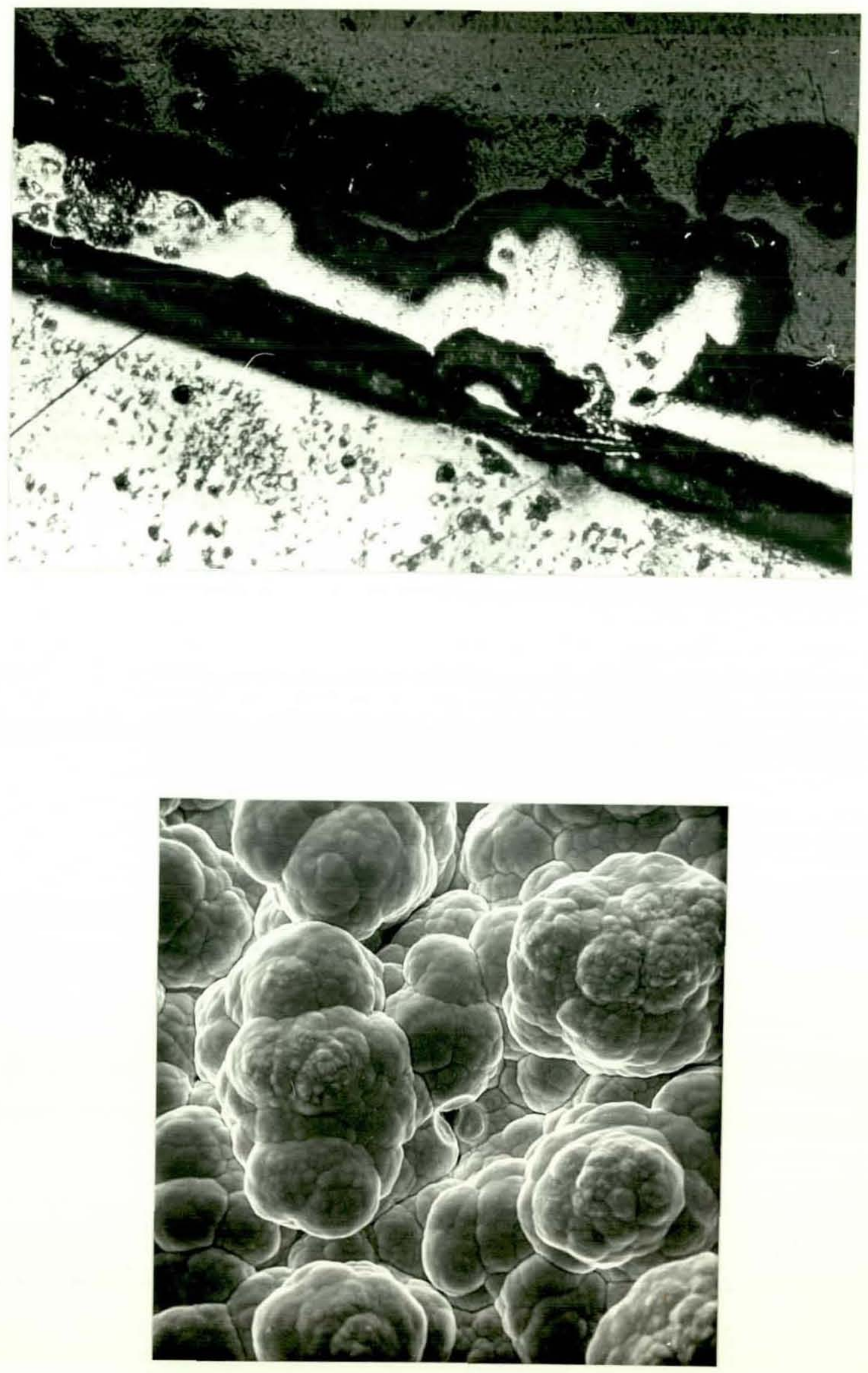
Fig. 31

Triple Deposit on a Compact wity 5\% Porosity. (S.E.M.) x 1200

Fig. 32

Copper Deposit on a Compact with $5 \%$ Porosity at Low Current Density and Plating Time. (S.E.M.) $\times 240$. 

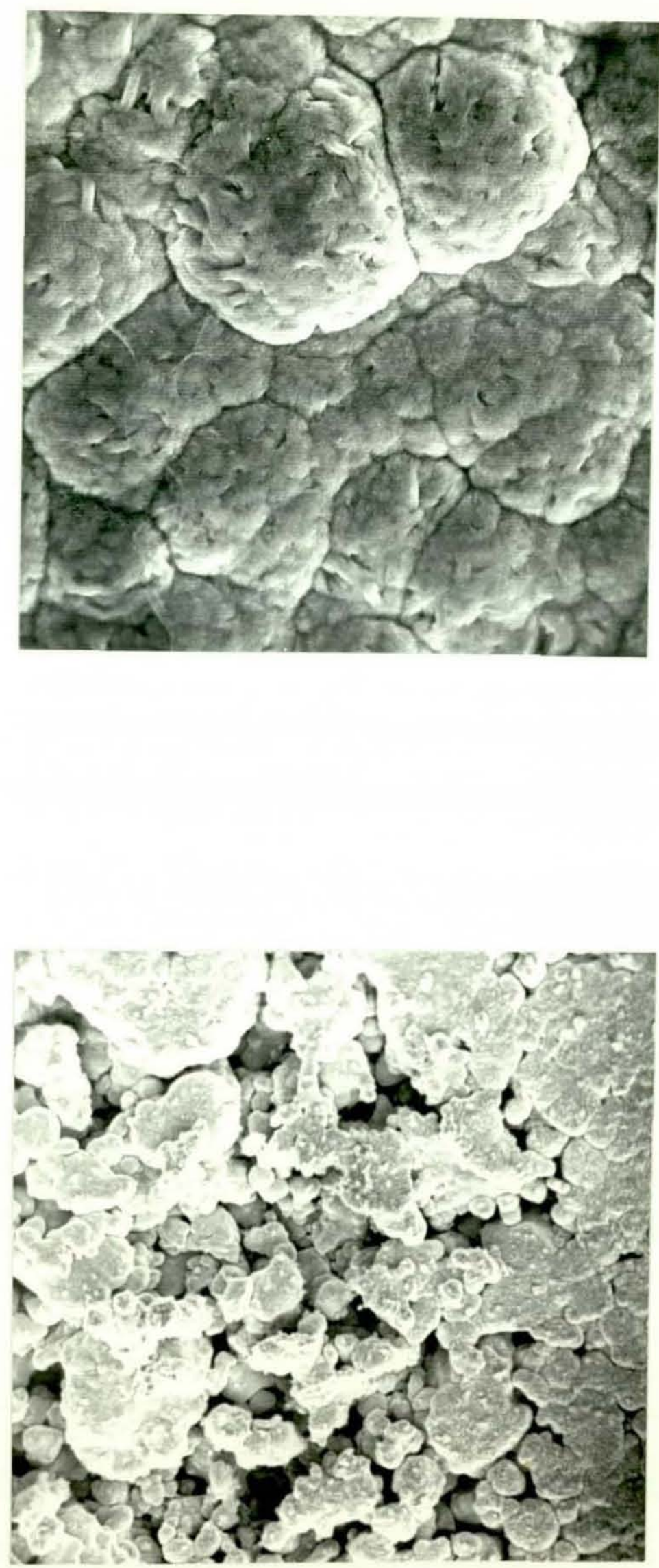
Fig. 33

\section{Copper Deposit on a Compact with 5\% Porosity at Low Current} Density. (S.E.M.) $\times 1200$.

Fig. 34

Copper Deposit from Copper Pyrophosphate Solution on a Compact with 5\% Porosity. (S.E.M.) 1200 X. 

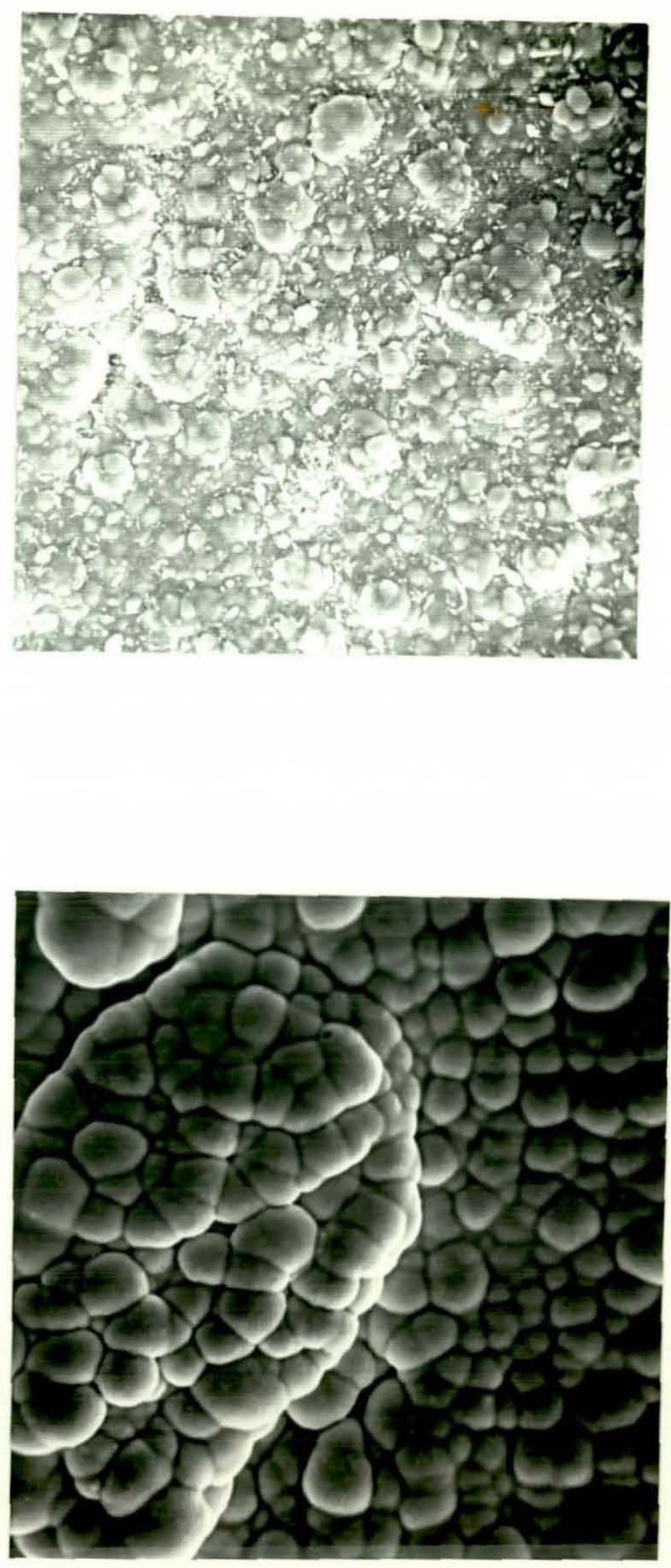
Fig. 35

Quadruple Deposit (Bright Nickel in the Top Coat) on a Compact with $10 \%$ Porosity. (S.E.M.) $\times 600$.

Fig. 36

Double Deposit (Copper from Acidic Solution in the Top) on a Compact with $10 \%$ Porosity. (S.E.M.) $\times 240$. 

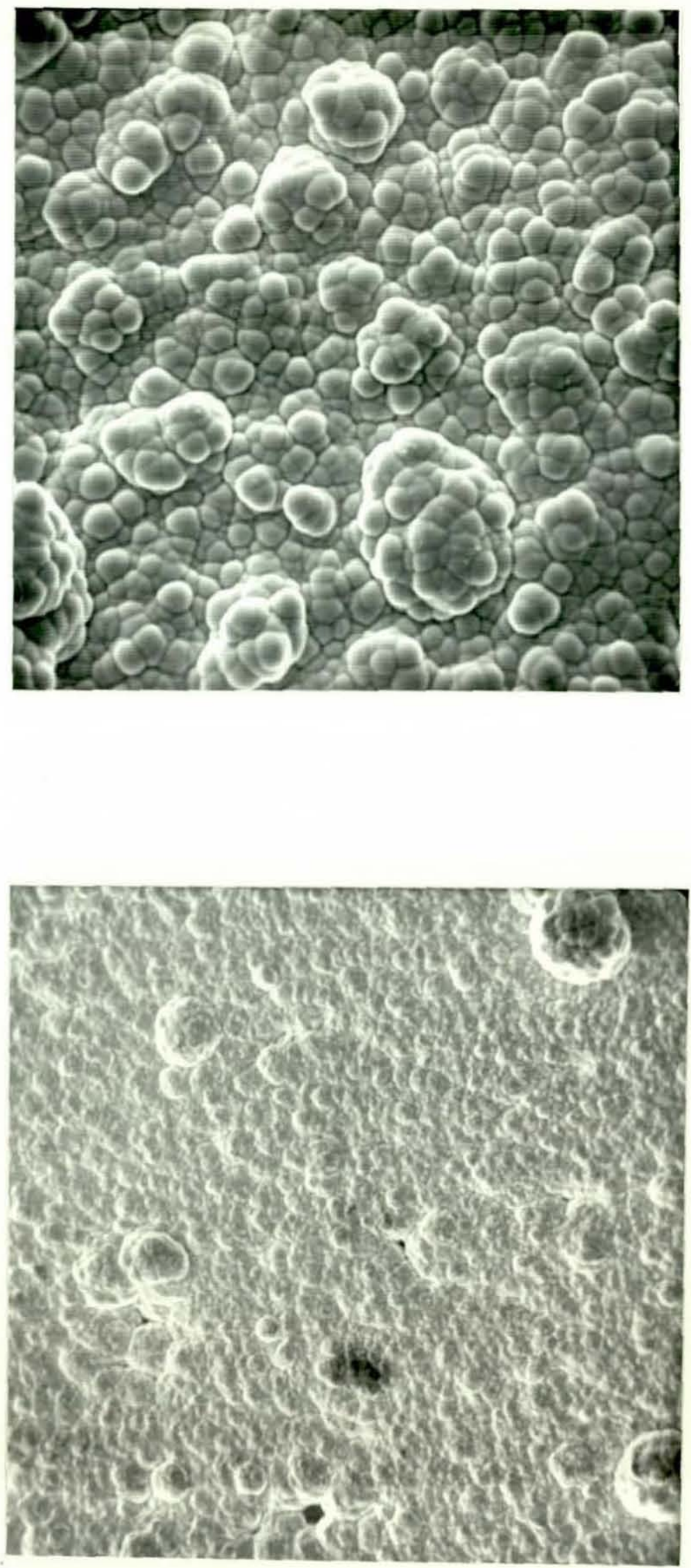
Fig. 37

Copper Deposit (from Cyanide Solution) on a Compact with 10\% Porosity (S.E.M.) $600 \mathrm{x}$.

Fig. 38

Cross Section of a Compact with $10 \%$ Porosity Plated with Copper from Copper Cyanide Solution. As Polished $\times 600$. 

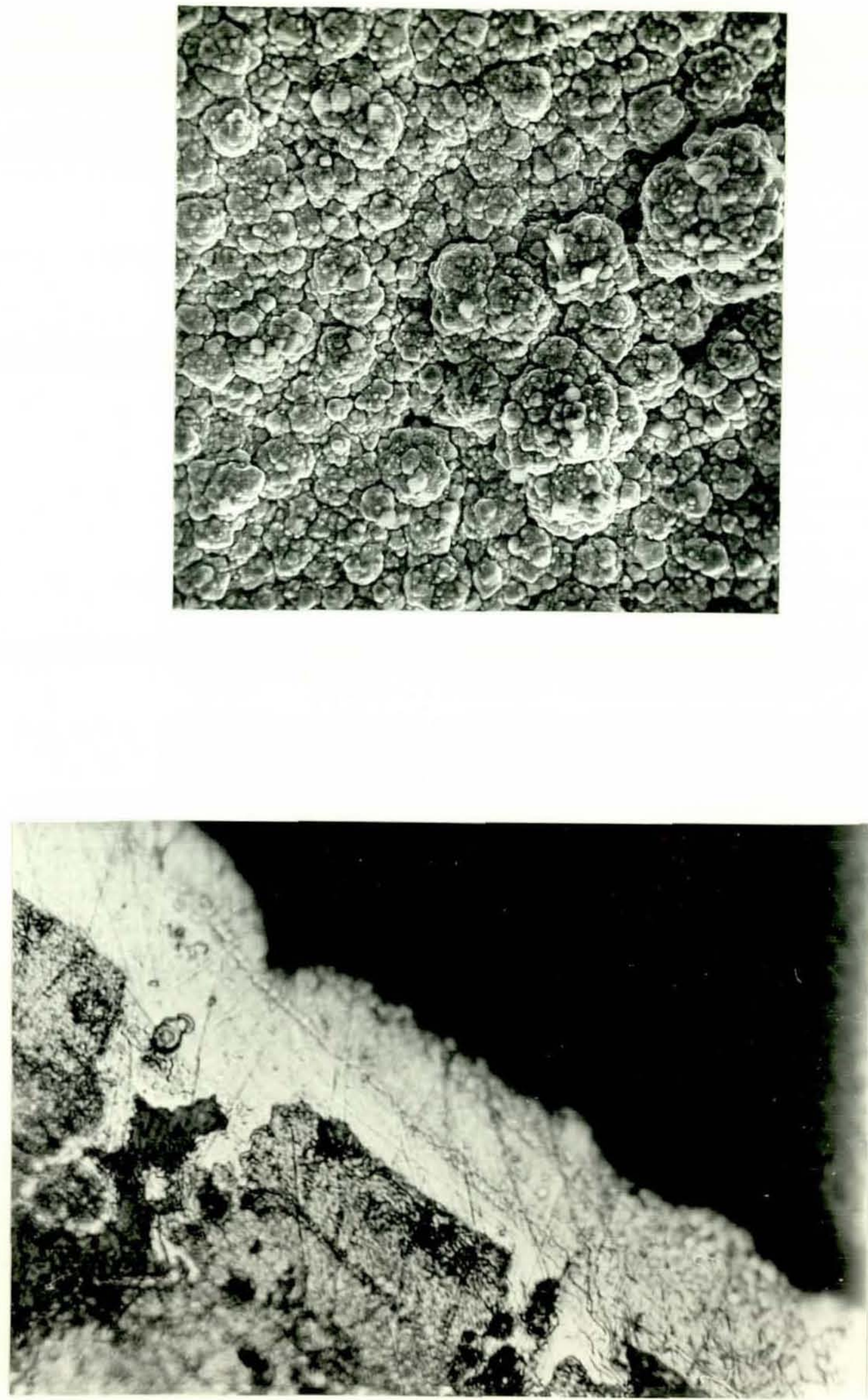
Fig. 39

Cross Section of a Triple Deposit on a Compact with 10\% Porosity. As Polished x 64 . 


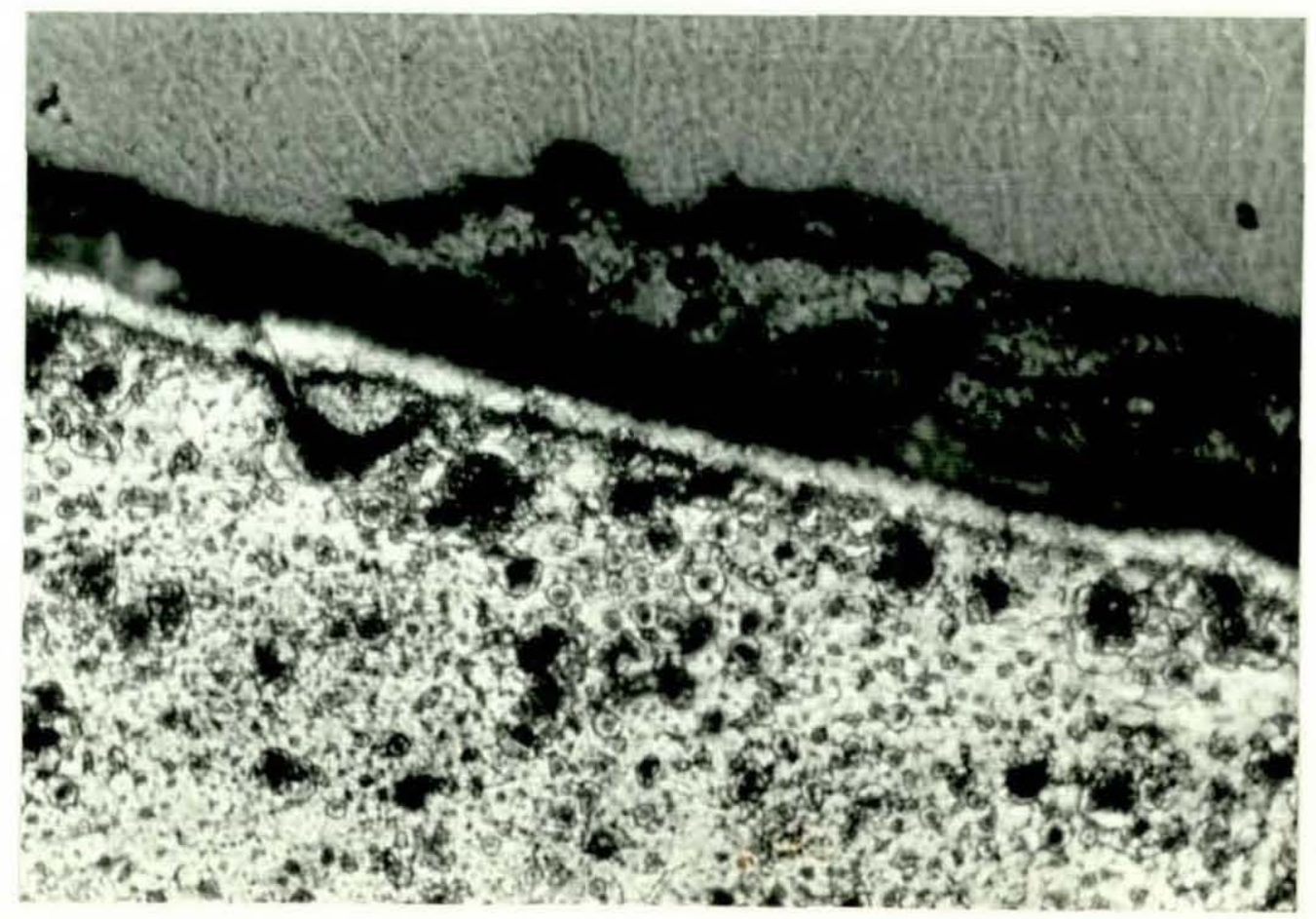


Fig. 40

Cross Section of a Quadruple Deposit on a Compact with $10 \%$ Porosity. As Polished $x 64$.

Fig. 41

Quadruple Deposit (Bright Nickel is the Top Coat) on a Compact with 10\% Porosity. (S.E.M.) X 1200. 

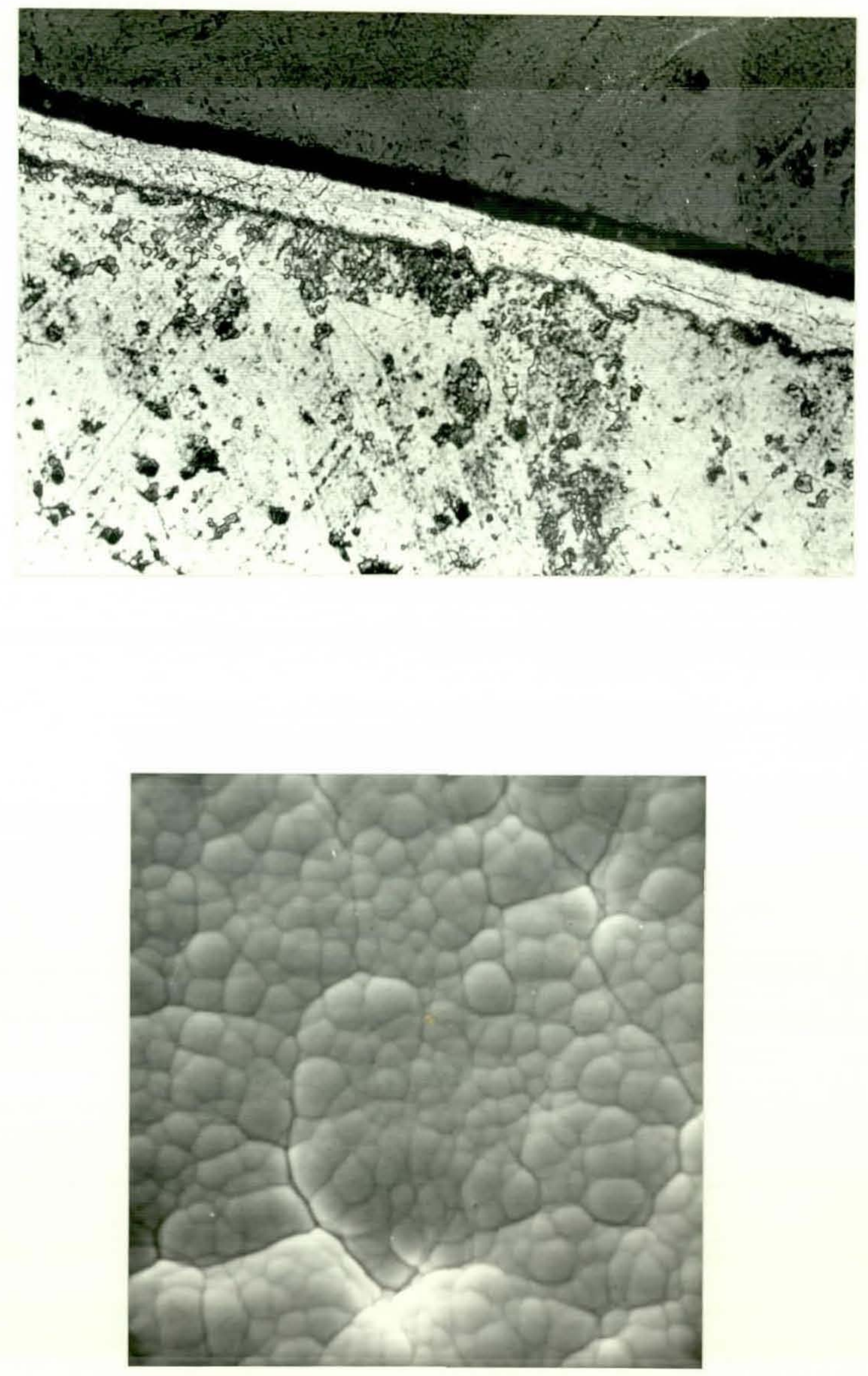
Fig. 42

Quadruple Deposit (Zn Deposit from Acidic Solution is the Top Coat on a Compact with $10 \%$ Porosity. (S.E.M.) $\times 600 \times$

Fig. 43

Zinc Deposit on a Compact with $10 \%$ Porosity (S.E.M.) x 240 . 

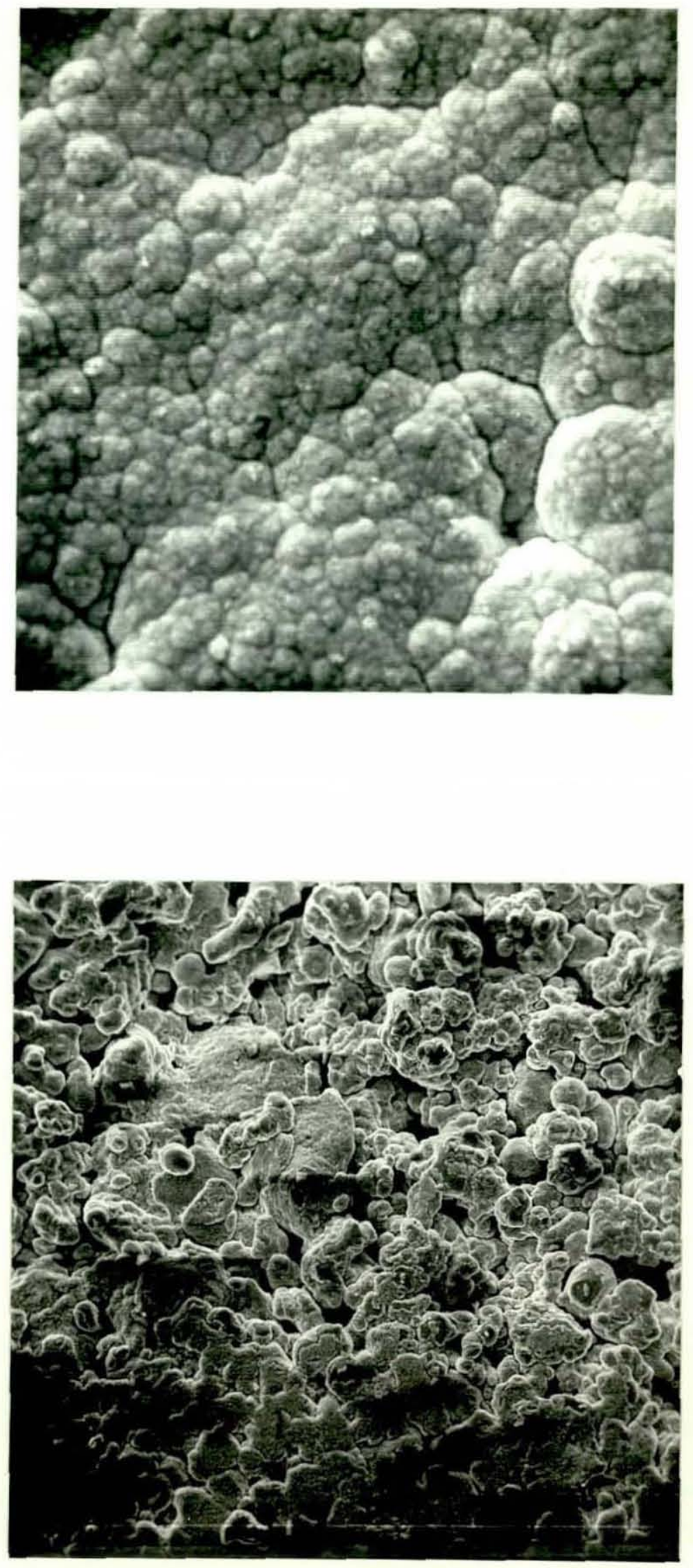
Fig. 44

Zinc Deposit (15 minutes Plating) from Cyanide Solution on a Compact with $10 \%$ Porosity. (S.E.M.) $x 240 \mathrm{x}$.

Fgi 45

Cover Deposit from Pyrophosphate Solution on a Compact with $10 \%$ Porosity. (S.E.M.) $\times 625$. 

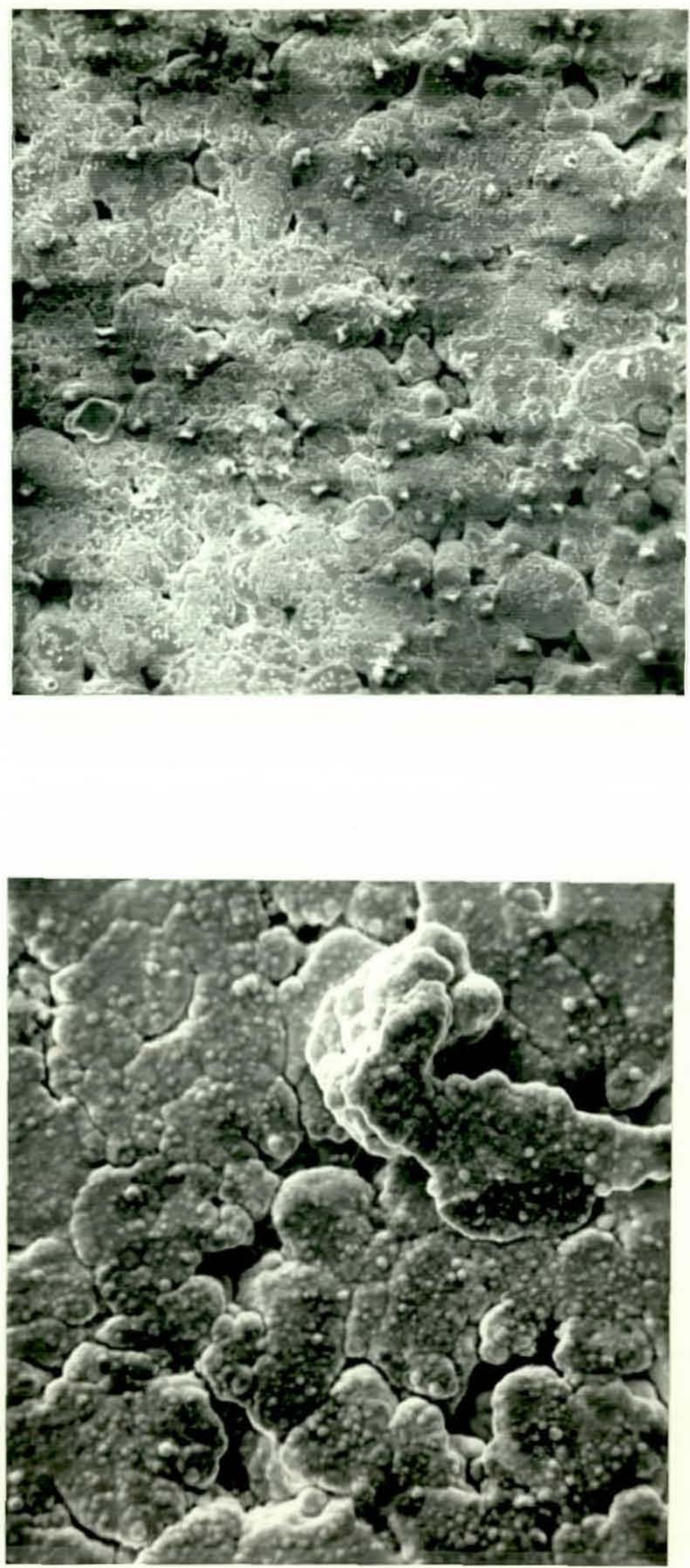
Fig. 46

Cross Section of a Compact with $10 \%$ Porosity Plated with Copper at Low Current Density. As Polished $x$ 160x.

Fig. 47

Copper Deposit from Cyanide Solution on a Compact with 10\% Porosity (S.E.M.) $\times 240$. 

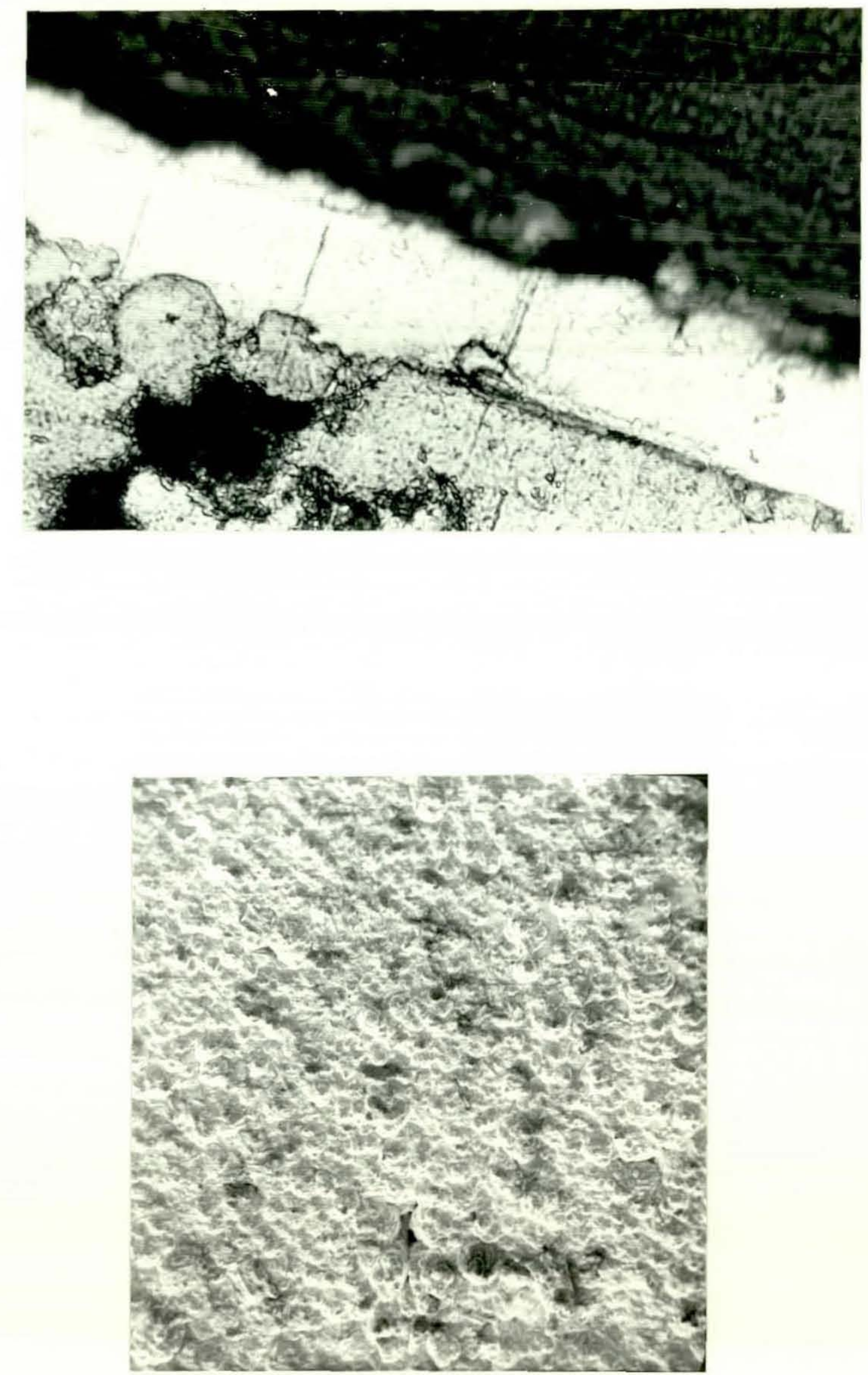
Fig. 48

Copper Deposit on Compact with 15\% Porosity, 15 minutes plating (S.E.M.) $\quad$ X 250 .

Fig. 49

Copper Deposit on Compact with $15 \%$ Porosity 10 minutes Plating.

(S.E.M.) X 1250 . 

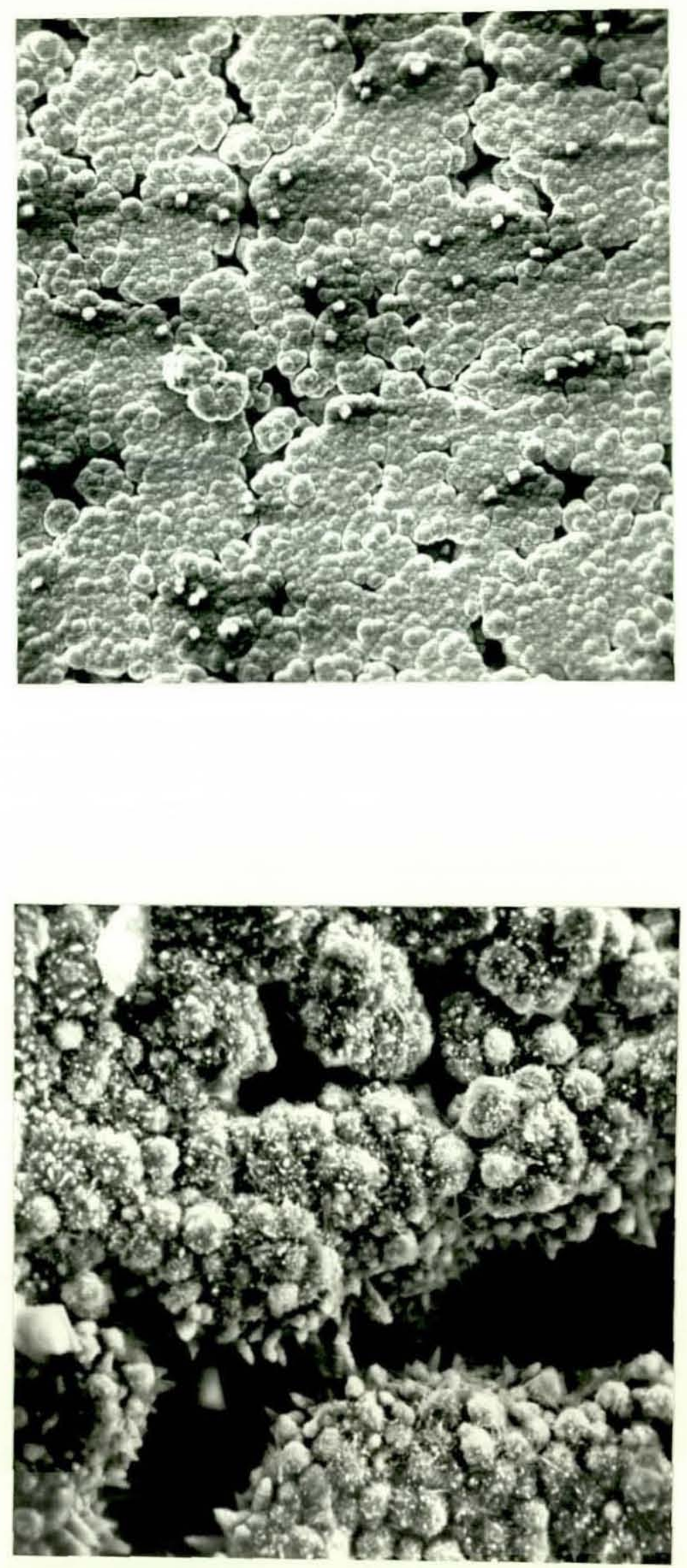
Fig, 50

Double Copper Deposit on Compact with $15 \%$ Porosity.

(S.E.M.) $\mathrm{x} 1250$.

Fig. 51

Triple Deposit (Zn is the Top Deposit) on Compact with 15\% Porosity. (S.E.M.) $\times 260$. 

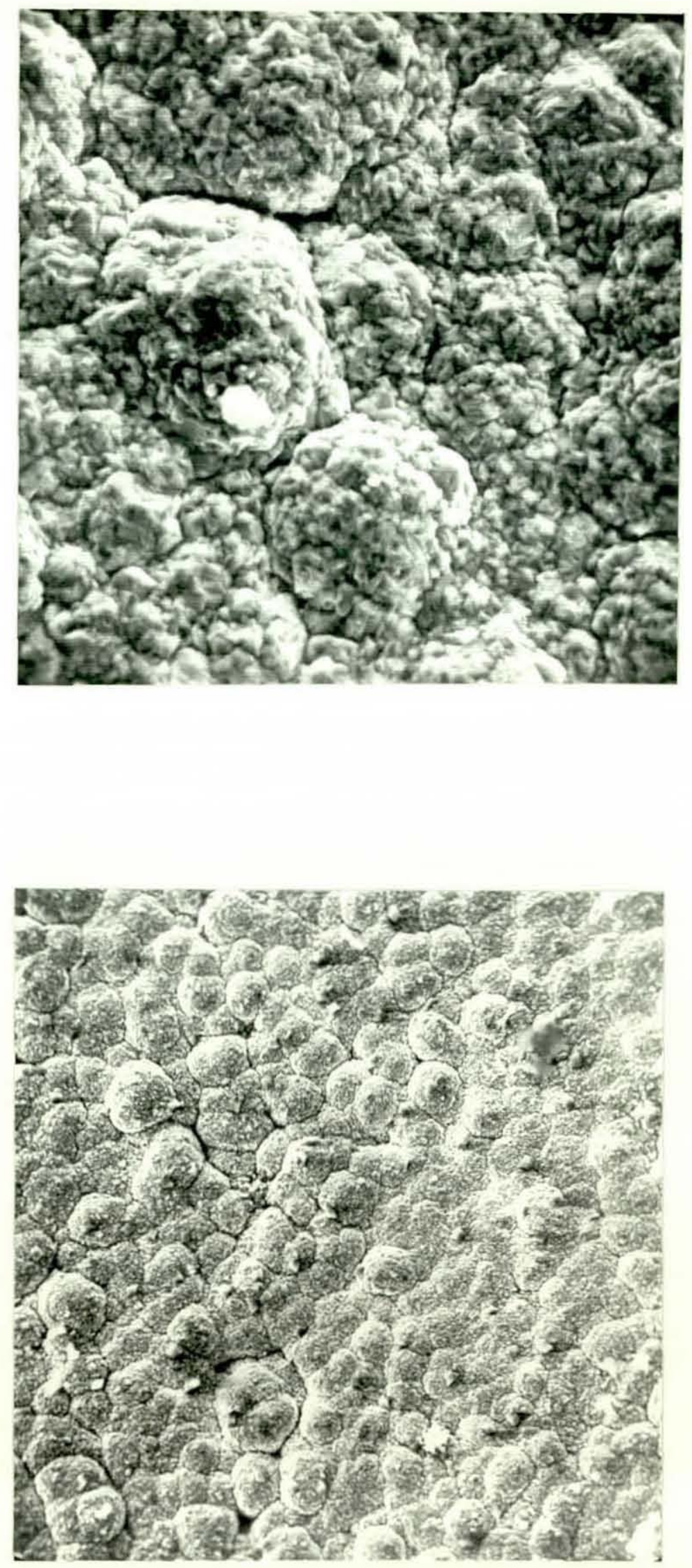
Fig. 52

Triple Deposit (Bright Nickel is the Top Deposit) on Compact with 15\% Porosity. (S.E.M.) X 1300.

Fig. 53

Cross Section of a Triple Deposit on compact with 15\% Porosity As Polished $\times \quad 64$ 

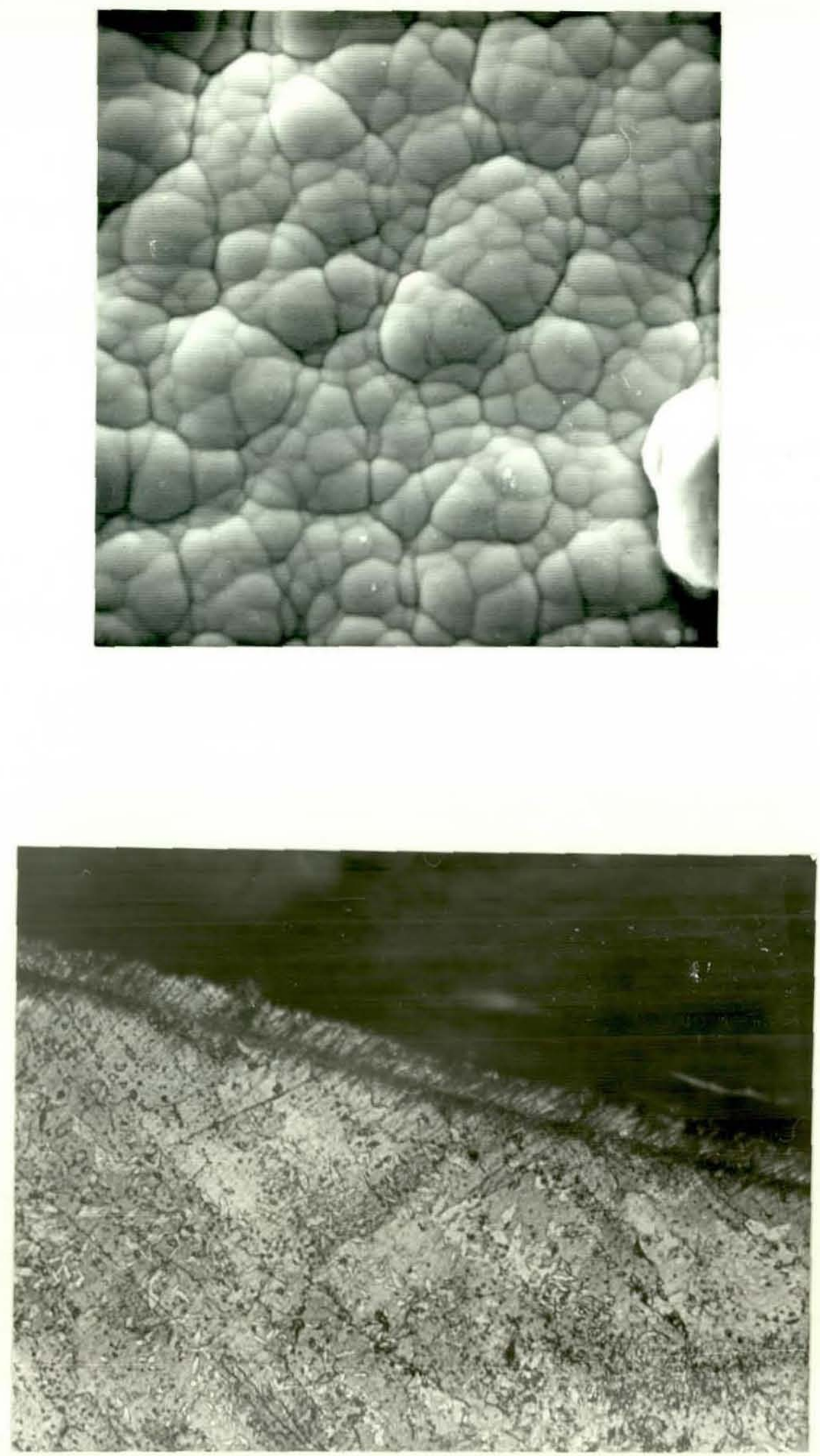
Fig. 54

Quadruple Deposit ( $\mathrm{Zn}$ is the Top Coat) on Compact with $15 \%$ Porosity. (S.E.M.) $\times 260$.

Fig. 55

Cross Section of a Quadruple Deposit on Compact with 15\% Porosity. As Polished x 160 . 

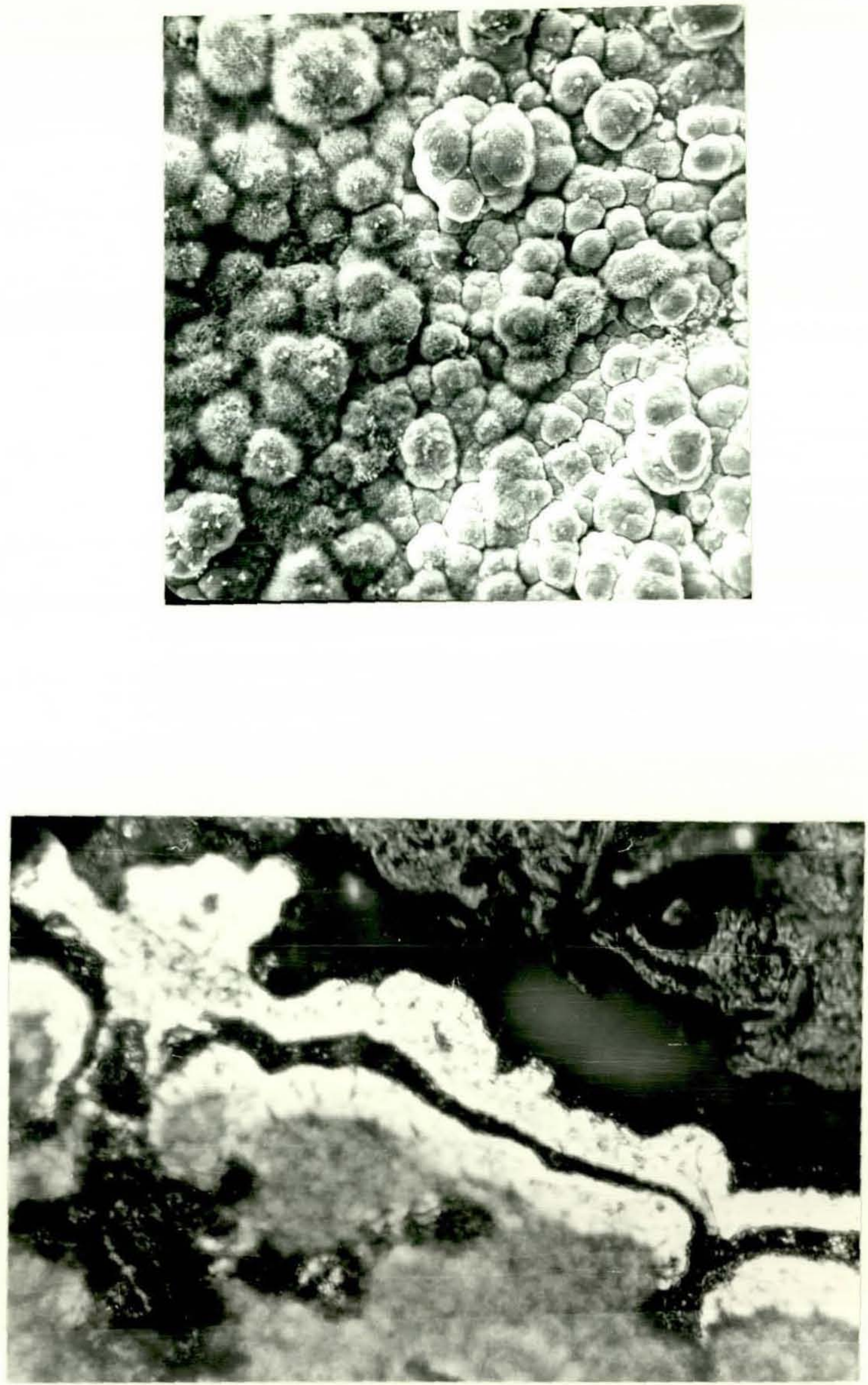
Fig. 56

Cross Section of Compact with $15 \%$ Porosity plated by Sinc Cyanide Solution. As Polished $x 64$.

Fig. 57

Cross Section of a Quadruple Deposit on a tompact with 15\% Porosity. As Polished x 64 . 

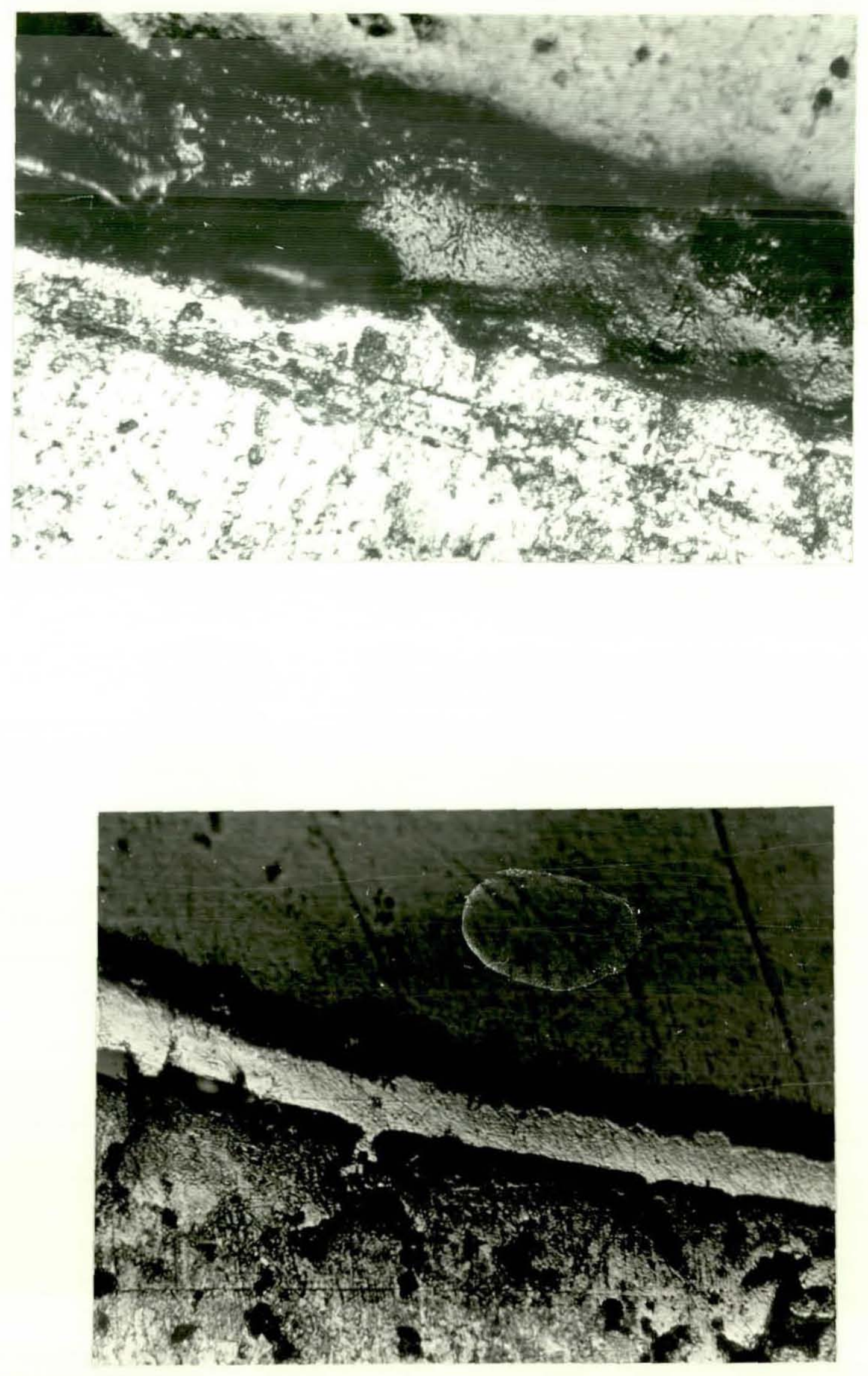
Fig. 58

Quadruple Deposit ( $\mathrm{Zn}$ is the Top Deposit) on Compact with 15\% Porosity. (S.E.M.) $\times 650$.

Fig. 59

Cross Section of a Quadruple Deposit on Compact with $15 \%$ Porosity. As Polished x 160 . 

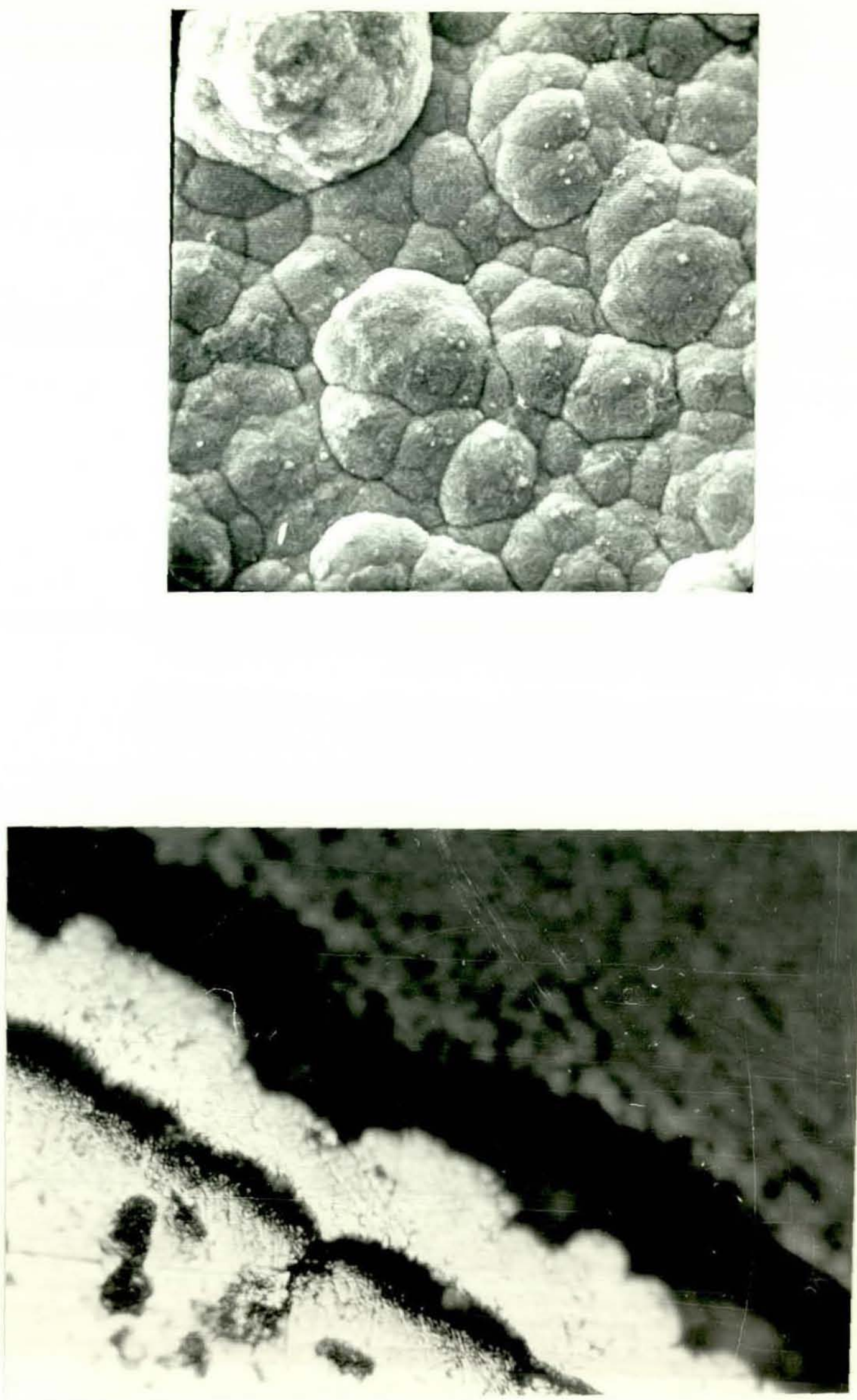
Fig. 60

Cross-Section of Compact with 15\% Porosity. (Unsintered).

As Polished $\times 64$.

Fig. 61

Deposit on Compact (Unsintered) with 15\% Porosity.

(S.E.M.) $\times 1200$ 

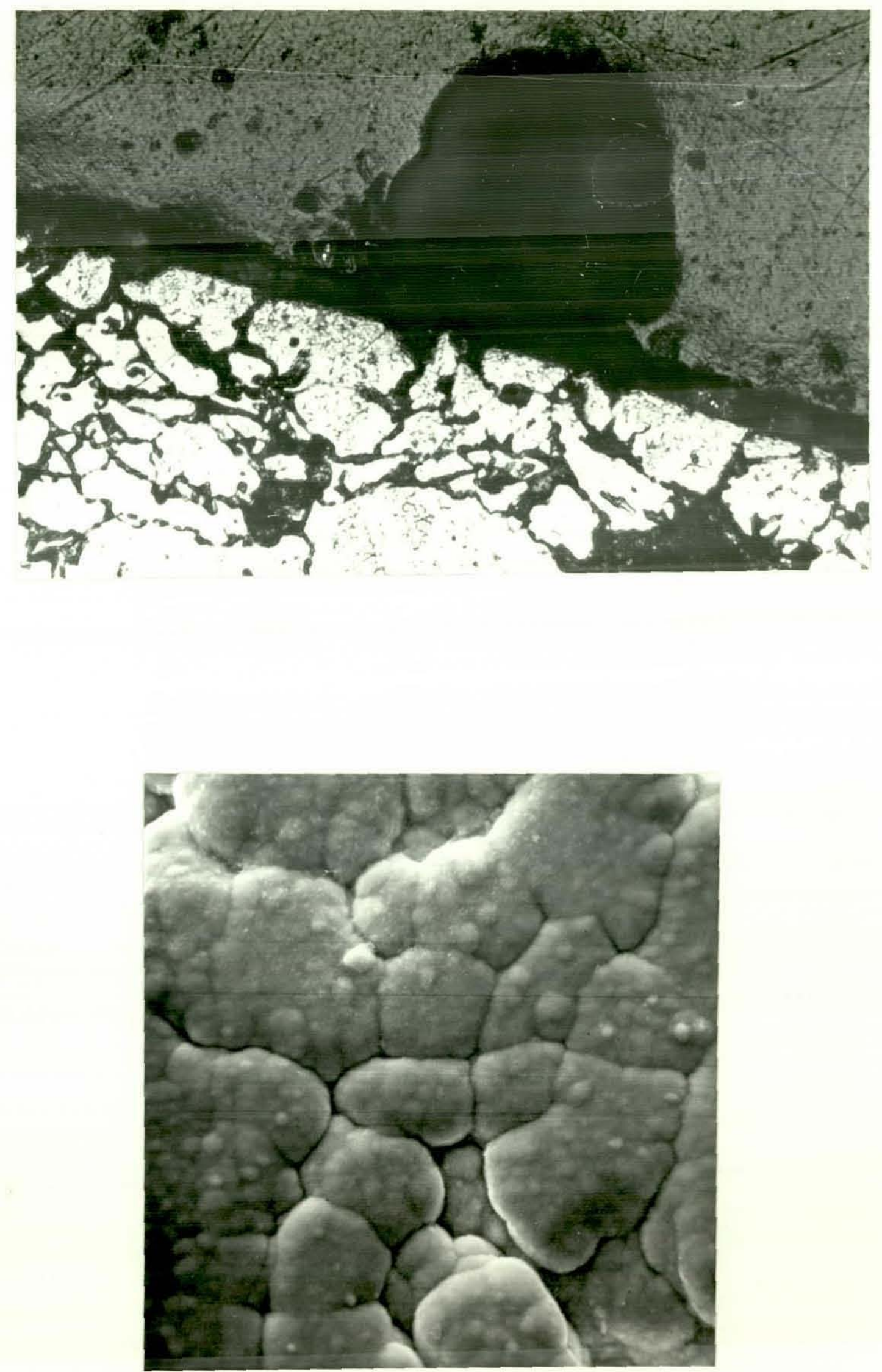
Fig. 62

Cross- Section of Compact with $15 \%$ Porosity Plated three times with Acid Zinc Solution. As Polished x 64 .

Fig. 63

Cross-Section of Compact with $15 \%$ Porosity. Plated with Bright Nicke1, As Polished x 64 . 

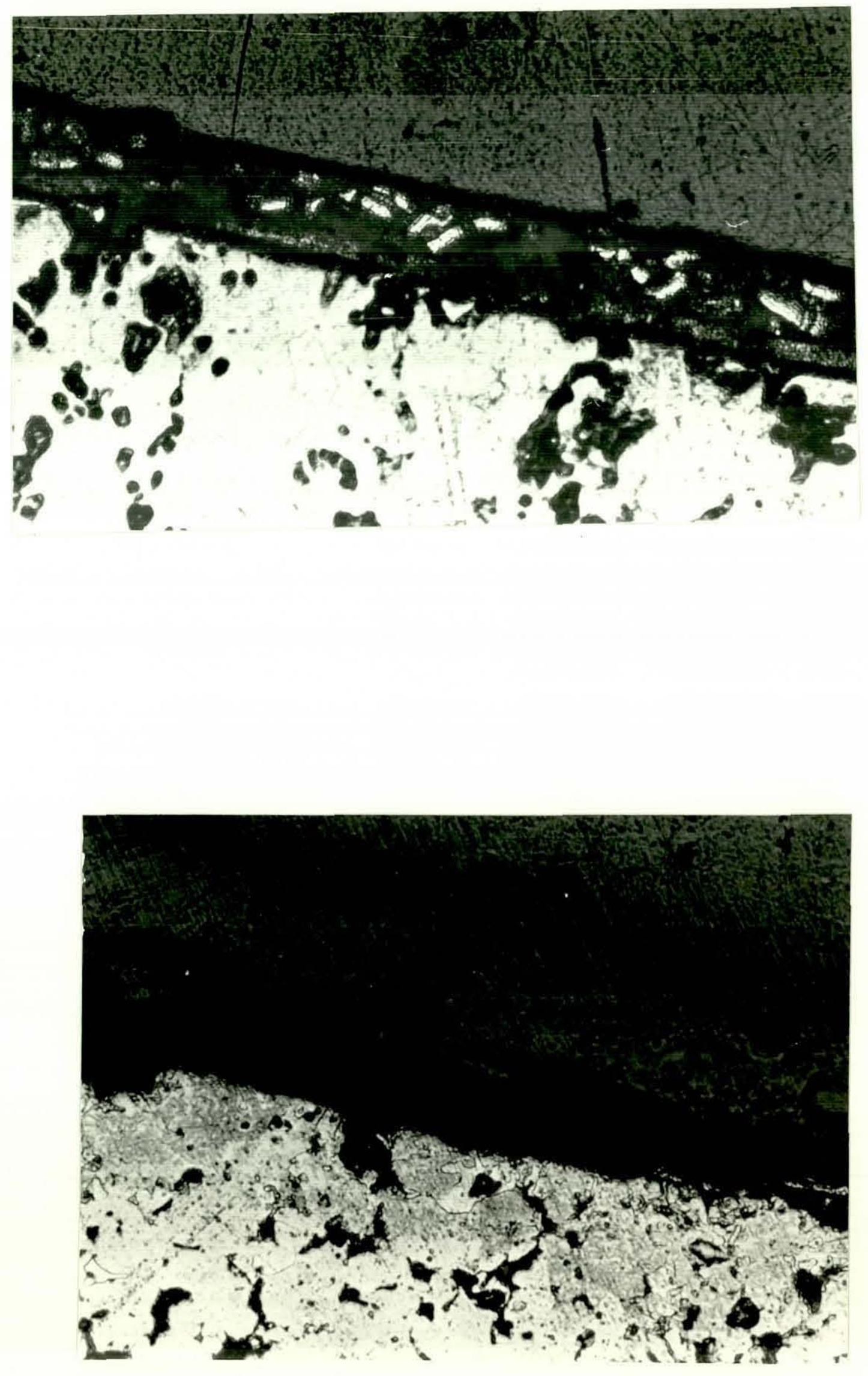
Fig. 64

Nickel Deposit on a Compact with $15 \%$ Porosity.

(S.E.M.) $\times 625$ 


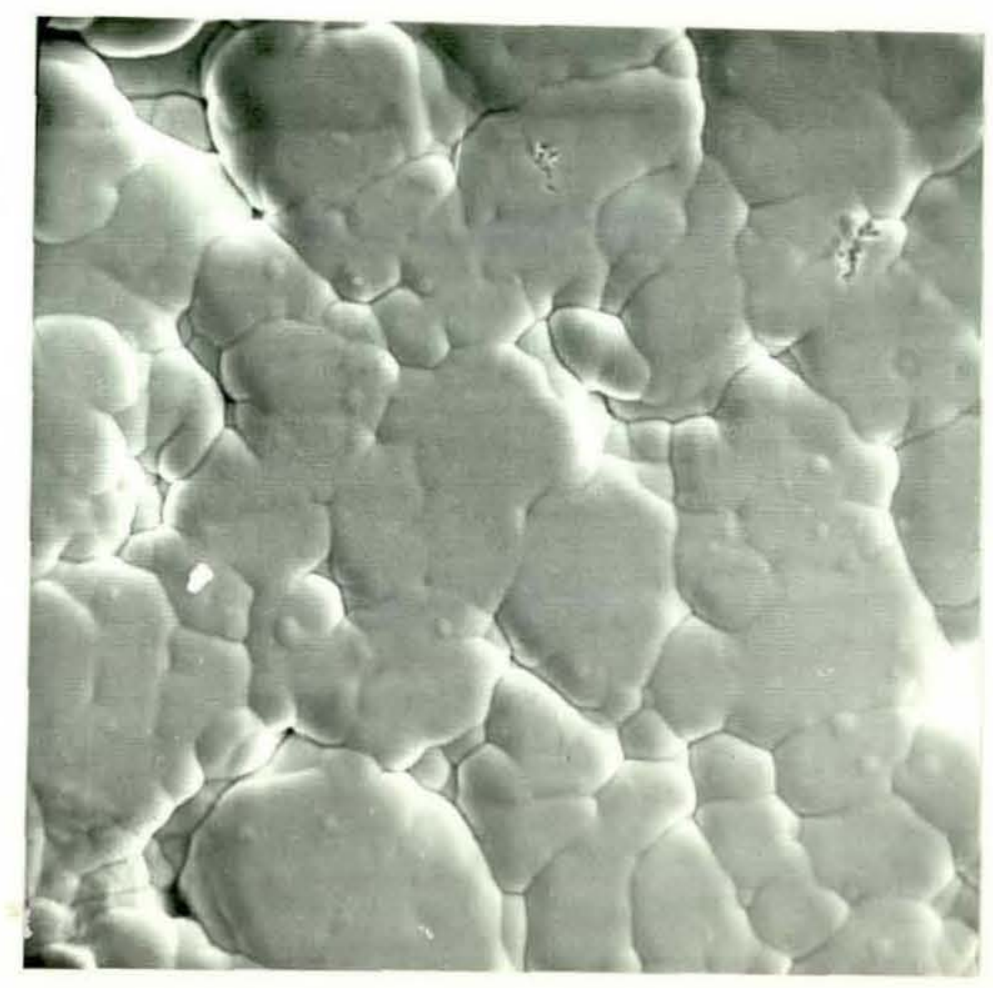


Fig. 65

Copper Pyrophosphate Deposit on a Compact with 15\% Porosity

$$
\text { (S.E.M.) } \times 625 \text {. }
$$

Fig. 66

Cross-Section of Compact with $15 \%$ Porosity Plated with

Bright Nickel Solution. As Polished $\times 6.4$ 

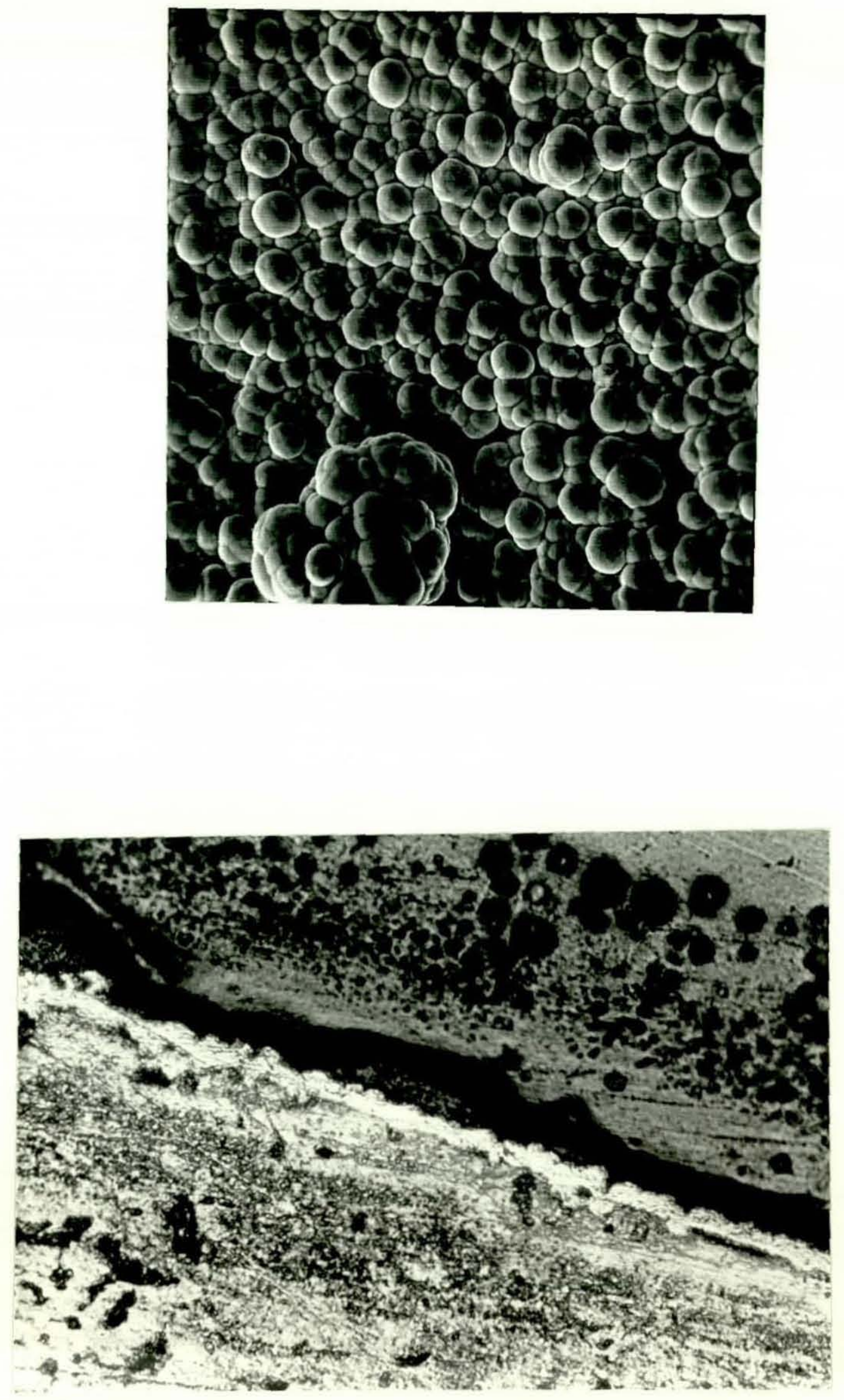
Fig. 67

Cross- Section of Compact with 15\% Porosity Plated with

Zinc Cyanide Solution. As Polished x 160 . 


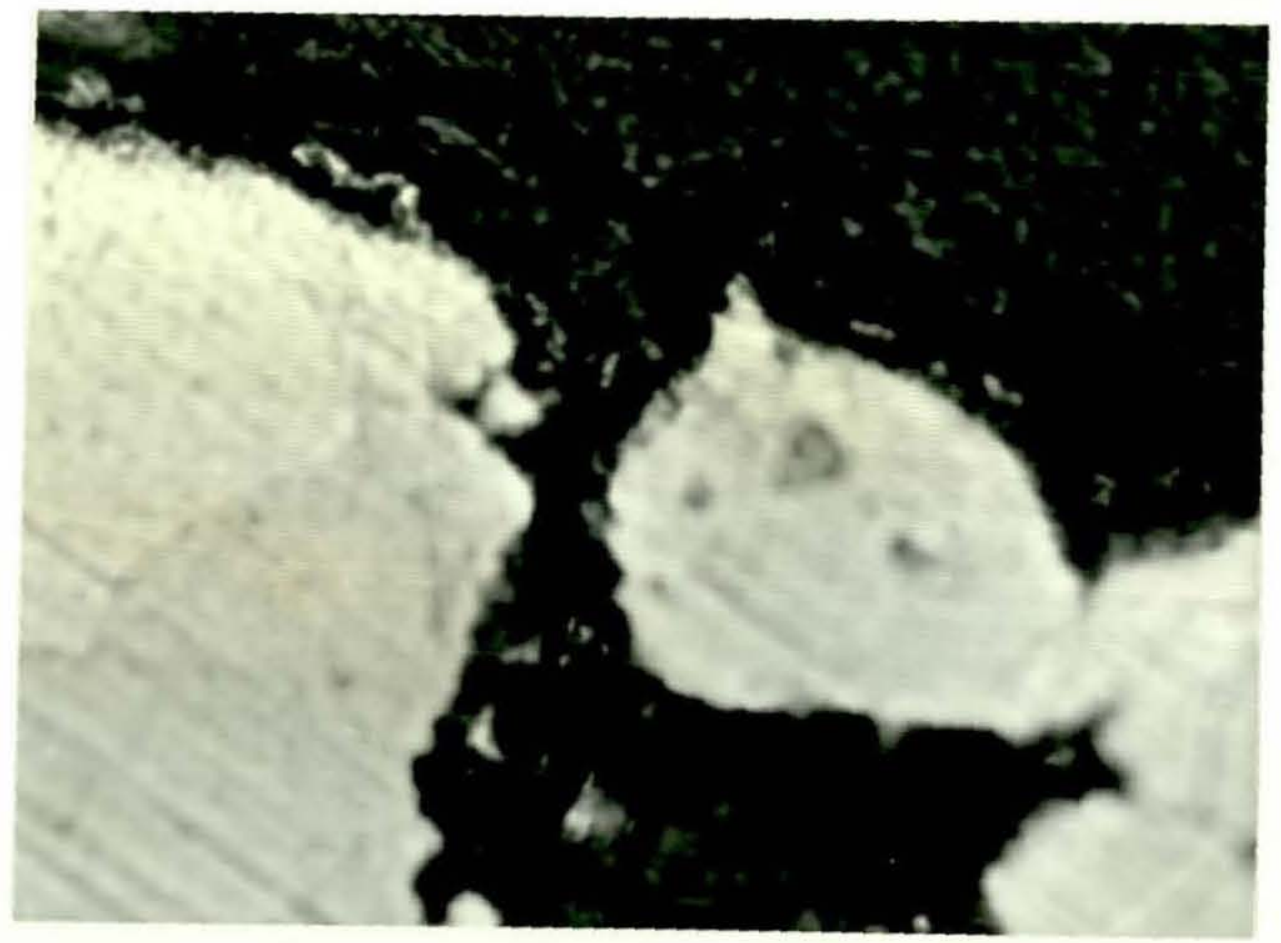


,

7
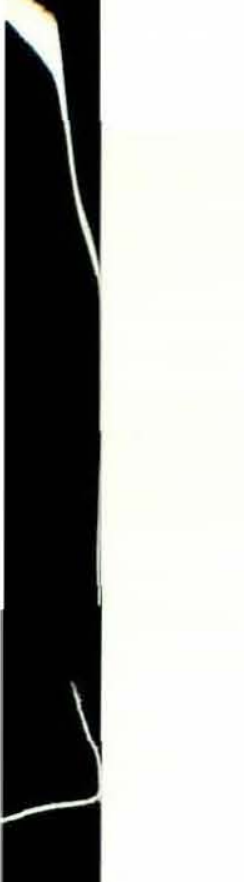